\title{
CURADORIA DIGITAL E POLÍTICAS DE DIGITALIZAÇÃO
}

Notas do III Simpósio Curadoria Digital - TOI 2020

VI Simpósio Tecnologia e Organização da Informação

Série Tecnologia e Organização da Informação

Francisco Carlos Paletta Rodrigo Moreira Garcia organizadores 

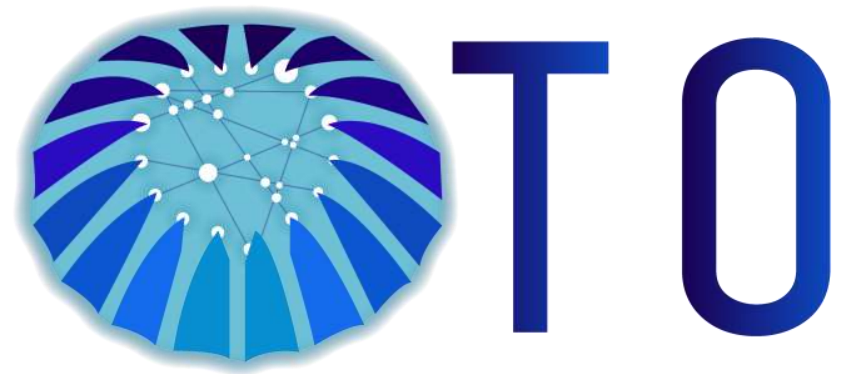

CONGRESSO INTERNACIONAL EM TECNOLOGIA E ORGANIZAÇÃO DA INFORMAÇÃO

III Simpósio Curadoria Digital

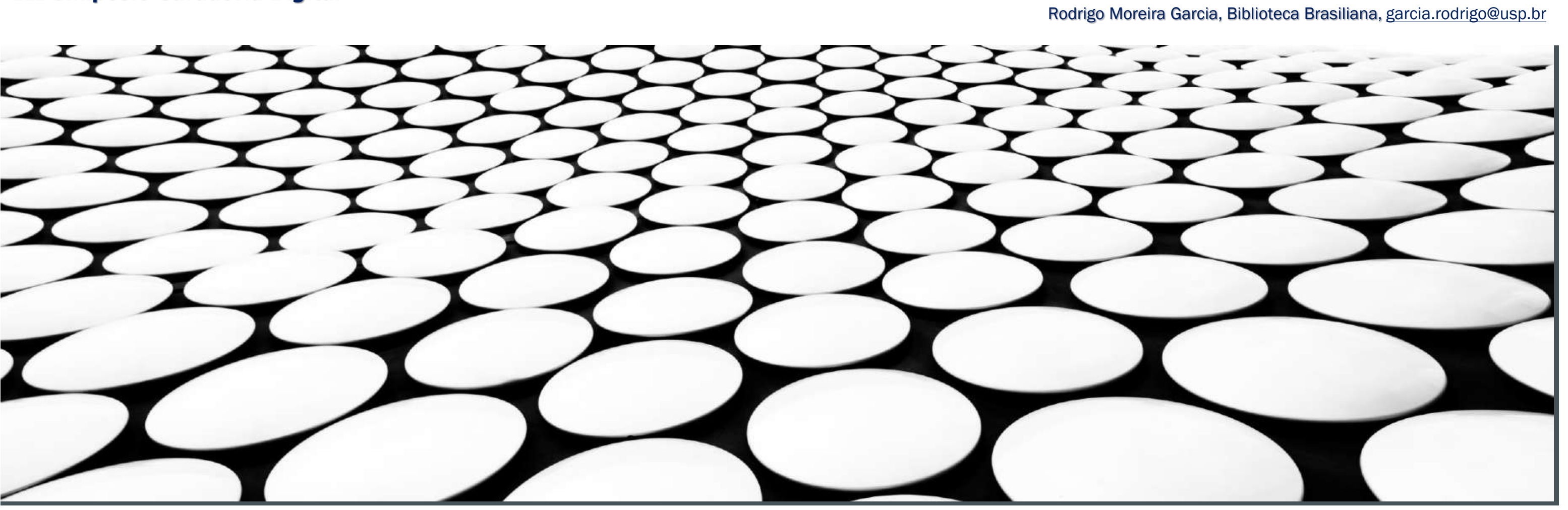

\section{LIBRARY AND INFORMATION SCIENCE CONFERENCE}

\section{CURADORIA DIGITAL E POLÍTICAS DE DIGITALIZAÇÃo}

Francisco Carlos Paletta, Universidade de São Paulo fcpaletta@usp.br

Rodrigo Moreira Garcia, Biblioteca Brasiliana, garcia.rodrigo@usp.br 


\section{SÉRIE TECNOLOGIA E ORGANIZAÇÃO DA INFORMAÇÃO \\ CURADORIA DIGITAL E POLÍtICAS DE DIGITALIZAÇÃO}

Notas do III Simpósio Curadoria Digital - TOI 2020

ORGANIZAÇÃo

Francisco Carlos Paletta 


\section{Catalogação na Publicação}

Serviço de Biblioteca e Documentação

Escola de Comunicações e Artes da Universidade de São Paulo

C975

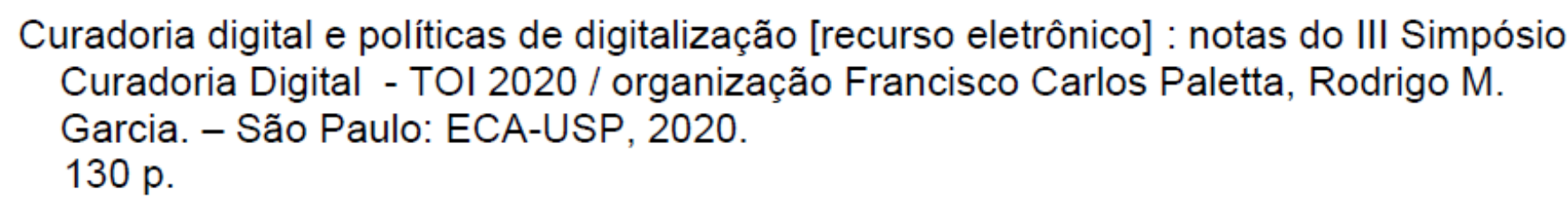

Curadoria digital e políticas de digitalização [recurso eletrônico] : notas do III Simpósio Curadoria Digital - TOI 2020 / organização Francisco Carlos Paletta, Rodrigo M. Garcia. - São Paulo: ECA-USP, 2020.

$130 \mathrm{p}$.

ISBN 978-65-990224-9-4

1. Informação - Organização - Congressos. 2. Preservação digital. 3. Curadoria digital. I. Paletta, Francisco Carlos. II. Garcia, Rodrigo M. III. Simpósio Curadoria Digital - TOI (3. : 2020 : São Paulo). 


\section{Apoio}

Escola de Comunicações e Artes da Universidade de São Paulo

Comissão de Cultura e Extensão

Comitê Consultivo: Científico e Editorial

Prof. Dr. Audilio GONZALEZ AGUILAR

Université Paul Valéry Montpellier III. Département de Documentation https://orcid.org/0000-0001-8693-2076

Prof. Dr. José Antonio Moreiro González

Universidad Carlos III, Madrid - Departamento de Biblioteconomía y Documentación https://orcid.org/0000-0002-8827-158X

Copyright (C) 2020 Escola de Comunicação e Artes da Universidade de São Paulo

$$
\text { 1ํ. Edição } 2020
$$

\section{SÉRIE TECNOLOGIA E ORGANIZAÇÃo DA INFORMAÇÃO Contribuições para a Ciência da Informação}

ISBN: 978-65-990224-9-4 .

Título: Curadoria digital e políticas de digitalização

Subtítulo: notas do III Simpósio Curadoria Digital - TOI 2020

Formato: Livro Digital

Veiculação: Digital 


\section{SUMÁRIO}

CURADORIA DIGITAL E POLÍtICAS DE DIGITALIZAÇÃo - Contribuições para a Ciência da Informação: I Simpósio Curadoria Digital Francisco Carlos Paletta

Rodrigo Moreira Garcia

A TEORIA DA PRESERVAÇÃo DIGITAL: Digitalização, Curadoria e Redes

Miguel Angel Mardero Arellano

A DIGITALIZAÇÃo DE ACERVOS NO BRASIL SEGUNDO A PESQUISA TIC CULTURA

Luciana Piazzon Barbosa Lima

CREATIVE COMMONS E SEU USO NA DISPONIBILIZAÇÃo DE ACERVOS CULTURAIS

Juliana Monteiro

BIOGRAFIA AUTORES 


\section{School of}

\section{Communication and}

\author{
Arts ECA
}

\section{University of São}

Paulo
The School of Communication and Arts (ECA) of University of São Paulo, was created in 1966 and its first name was School of Cultural Communication. Due to the diversities of areas and careers offered, ECA's first characteristic is that it is contemporary. It is a school linked to the innovations and the transformations of superior education. ECA is organized in eight departments and one technical school. There are 22 professional careers in undergraduate regular courses, from which 15 are devoted to Arts: Scenic Design, Theater Direction, Theater Acting, Theory of Theater, Sculpture, Engraving, Multimedia, Inter-media, Painting, Chant and Lyrical Art, Composition, Musical Instruments, Conducting and graduation in Art Education, Acting Performances, Fire Arts and Music. There are 4 qualifications in Social Communication: Journalism, Publishing, Advertising and Propaganda and Public Relations, besides the courses of Librarianship, Tourism and Audio-visual. Furthermore, ECA has inside its structure the School of Drama that is a traditional school of theater sponsored by the course of "Actor Performance". Besides the regular courses, ECA offers diverse activities which provide the community with social services. These are essential functions inside the University, such as Cultural Extension courses in different themes and Project of University Open to the Elderly. The research centers are a very active area the school. Beside the work on scientific investigation, they have a straight relationship with the Community producing important works of public utility, which are frequently done in partnership with government agencies. The Graduate Program incentivates the cultural exchange and research and has agreements with the most prominent Universities worldwide. The most important cultural and pedagogical investment of ECA has been the constant recycling and actualization of methods and use of the new education technologies. 
oco

ESCOLA DE COMUNICAÇŌESS E ARTES UNIVERSIDADE DE SÃO PAULO

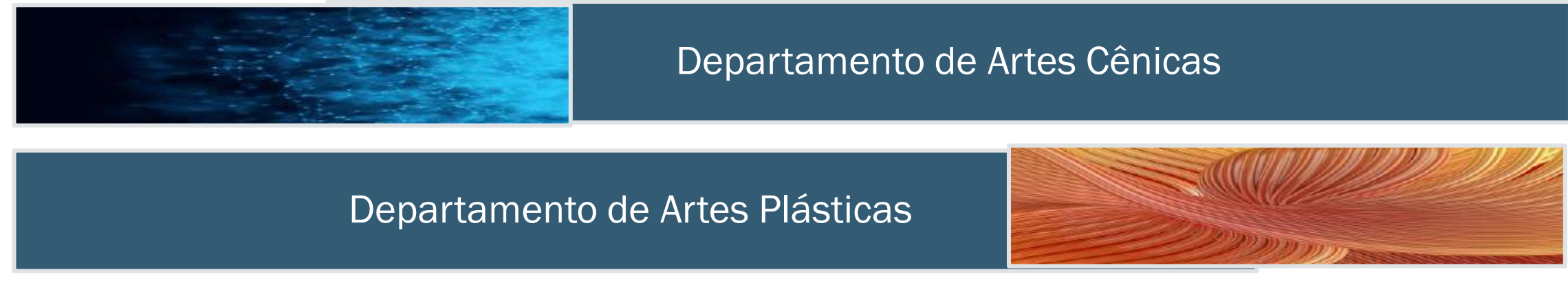

Departamento de Informação e Cultura

Departamento de Comunicações e Artes

Departamento de Jornalismo e Editoração

Departamento de Música

Departamento de Relações Públicas, Propaganda e Turismo 


\section{cco}

UNIVERSIDADE DE SAEO PAULO

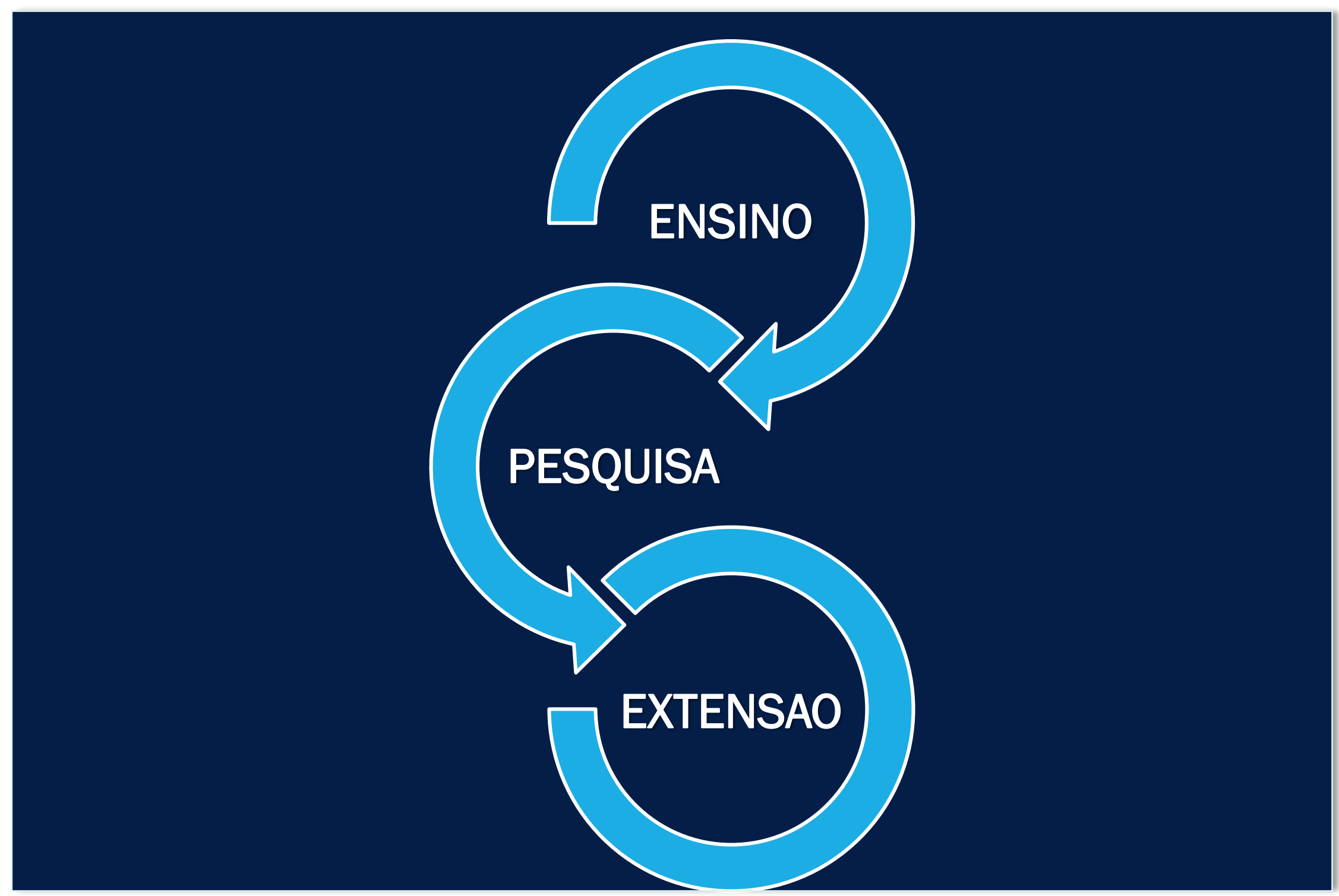




\section{SIMPÓSIO CURADORIA DIGITAL}

\section{Curadoria Digital e Políticas de Digitalização}

\section{OBJETIVO}

Entendemos Curadoria Digital como um campo emergente que engloba o planejamento e gerenciamento de ativos digitais ao longo de sua vida útil, desde a conceituação e apresentação até a preservação de longo prazo em um repositório para reutilização futura. Está associada com a preservação da informação e com a memória científica.

Na Era Digital, a criação e disponibilização de conteúdos digitais à um ritmo acelerado demanda por profissionais com competências no campo de gerenciamento dos ativos digitais preparados para atuar com políticas e estratégias de preservação da informação digital criando padrões e melhores práticas para a gestão digital do patrimônio cultural neste campo emergente e transdisciplinar.

O III Simpósio Curadoria Digital apresenta como proposta promover o debate no uso de Tecnologias da Informação e Comunicação nos Equipamentos Culturais Brasileiros, as Políticas de Digitalização e Fundamentos de Curadoria Digital. 


\section{PÚBLICO ALVO}

O III SIMPÓSIO CURADORIA DIGITAL - um dos eixos temáticos do VI Congresso Internacional em Tecnologia e Organização da Informação, tem como público alvo profissionais da informação, bibliotecários, arquivistas e museólogos; docentes e pesquisadores; estudantes, empresas, startups, gestores, analistas, especialistas e consultores que atuam na área de gestão, organização e preservação da informação e do conhecimento como elementos de convergência na Era Digital. Objetiva reunir especialistas em compartilhar as melhores práticas associadas à Curadoria Digital e os desafios em lidar com volumes significativos de informação e conhecimento bem como avaliar sistemas de gestão da informação no âmbito do ciclo de Curadoria Digital na era da Ciência de Dados.

\section{Dia 18 de agosto $09 \mathrm{~h} 00$ as $12 \mathrm{~h} 00$}

EVENTO GRATUÍTO - VAGAS LIMITADAS - CERTIFICADO USP até Novembro 2020

LOCAL:

\section{Universidade de São Paulo}

Escola de Comunicações e Arte - ECA I Departamento de Informação e Cultura - CBD

INSCRIÇÕES: https://doity.com.br/vi-congresso-internacional-em-tecnologia-e-organizacao-da-informacao

SITE VI TOI 2020 ONLINE: toi.eca.usp.br

Histórico: www.toiomtid.com.br 


\section{CURADORIA DIGITAL E POLÍTICAS DE DIGITALIZAÇÃO}

\section{PROGRAMAÇÃO}

\section{Abertura}

Escola de Comunicações e Artes, ECA USP - Prof. Dr. Francisco Carlos Paletta - VI TOI

Biblioteca Brasiliana Guita e José Mindlin - Msc. Rodrigo Garcia

\section{A TEORIA DA PRESERVAÇÃo DIGITAL: Digitalização, Curadoria e Redes}

\section{Miguel Angel Mardero Arellano}

Fundamentos e Conceitos da Preservação Digital

Digitalização

Curadoria Digital e suas Aplicações

Redes de Preservação 


\section{CURADORIA DIGITAL E POLÍTICAS DE DIGITALIZAÇÃO PROGRAMAÇÃO}

\section{A DIGITALIZAÇÃo de ACERVOS NO BRASIl SEGUNDO A PESQUISA TIC CULTURA}

\section{Luciana Piazzon Barbosa Lima}

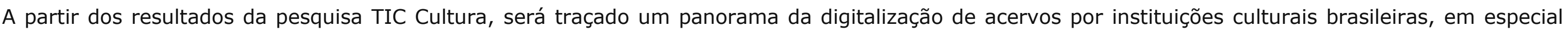
arquivos, bibliotecas e museus. A apresentação trará indicadores sobre a presença, a digitalização e a disponibilização de acervos na Internet, além dos principais desafios enfrentados por tais instituições na criação, preservação e difusão de acervos digitais. A pesquisa TIC Cultura é realizada pelo Centro Regional de Estudos para o Desenvolvimento da Sociedade da Informação (Cetic.br), departamento do Núcleo de Informação e Coordenação do Ponto BR (NIC.br), ligado ao Comitê Gestor da Internet no Brasil (CGI.br).

Pesquisa sobre o uso das Tecnologias de Informação e Comunicação nos equipamentos culturais brasileiros - TIC Cultura 2018:

https://cetic.br/pt/publicacao/pesquisa-sobre-o-uso-das-tecnologias-de-informacao-e-comunicacao-nos-equipamentos-culturais-brasileiros-tic-cultura-2018/

Panorama Setorial da Internet - Acervos digitais: https://cetic.br/pt/publicacao/ano-xi-n-3-acervos-digitais/ 


\section{CURADORIA DIGITAL E POLÍTICAS DE DIGITALIZAÇÃO \\ PROGRAMAÇÃO}

\section{CREATIVE COMMONS E SEU USO NA DISPONIBILIZAÇÃO DE ACERVOS CULTURAIS}

\section{Juliana Monteiro}

A palestra terá como objetivo apresentar o sistema de licenças Creative Commons e discuti-lo frente à cultura do acesso aberto. Além disso, terá como objetivo também discutir seu uso prático na disponibilização de acervos culturais, particularmente museus.

\section{PAINEL}

Moderador: Prof. Dr. Francisco Carlos Paletta, Universidade de São Paulo

Relatoria: Prof. Dr. Francisco Carlos Paletta USP, Escola de Comunicações e Artes, ECA USP

Rodrigo Garcia, Biblioteca Brasiliana Guita e José Mindlin

\section{Organização}

Prof. Dr. Francisco Carlos Paletta USP, Escola de Comunicações e Artes, ECA USP

Prof. Msc. Rodrigo Garcia BBM, Biblioteca Brasiliana Guita e José Mindlin 


\section{Biblioteca Brasiliana ejuse Mindlin}

- Aberta ao público em 2013, a Biblioteca Brasiliana Guita e José Mindlin (BBM) é um órgão da Pró-Reitoria de Cultura e Extensão Universitária da Universidade de São Paulo (USP). Foi criada em janeiro de 2005 para abrigar e integrar a coleção brasiliana reunida ao longo de mais de oitenta anos pelo bibliófilo José Mindlin e sua esposa Guita. Com o seu expressivo conjunto de livros e manuscritos, a brasiliana reunida por Guita e José Mindlin é considerada a mais importante coleção do gênero formada por particulares.

São cerca de 32 mil títulos que correspondem a 60 mil volumes aproximadamente.

- Uma extraordinária coleção sobre o Brasil: A biblioteca formada por José Mindlin ao longo de sua vida estava organizada em quatro principais vertentes temáticas: assuntos brasileiros, literatura em geral, livros de arte, e livros como objeto de arte em virtude de seus traços tipográficos, de sua diagramação, ilustração, encadernação etc.O acervo doado à USP em 2006 reúne material sobre o Brasil ou que, tendo sido escrito e/ou publicado por brasileiros, sejam importantes para a compreensão da história e cultura do país. $O$ conjunto é constituído por obras de literatura, história, relatos de viajantes, manuscritos históricos e literários, periódicos, mapas, livros científicos e didáticos, iconografia e livros de artistas. A Biblioteca Brasiliana Guita e José Mindlin tem o objetivo de expandir seu acervo - torná-la uma biblioteca viva, conforme os ideais de José Mindlin -, adquirindo novos títulos e coleções que dialoguem com as vertentes iniciais do acervo. 
III SIMPÓSIO CURADORIA DIGITAL: Curadoria Digital e Políticas de Digitalização evento Satélite do VI Congresso em Tecnologia e Organização da Informação TOI 2020 ONLINE em colaboração com a Biblioteca Brasiliana BBM.

ACESSO CANAL BBM YOUTUBE: https://www.youtube.com/watch?v=h74zXDH3c20

ACESSO CANAL TOI YOUTUBE: https://www.youtube.com/playlist?list=PLmSHeBiOTButPK-HMewuyjROJ2aeiqVOV

INSCRIÇÃO: https://doity.com.br/vi-congresso-internacional-em-tecnologia-e-organizacao-da-informacao

Escola de Comunicações e Arte - ECA I Departamento de Informação e Cultura - CBD

SITE VI TOI 2020 ONLINE: http://toi.eca.usp.br

Histórico: www.toiomtid.com.br

O III Simpósio de Curadoria Digital - um dos eixos temáticos do VI Congresso Internacional em Tecnologia e Organização da Informação - apresenta como proposta, promover o debate no uso das Tecnologias de Informação e Comunicação nos Equipamentos Culturais Brasileiros, as Políticas de Digitalização e os Fundamentos de Curadoria Digital.

Grupo de pesquisa CNPq: Observatório do Mercado de Trabalho em Informação na Era Digital - dgp.cnpq.br/dgp/espelhogrupo/1137720761096165

Agradecimento FAPESP: Processo 19/01128-7 
Francisco Carlos Paletta: Professor no Departamento de Informação e Cultura da Escola de Comunicações e Artes da Universidade de São Paulo ECA USP. Pós-Doutorado pelo Instituto de Pesquisas Energéticas e Nucleares. Doutor em Ciência, Mestre em Engenharia de Produção, Mestre em Gestion de 1'Information et de la Connaissance Université PaulValery Montpellier III - França. MBA em Altos Estudos de Estratégia e Geopolítica, MBA em Marketing, Bacharel em Engenharia Elétrica. Pós Doutorando em Ciência da Informação pela Universidade do Porto - Portugal. Coordenador do Observatório do Mercado de Trabalho em Informação e Documentação CNPq ECA USP. Presidente da Comissão de Cultura e Extensão Universitária ECA USP. Vice-Chefe do Departamento de Informação e Cultura ECA USP. Docente no curso de Biblioteconomia e Docente/Orientador nos Programas de Pós-Graduação em Ciências da Informação PPGCI ECA USP; e Mestrado Profissional em Gestão da Informação da ECA USP.

Rodrigo Moreira Garcia: Mestrado Acadêmico em Ciência da Informação pela Universidade Estadual Paulista Júlio de Mesquita Filho - UNESP (2007, Bolsista CAPES), graduação em Biblioteconomia pela Universidade Estadual Paulista Júlio de Mesquita Filho - UNESP (2004, IC FAPESP: http://www.bv.fapesp.br/pt/bolsas/47743/) e cursou Processos de Produção pela Faculdade de Tecnologia de São Paulo - FATEC (1998). Atualmente é Bibliotecário, Repr. Téc., na Biblioteca Brasiliana Guita e José Mindlin da Universidade de São Paulo - USP (BBM) e membro do Grupo de Pesquisa CNPq Estudos e Práticas de Preservação Digital do IBICT. Atuou como Bibliotecário-Chefe da Biblioteca Virtual em Saúde da Faculdade de Medicina Veterinária e Zootecnia da USP (BVSVET) (2010-2012). Anteriormente foi Webmaster e Analista de Informação do Centro Latino Americano e do Caribe de Informação em Ciências da Saúde - BIREME/PAHO/WHO (http://bvsalud.org/) - atuando na Coordenação Técnica de diversos Projetos nacionais e internacionais. Tem experiência na área de Biblioteconomia e Ciência da Informação, com ênfase em Representação, Organização e Recuperação da Informação, atuando principalmente nas seguintes áreas: Técnicas e Estratégias de Busca, Modelos de Comportamento Informacional, e, nos últimos anos, tem trabalhado no Desenvolvimento, Gestão e Coordenação (envolvendo equipes Multidisciplinares) de Projetos de Tecnologia da Informação e Comunicação como Bibliotecas Digitais, Repositórios, Sites, Portais, aplicações Web, Gestão de Metadados, Mídias Sociais, Cursos EaD; Além de Serviços de Biblioteca, Organização de Acervo, entre outros.

É permitida a reprodução parcial ou total desta obra, desde que citada a fonte e autoria, proibindo qualquer uso para fins comerciais. Licença Creative Commons

\section{(1) $\otimes \ominus$}




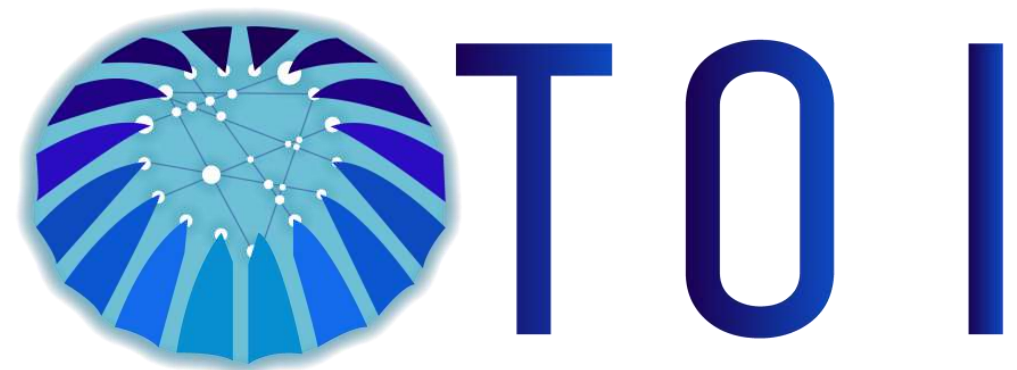

CONGRESSO INTERNACIONAL EM TECNOLOGIA E ORGANIZAÇÃO DA INFORMAÇÃO
TOI - VI Congresso Internacional em Tecnologia e Organização da Informação

\section{LIBRARY AND INFORMATION SCIENCE CONFERENCE}

\section{A TEORIA DA PRESERVAÇÃO DIGITAL:}

digitalização, curadoria e redes

Miguel Angel Márdero Arellano miguel@ibict.br Orcid: : 0000-0001-5306-919X

\section{Simpósio Curadoria Digital}

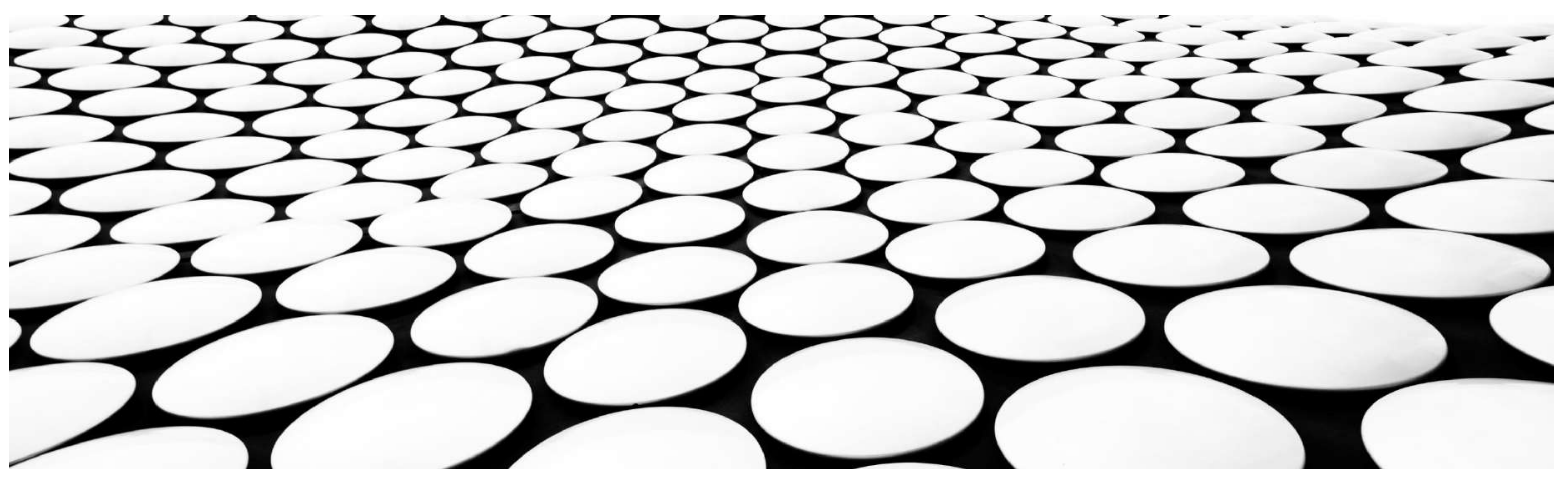




\section{A TEORIA DA PRESERVAÇÃO DIGITAL}

A medida que o que somos é mais e mais expresso em formato digital, os desafios que enfrentamos em termos de preservação de nossa memória cultural vão muito além das bibliotecas e dos arquivos.

É fundamental ver a preservação digital neste sentido mais amplo e conectar o que fazemos a esse desafio que vai muito além de nossas instituições.

Mas, no contexto do que fazemos em bibliotecas arquivos, o foco está nos recursos exclusivos que temos em nossos repositórios institucionais, nossas coleções digitalizadas, nossos dados de pesquisa.

O novo conhecimento se baseia no conhecimento existente e em um ambiente de rede, onde ferramentas como o Google Scholar e Internet Archives podem reunir informações de todo o mundo,

Cabe a nós nas instituições e em nível regional garantir que nosso material esteja acessível a longo prazo. 


\section{A TEORIA DA PRESERVAÇÃO DIGITAL}

\section{O caráter social da Arquivologia e da Biblioteconomia}

As bibliotecas, semelhante aos arquivos, constituem organismos em crescimento, no entanto, armazenam uma coleção de documentos bibliográficos (livros, periódicos etc.) e não bibliográficos (gravuras, mapas, filmes, discos etc.) organizada e administrada para formação, consulta e recreação de todo o público ou de determinadas categorias de usuários (ARAÚJO; OLIVEIRA, 2005).

O lugar que essa unidade informacional ocupa no mundo atual decorre da importância que a informação tem para cada sociedade. Desse modo, a biblioteca participa do aprimoramento intelectual, humanístico, técnico e científico de todos os segmentos sociais (ANDRADE; OLIVEIRA, 2005). 


\section{A TEORIA DA PRESERVAÇÃO DIGITAL}

\section{O caráter social da Arquivologia e da Biblioteconomia}

Os arquivos compreendem o conjunto de documentos de qualquer instituição pública ou privada que tenham adquirido algum valor, merecendo preservação permanente para fins de referência e de pesquisa e que hajam sido depositados ou selecionados para depósito, em um arquivo de custódia permanente (SCHELLENBERG, 2005).

A disseminação da informação é o resultado da implantação da gestão documental, cuja abordagem pós-custodial enfatiza a participação do profissional arquivista nos procedimentos de gerenciamento informacional e na presunção ativa da disseminação da informação. (TERRY COOK, 2012)

O importante é que as duas áreas sustentem os anseios da sociedade do futuro, através da disseminação da informação, independente do tipo de informação e da forma como ela é gerenciada. 


\section{A TEORIA DA PRESERVAÇÃO DIGITAL}

\section{A PRESERVAÇÃO DIGITALÉ...}

"A série de atividades de gestão necessárias para garantir o acesso contínuo aos materiais digitais pelo tempo que for necessário."

Digital Preservation Coalition

- Identificação e seleção de materiais digitais

- Armazenamento e proteção de objetos digitais

- Fornecimento do acesso

- Políticas, procedimentos, fluxos de trabalho, pessoal, experiência, etc.

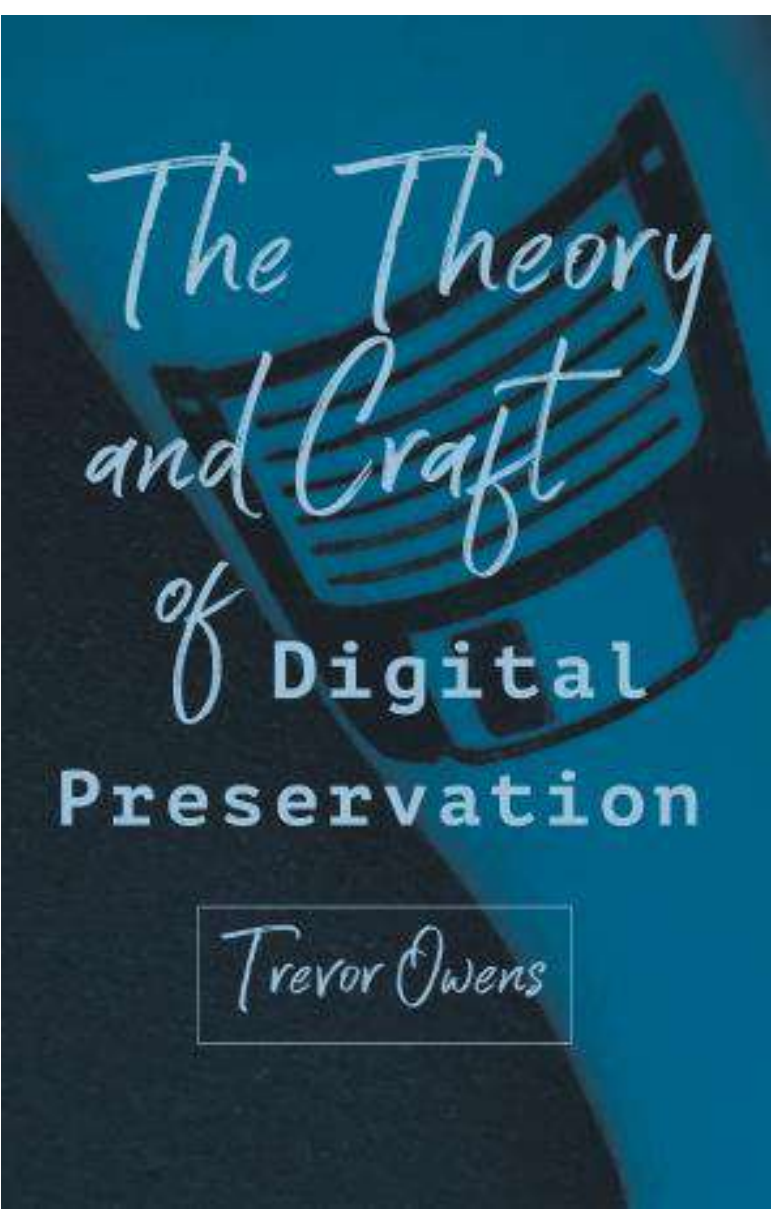




\section{A TEORIA DA PRESERVAÇÃO DIGITAL}

A preservação digital não é sobre um sistema particular, ou uma série de ações de preservação.

Trata-se de preparar conteúdo e coleções para o primeiro em uma grande cadeia de transferências.

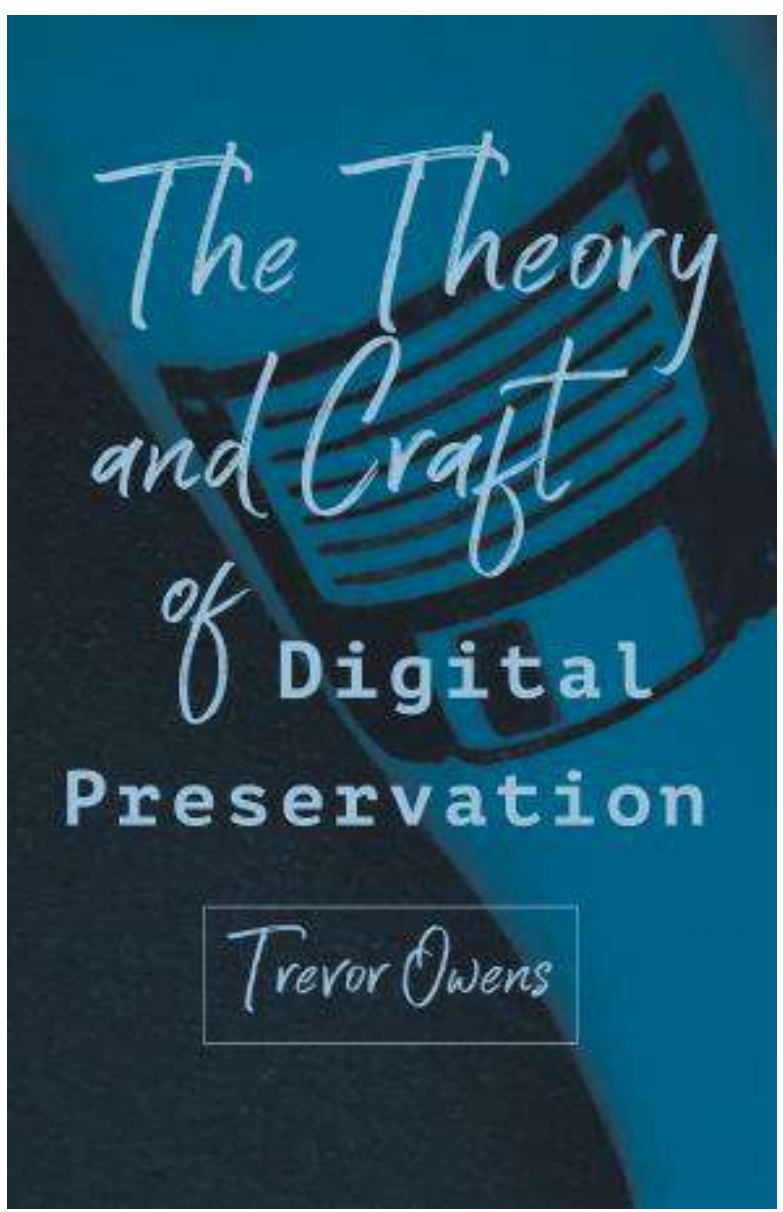

Trevor Owens, 2018 


\section{A TEORIA DA PRESERVAÇÃO DIGITAL}

\section{A PRESERVAÇÃO DIGITAL...}

- Não é backup ou armazenamento.

- Não é digitalização.

- Não é ter uma instância de Archivematica em execução na instituição.

- Não é, sem dúvida, nem mesmo principalmente um desafio técnico.

São todas as coisas que uma organização faz para garantir o acesso contínuo ao conteúdo digital para garantir que, à medida que hardware, software e formatos de objetos digitais vêm e vão, e todas as interdependências complexas que isso incorpora, as informações que são críticas para nossas comunidades permanecem interpretáveis ou humanamente legiveis.

\section{PRE IIIIS}
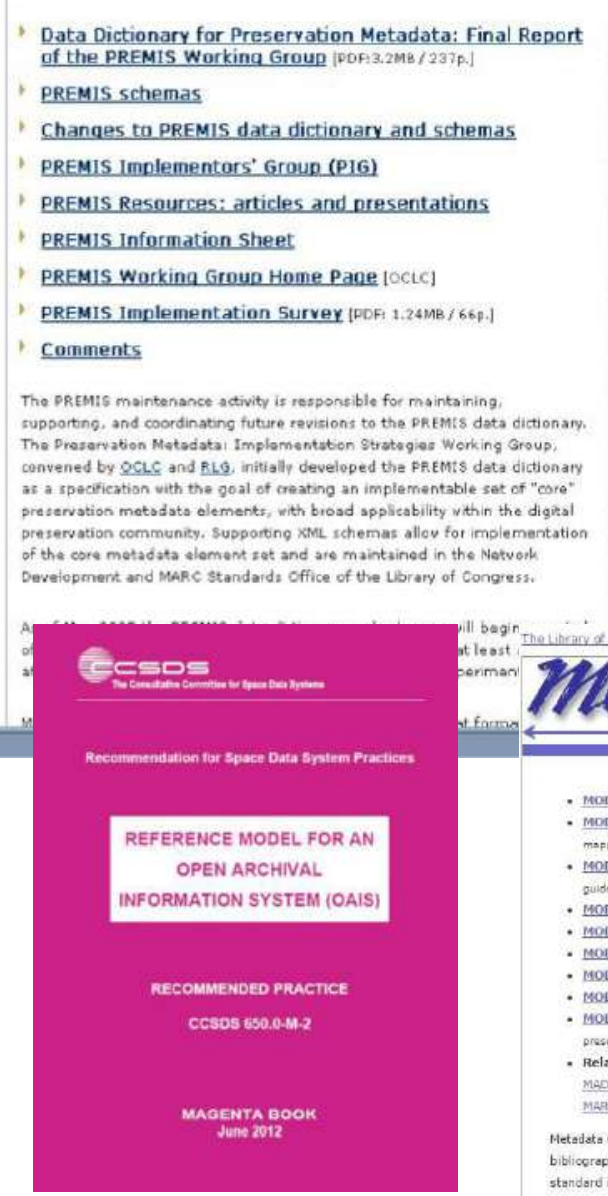

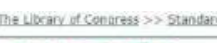

WEST Metadata Encoding \& Transmission Standard

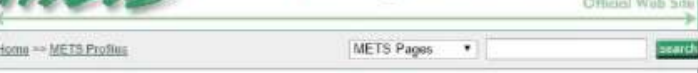
Registered Profiles

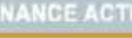

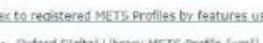

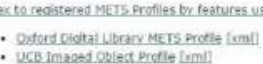

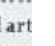

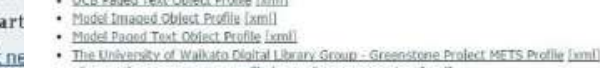

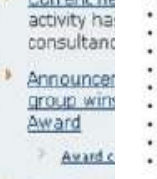

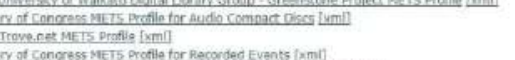

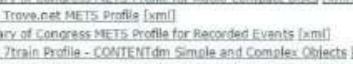

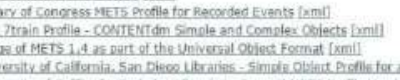

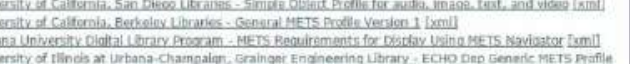

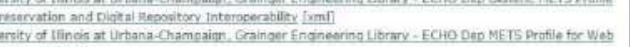

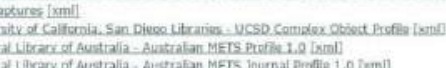

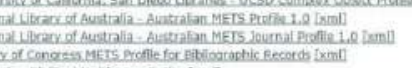

, Lbrany Tre

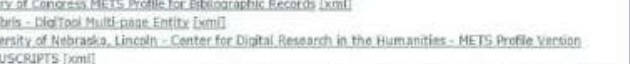

PREMISIm :

(num

An unnoderated listserv open to

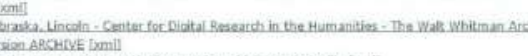

12025. Metadata Object Description Sche

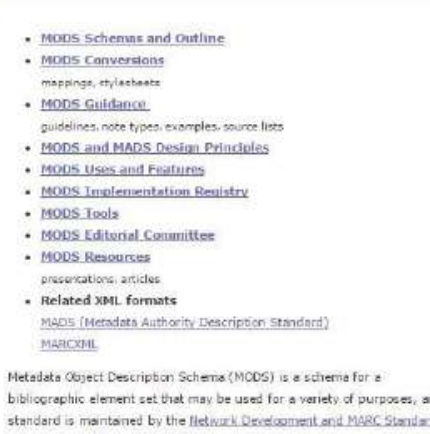

MODS Nows \& Announcoment
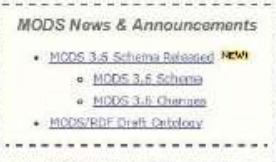

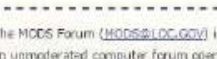

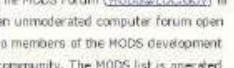


O PLANEJAMENTO DA PRESERVAÇÃO DIGITAL

0 planejamento de preservação é a peça central do modelo de referência para um Sistema Aberto de Informação de Arquivos (OAIS, padrão ISO 14721).

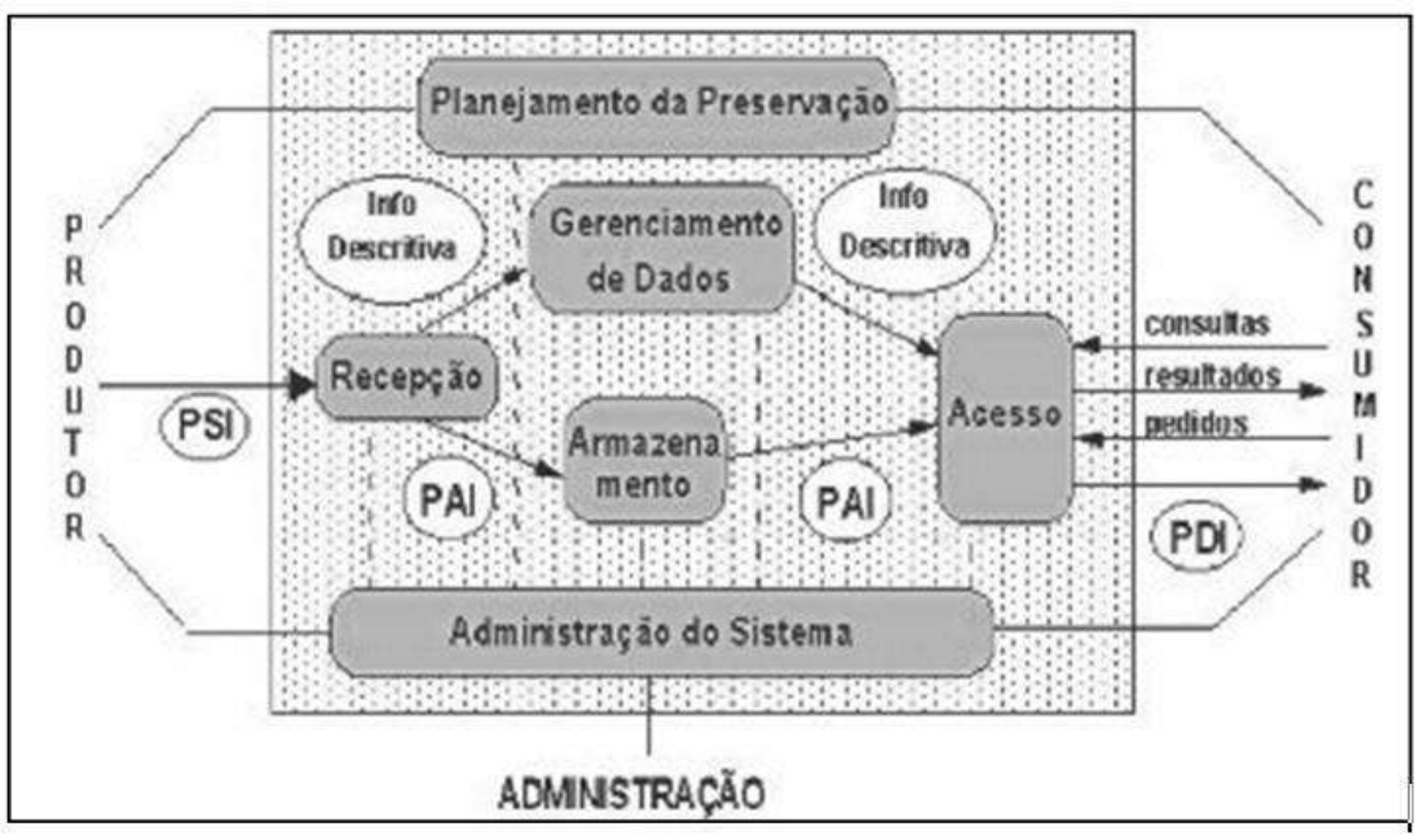




\section{O PLANEJAMENTO DA PRESERVAÇÃO DIGITAL}

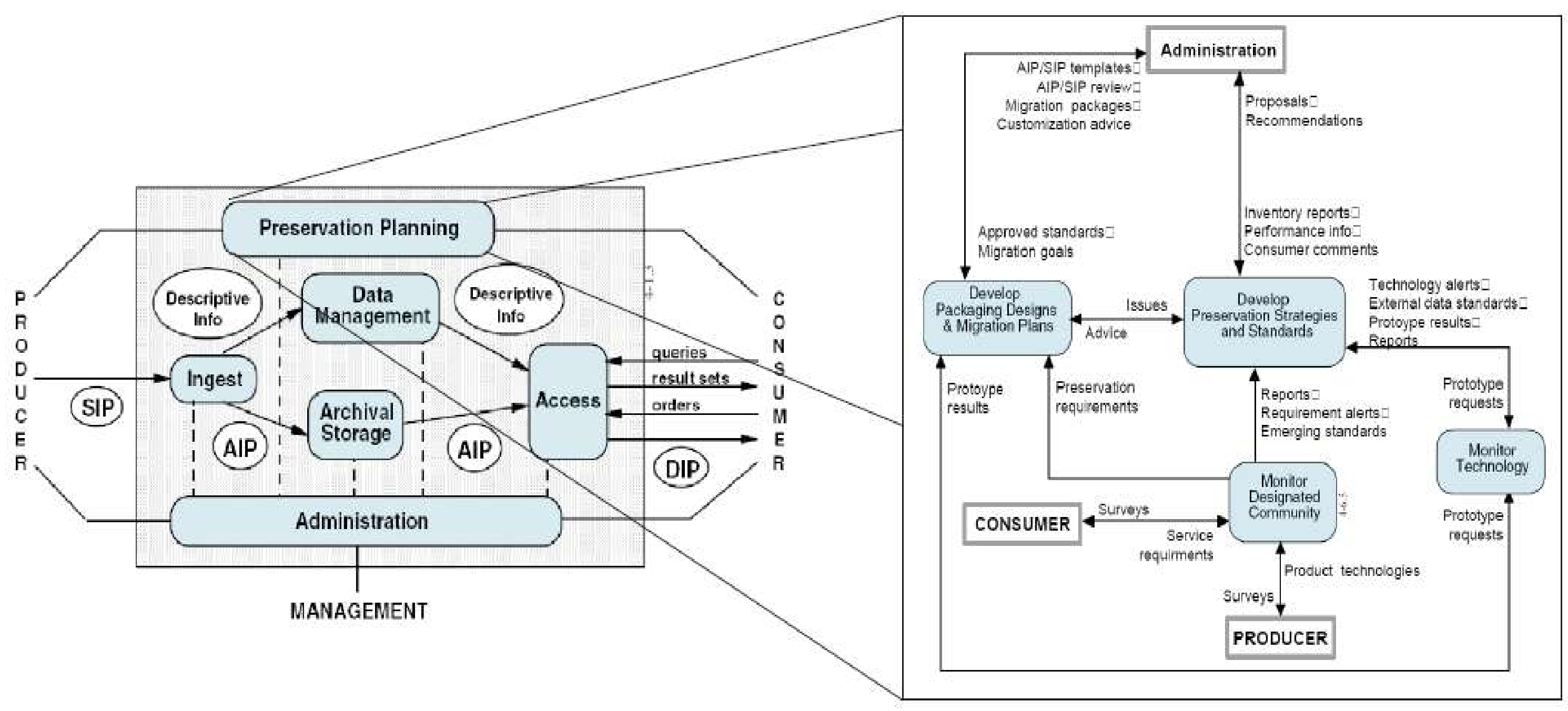




\section{O PLANEJAMENTO DA PRESERVAÇÃO DIGITAL}

A produção de planos de preservação digital tem como objetivo a produção de um documento estratégico que contenha políticas, procedimentos e práticas/atividades para a constituição de uma estrutura técnica e organizacional que permita preservar e gerir de forma continuada os objetos digitais, para mantê-los utilizáveis, do ponto de vista administrativo e eventualmente patrimonial durante o período de tempo considerado necessário.

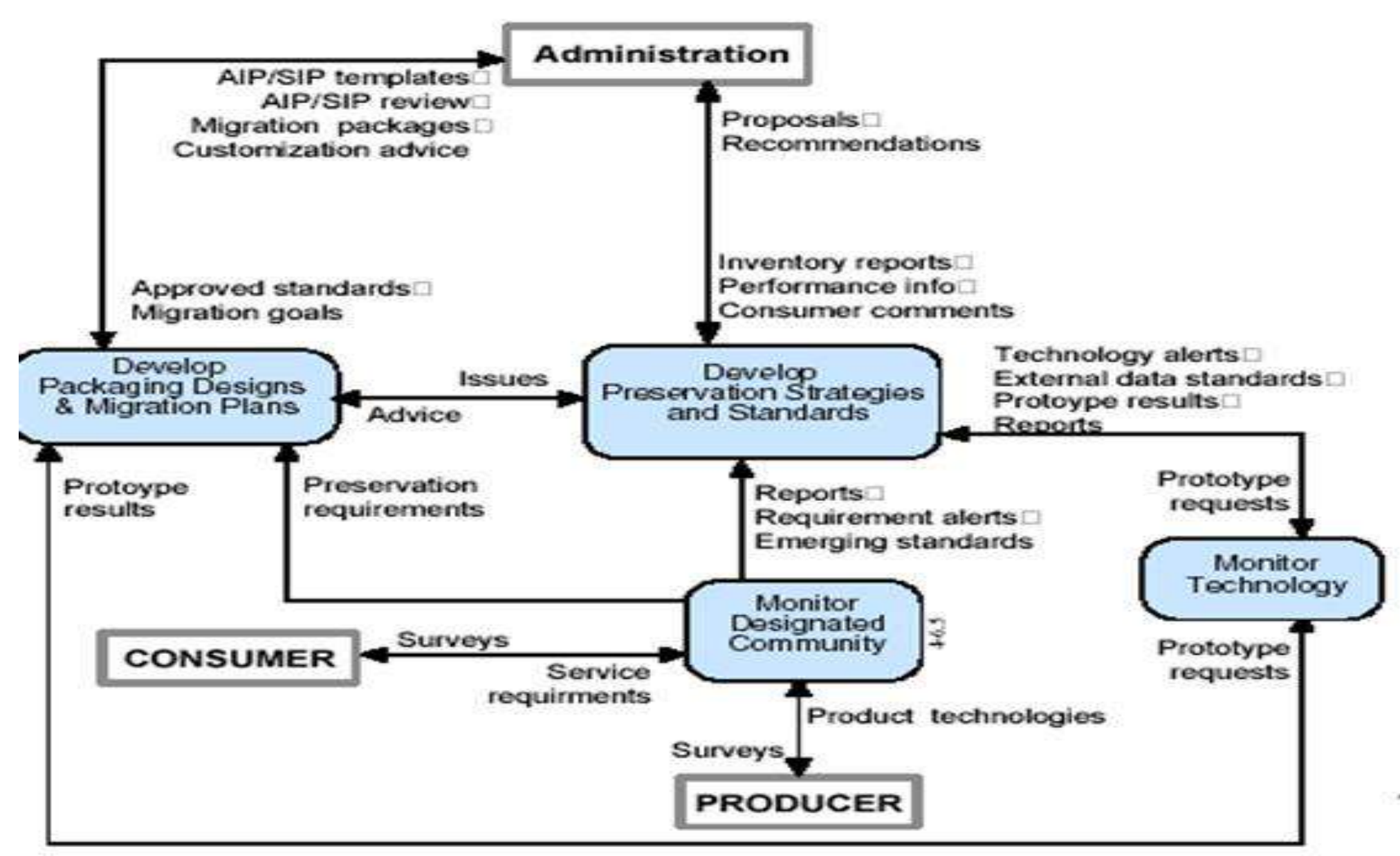




\section{O PLANEJAMENTO DA PRESERVAÇÃO DIGITAL}

Um plano de preservação digital é o compromisso de gestores e agências de financiamento de uma instituição de preservar a longo prazo sus produção digital.

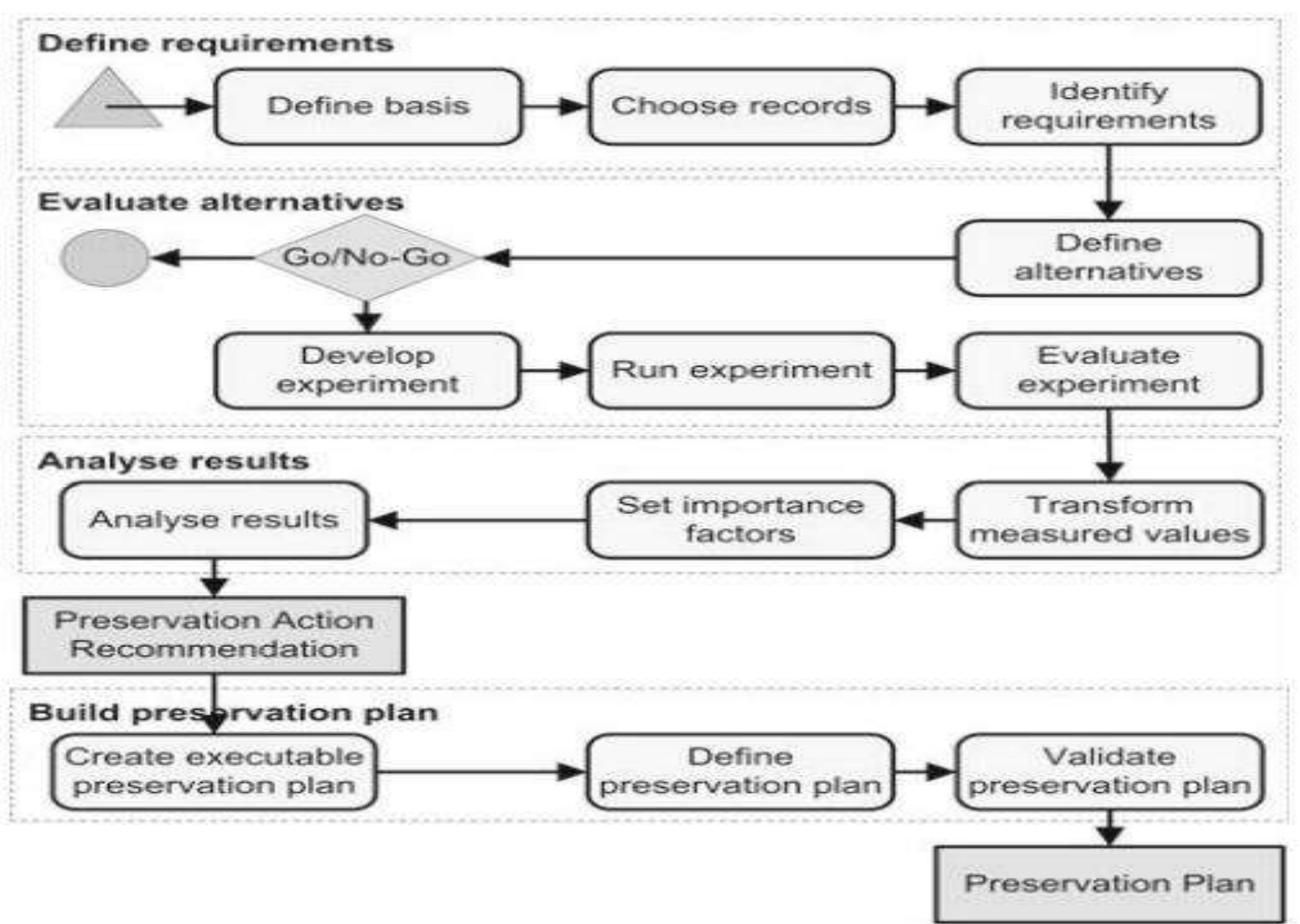

Fluxo de trabalho do planejamento da preservação digital (BECKER et al., 2009) 
0 planejamento de atividades de preservação futuras deve levar em consideração a necessidade óbvia de preservar os resultados intermediários da pesquisa, bem como as publicações finais.

Ao mesmo tempo, devem ser consideradas as consequências da mudança na organização social das atividades de pesquisa. Isso aponta para um foco maior nas redes de pesquisadores como esferas de comunicação e, portanto, para novos itens para preservação futura. 


\section{O PLANEJAMENTO DA PRESERVAÇÃO DIGITAL}

- Lidar com o acúmulo de conteúdo digitalizado em escala e de forma acessivel

- Acompanhar a digitalização de alto volume. Com um plano acessível para armazenamento junto a um plano de preservação para os materiais com valor de longo prazo,

- Com descrição documentada da proveniência das coleções digitais

- Incluindo o arquivamento escuro

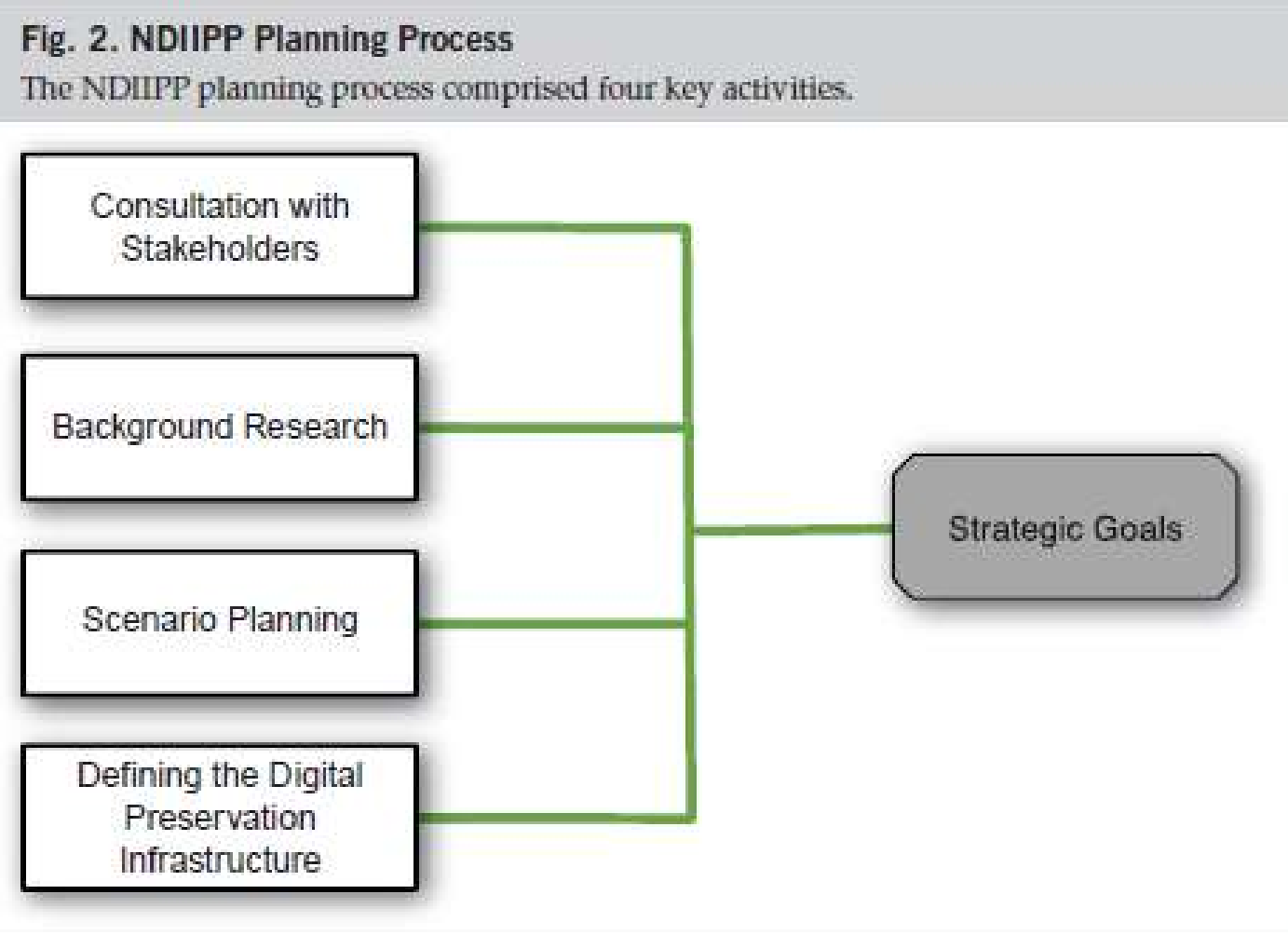




\section{DIGITALIZAR PARA PRESERVAR}

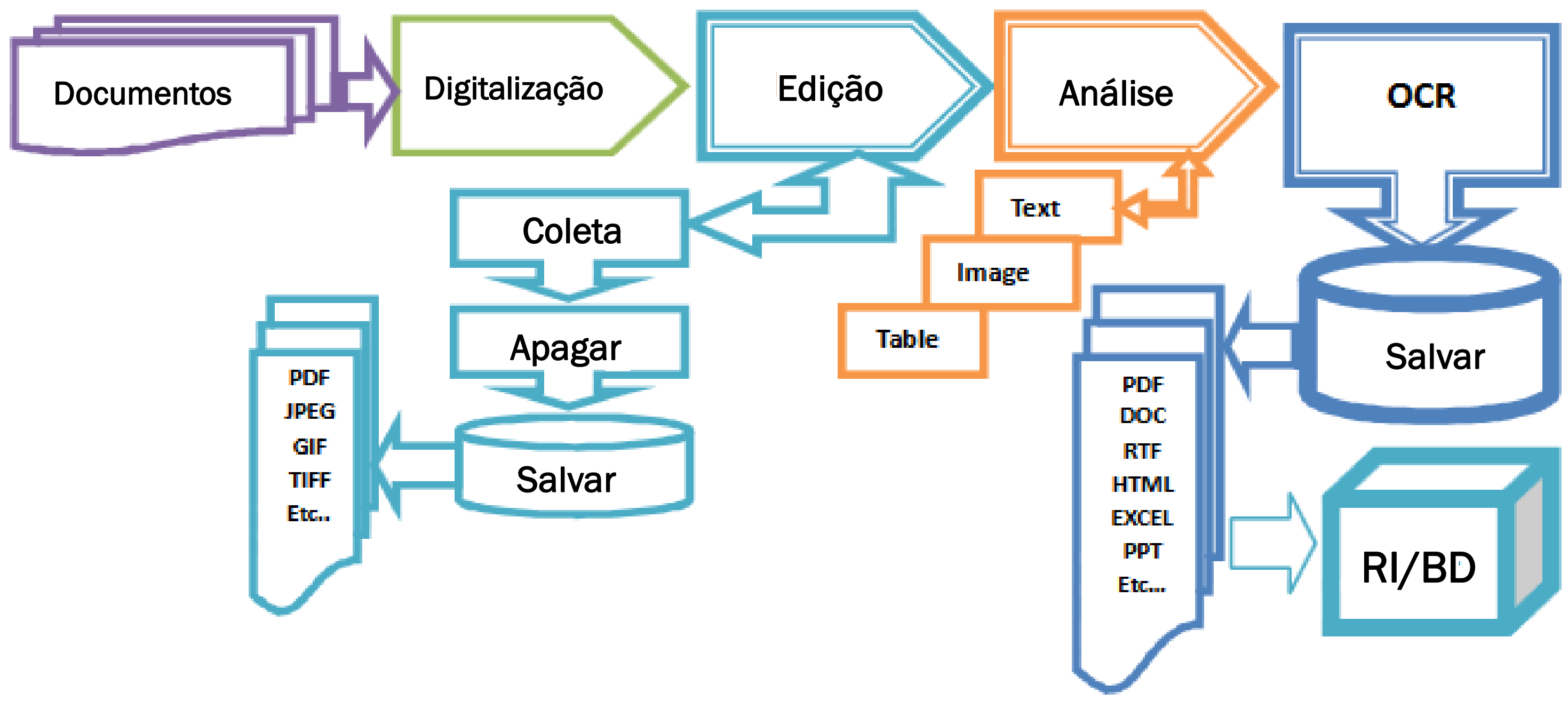




\section{DIGITALIZAR PARA PRESERVAR}

Facilitar o acesso, a divulgação e a preservação de acervos, em especial aqueles que tem valor histórico e necessitam estar protegidos de manuseio excessivo ou inadequado.

Para eles poder ser incluídos na política de preservação e conservação documental da instituição.

Digitalização externa Armazenamento redundante

Normalização
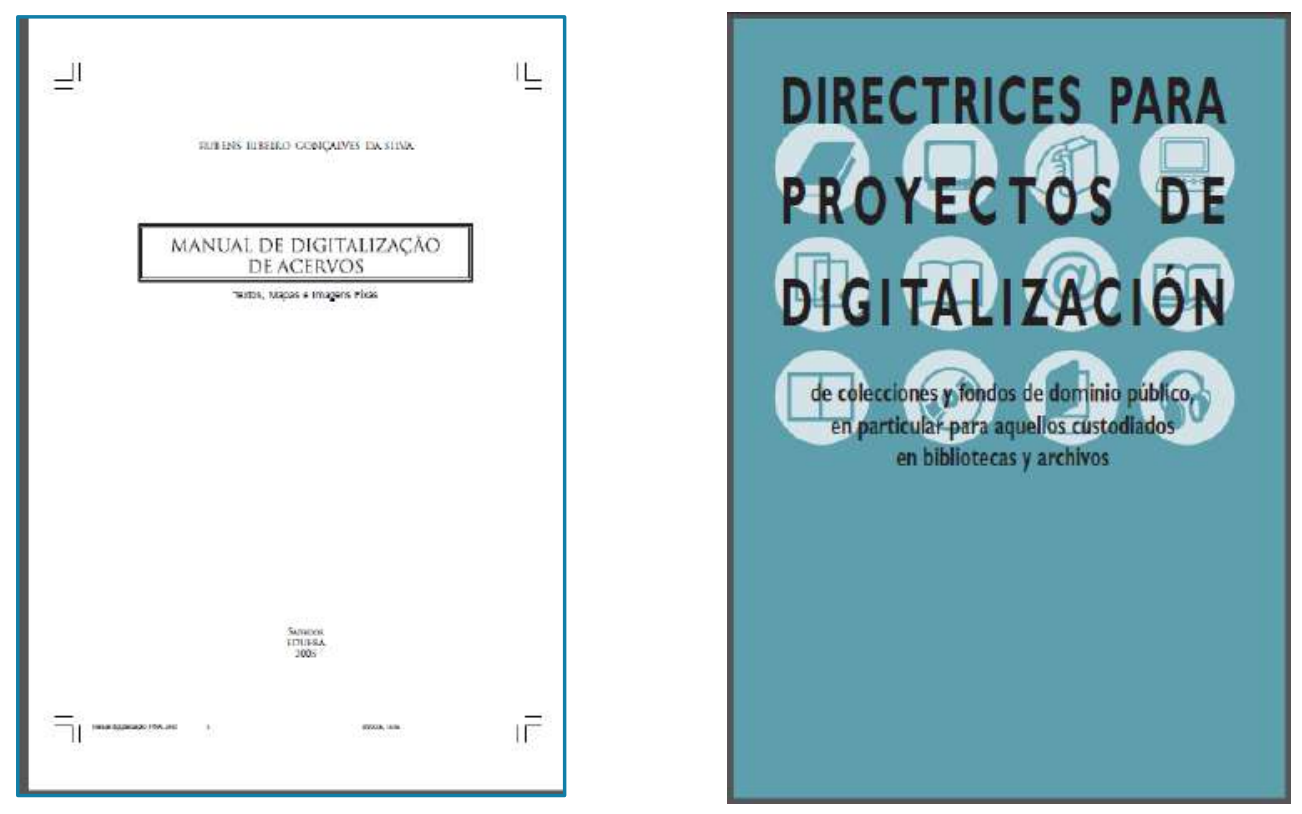

Migração de formatos

Desenvolvendo o plano de preservação

Verificações de fixidez

Seleção para digitalização (política escrita)

Compartilhamento de digitalização

Integração de materiais já digitalizados 


\section{DIGITALIZAR PARA PRESERVAR}

A digitalização não resolve ações que estão diretamente ligadas à Gestão Documental, como:

- elaboração e aplicação de tabelas de temporalidade documental,

- cumprimento de prazos prescricionais estabelecidos em legislação para diferentes documentos,

- politicas de preservação, sigilo e acesso a documentos.

A digitalização em massa permite que as bibliotecas repensem o papel do espaço físico, mas, mais importante, ela permite que as bibliotecas repensem o que as bibliotecas fazem em relação às coleções. (Google e Internet Archive).

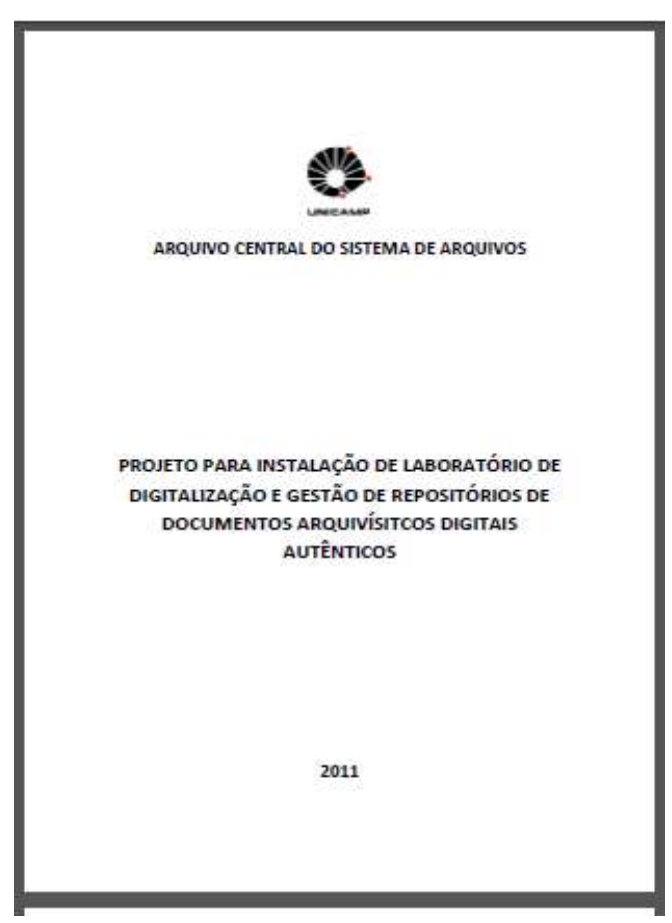




\section{DIGITALIZAR PARA PRESERVAR}

Ao se analisar políticas de digitalização, há documentos que requerem muito mais atenção.

Um exemplo desta preocupação, podem ser ações de digitalização para grandes massas ou volumes de fotografias.

A digitalização de imagens não dispensa os processos de identificação e tratamento técnico das imagens, que para efeito de documentação histórica possuem um grau de detalhamento que os programas hoje utilizados passam muito distantes.

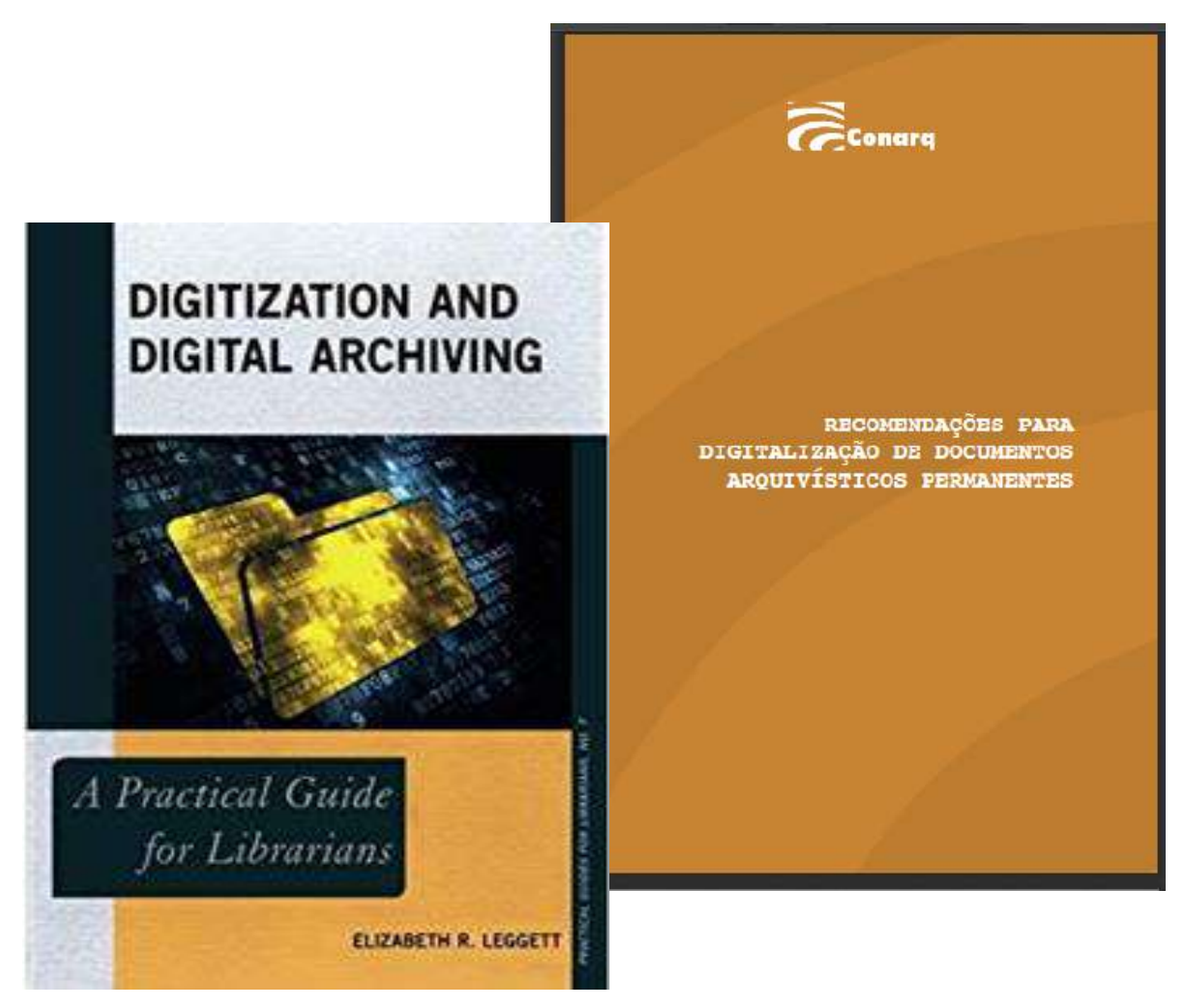




\section{DIGITALIZAR PARA PRESERVAR}

\begin{tabular}{|c|c|c|c|c|c|c|}
\hline \multicolumn{7}{|c|}{$\begin{array}{c}\text { FIGURE } 31 \\
\text { DIGITIZATION POLICIES }\end{array}$} \\
\hline \multirow[b]{3}{*}{ Policy } & \multicolumn{6}{|c|}{ Survey Year } \\
\hline & \multicolumn{3}{|c|}{$2001(n-227)$} & \multicolumn{3}{|c|}{$2004(n-218)$} \\
\hline & $\begin{array}{l}\text { Policies } \\
\text { in place }\end{array}$ & $\begin{array}{c}\begin{array}{c}\text { Policies in } \\
\text { development }\end{array} \\
\end{array}$ & $\begin{array}{l}\text { No policies in } \\
\text { place or in } \\
\text { development/ } \\
\text { Don't know }\end{array}$ & $\begin{array}{l}\text { Policies } \\
\text { in place }\end{array}$ & $\begin{array}{c}\text { Policies in } \\
\text { development }\end{array}$ & $\begin{array}{l}\text { No policies in } \\
\text { place or in } \\
\text { development/ } \\
\text { Don't know }\end{array}$ \\
\hline Access & $1.3 \%$ & $7.5 \%$ & $91.2 \%$ & $20.6 \%$ & $7.8 \%$ & $71.6 \%$ \\
\hline Best practices & $0.9 \%$ & $3.5 \%$ & $95.6 \%$ & $10.7 \%$ & $5.1 \%$ & $84.2 \%$ \\
\hline $\begin{array}{l}\text { Conversion of digital files } \\
\text { to next-generation formats }\end{array}$ & $0.4 \%$ & $3.5 \%$ & $96.0 \%$ & $0.5 \%$ & $7.0 \%$ & $92.6 \%$ \\
\hline $\begin{array}{l}\text { Digital format (e.g., TIFF, } \\
\text { GIF, PAL) }\end{array}$ & $2.2 \%$ & $4.8 \%$ & $92.9 \%$ & $4.7 \%$ & $6.5 \%$ & $88.8 \%$ \\
\hline Evaluation & $1.3 \%$ & $4.4 \%$ & $94.3 \%$ & $5.1 \%$ & $7.0 \%$ & $87.9 \%$ \\
\hline Intellectual property issues & $0.9 \%$ & $7.9 \%$ & $91.2 \%$ & $9.8 \%$ & $7.0 \%$ & $83.2 \%$ \\
\hline Materials to be digitized & $2.6 \%$ & $10.1 \%$ & $87.2 \%$ & $2.3 \%$ & $11.7 \%$ & $86.0 \%$ \\
\hline Priorities for digitization & $2.2 \%$ & $11.0 \%$ & $86.8 \%$ & $3.3 \%$ & $10.7 \%$ & $86.0 \%$ \\
\hline Preservation & $0.4 \%$ & $6.2 \%$ & $93.4 \%$ & $4.2 \%$ & $11.2 \%$ & $84.6 \%$ \\
\hline Quality control & $1.3 \%$ & $5.3 \%$ & $93.4 \%$ & $6.0 \%$ & $8.4 \%$ & $85.6 \%$ \\
\hline Standards & $0.4 \%$ & $7.0 \%$ & $92.5 \%$ & $7.5 \%$ & $8.4 \%$ & $84.1 \%$ \\
\hline Other & $4.0 \%$ & $1.3 \%$ & $94.7 \%$ & $1.2 \%$ & $2.4 \%$ & $96.3 \%$ \\
\hline
\end{tabular}

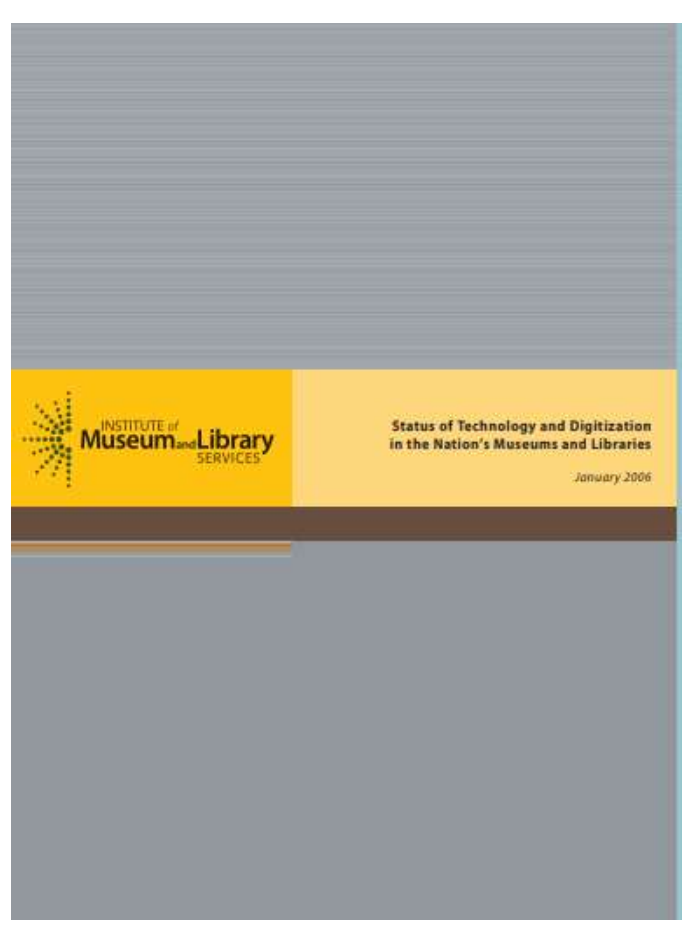


Conjunto de ações que garantam a qualidade, integridade e auditoria de conjuntos complexos de informação a partir de ações executadas durante o ciclo de vida dos objetos digitais.
Recentemente aplicado a materiais digitais, é sobre como manter e agregar valor a um corpo confiável de informação digital, tanto para uso atual e futuro: é a gestão ativa e avaliação de informação digital em todo o seu ciclo de vida.

Continuum de atividades, apoiando os requisitos tanto para uso corrente como futuro.
Envolvimento ativo de profissionais da informação na gestão, incluindo a preservação de dados digitais para uso futuro.
Atividade de gestão e promoção do uso dos dados a partir do momento de

criação, para assegurar que eles são adequados para uso contemporâneo e disponíveis para descoberta e reutilização.

Conhecimentos e práticas em preservação e acesso a recursos digitais que resultaram num conjunto de

estratégias, abordagens tecnológicas e atividades que agora são coletivamente conhecidas com 'curadoria digital'.

\section{CURADORIA DIGITAL}

Termo hiperonímio ou guarda-chuva

Atividade contínua de gestão e melhoria do uso de recursos digitais durante os seus ciclos de vida ao longo do tempo.

É cuidar de recursos. Ela envolve a seleção, avaliação, armazenamento e

Ações necessárias para manter dados de pesquisa em meio digital e outros materiais ao longo de seus ciclos de vida e do tempo para as gerações atuais e futuras de usuários.

Processo de estabelecimento

manutenção de um corpo confiável de informação digital dentro de repositórios de preservação a longo prazo para uso corrente e futuro.

\section{e
e
e
e}

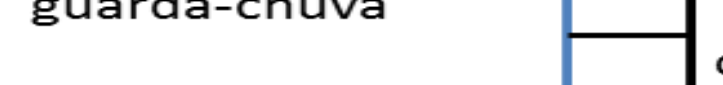




\section{A CURADORIA DE OBJETOS DIGITAIS}

\section{CURADORIA DIGITAL}

Neologismo para todas as ações necessárias para manter objetos e dados digitais ao longo de todo o seu ciclo de vida e ao longo do tempo para as gerações atuais e futuras de usuários, incluindo arquivamento e preservação digital; os processos necessários para uma boa criação e gestão de dados e para agregar valor aos dados para gerar novas fontes de informação e registros de conhecimento

- estende-se para além do controle de repositórios que arquivam recursos informacionais;

- envolve a atenção do criador de conteúdos e dos usuários

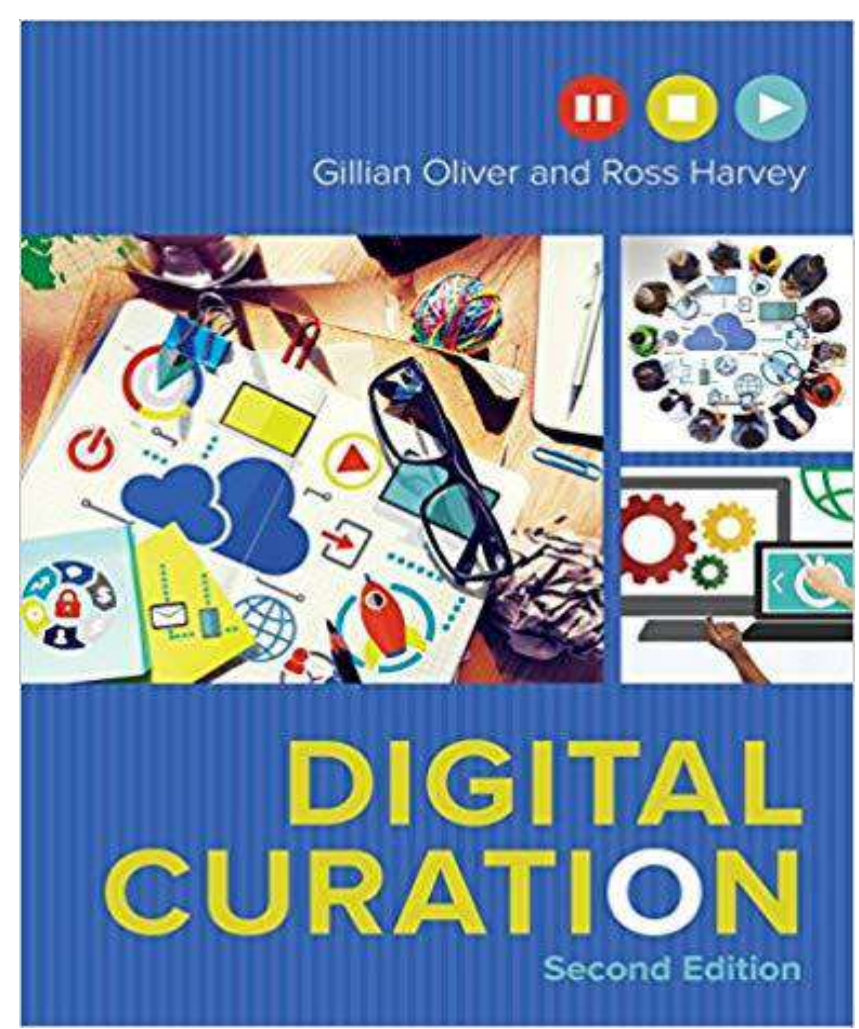
futuros;

- relaciona-se com todo o ciclo de vida de materiais digitais. 


\section{A CURADORIA DE OBJETOS DIGITAIS}

"Curadoria Digital envolve a manutenção, a preservação e a agregação de valor aos dados de pesquisa através de todo o seu ciclo de vida."

\section{Digital Curation Centre}

"A curadoria digital é um trabalho intervencionista, uma vez que se ocupa em agregar conteúdo à informação em meio digital afim que de enriquecê-lo para preservá-lo. Isso tudo para proporcionar ao usuário uma experiência fidedigna de uso daquela informação preservada."

\begin{tabular}{|c|c|c|}
\hline & Curadoria digital & Preservação digital \\
\hline Objetivo & $\begin{array}{l}\text { Garantir a sustentabilidade dos } \\
\text { dados a longo prazo }\end{array}$ & $\begin{array}{l}\text { Garantir acesso a longo prazo da } \\
\text { informação armazenada digitalmente }\end{array}$ \\
\hline Abordagem & $\begin{array}{c}\text { Envolve a manutenção, } \\
\text { preservação e agregação de valor } \\
\text { aos dados da pesquisa digital em } \\
\text { toda sua vida útil }\end{array}$ & $\begin{array}{l}\text { Envolve a retenção do objeto } \\
\text { informacional e seu significado }\end{array}$ \\
\hline Atividades necessárias & $\begin{array}{l}\text { Seleção, preservação, manutenção, } \\
\text { coleta, arquivamento e reavaliação } \\
\text { de ativos digitais. }\end{array}$ & $\begin{array}{c}\text { Seleção, manutenção, coleta, } \\
\text { arquivamento e reavaliação de ativos } \\
\text { digitais. }\end{array}$ \\
\hline Técnicas & $\begin{array}{c}\text { Criação de políticas, atividades em } \\
\text { cada etapa do ciclo de vida dos } \\
\text { objetos ; considera a natureza de } \\
\text { cada objeto }\end{array}$ & $\begin{array}{l}\text { Criação de políticas, emulação, } \\
\text { migração de dados e encapsulamento; } \\
\text { considera a natureza de cada objeto }\end{array}$ \\
\hline Longevidade & Considerada atividade contínua & Considerada atividade contínua \\
\hline
\end{tabular}




\section{A CURADORIA DE OBJETOS DIGITAIS}

\section{O planejamento da curadoria}

Desenvolver uma política e estratégia por escrito para apoiar as atividades e ajudar a proteger os recursos

Trabalhar com a consciência da distinção entre funções de acesso e preservação.

Desenvolver modelos de financiamento sustentáveis e gestão responsável.

Melhorar as ações curatoriais e de controle de qualidade, seja por meio de formatos de dados, padrões de metadados, serviços de migração, etc.

Replicar documentos digitais em vários repositórios certificados e distribuídos.

Substituir a redundância aleatória pela redundância planejada de conteúdo preservado.

Desenvolver diretrizes e critérios para lidar com o material preservado.

Participar de iniciativas colaborativas de preservação digital. 


\section{A PRESERVAÇÃO DIGITAL EM REDE}

\section{A preservação digital distribuída enfatiza a importância de fatores como:}

- replicação de conteúdo,

- independência e coordenação para garantir a longevidade dos objetos digitais

- Distribuição geográfica

- Heterogeneidade da infraestrutura

- Diversidade organizacional

Pensar no nível de rede, significa trabalhar juntos para que isso aconteça. Reconhecer porque não podemos fazer isso sozinhos.

Tentar pensar nisso da forma mais holística possível, como infraestrutura.

Agora, isso inclui os sistemas, redes e recursos computacionais necessários para fazer o trabalho, mas também as outras coisas mencionadas até aqui. 


\section{A PRESERVAÇÃO DIGITAL EM REDE}

\section{Uma infraestrutura de preservação digital distribuída com...}

- Ferramentas e serviços

- Recursos e redes computacionais

- Políticas e estruturas de financiamento que permitem a capacidade

- Expertise e habilidades

- Pesquisa

Indo além das ferramentas e serviços para construir capacidade institucional e de rede

Pensando em termos de infraestrutura robusta, além das

ferramentas e pensar em termos de capacitação e tudo o que isso envolve.
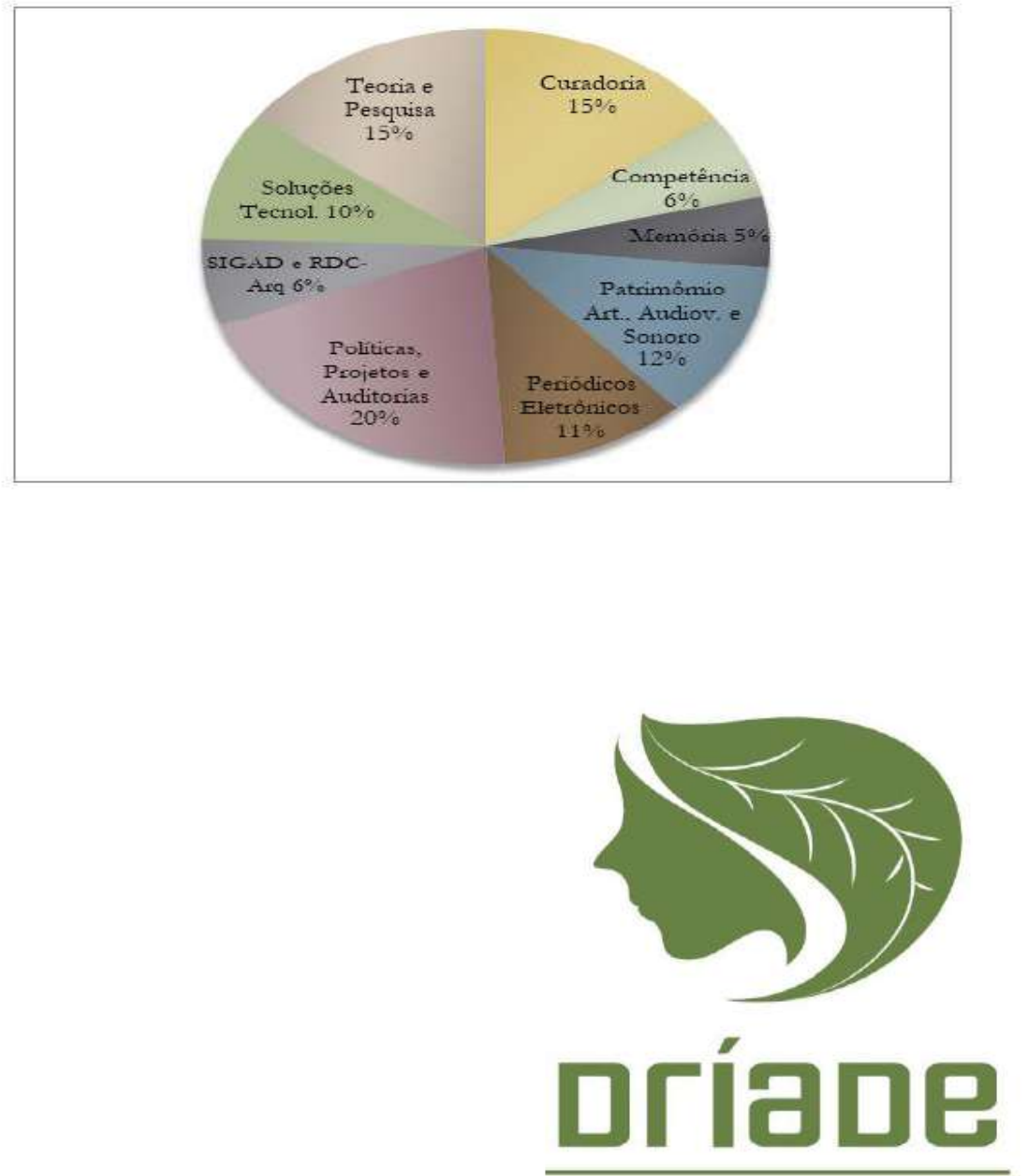


\section{A PRESERVAÇÃO DIGITAL EM REDE}

“As organizações de memória cultural podem e devem assumir a responsabilidade pelo gerenciamento de seus acervos digitais, e tais instituições podem obter muitas vantagens em estratégias colaborativas de preservação e acesso a longo prazo."

Katherine Skinner, Educopia

Manter o controle sobre o conteúdo e o repositório e a infraestrutura de preservação necessária para fornecer acesso a ele ao longo do tempo é fundamental.

Mas os esforços de colaboração estabelecem as bases para enfrentar os desafios futuros, dos quais haverá muitos! 


\section{A PRESERVAÇÃO DIGITAL EM REDE}

Uma das razões pela qual temos uma crise de sustentabilidade atual nos projetos de preservação digital é porque as bibliotecas e os arquivos não pensaram o suficiente sobre a importância de trabalhar juntas para atingir objetivos comuns.

Não podemos terceirizar a função central de administração que as bibliotecas e arquivos desempenham.

E trabalhando juntos, fazendo isso nós mesmos, construímos redes fortes que nos permitem enfrentar os desafios futuros.

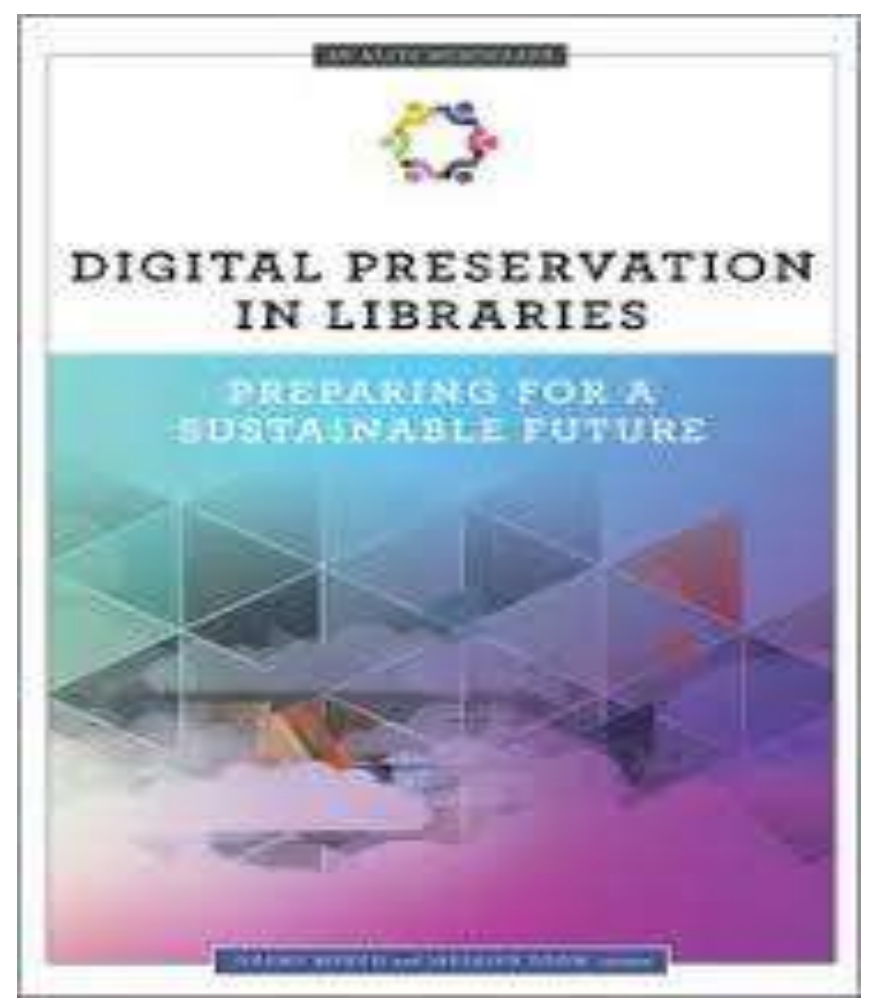




\section{NO BRASIL...}

Ainda há grande distância entre as propostas de iniciativas internacionais de preservação digital que surgem, e o status real no Brasil, dada a insuficiência de recursos e o planejamento inadequado das práticas para permitir o acesso de longo prazo.

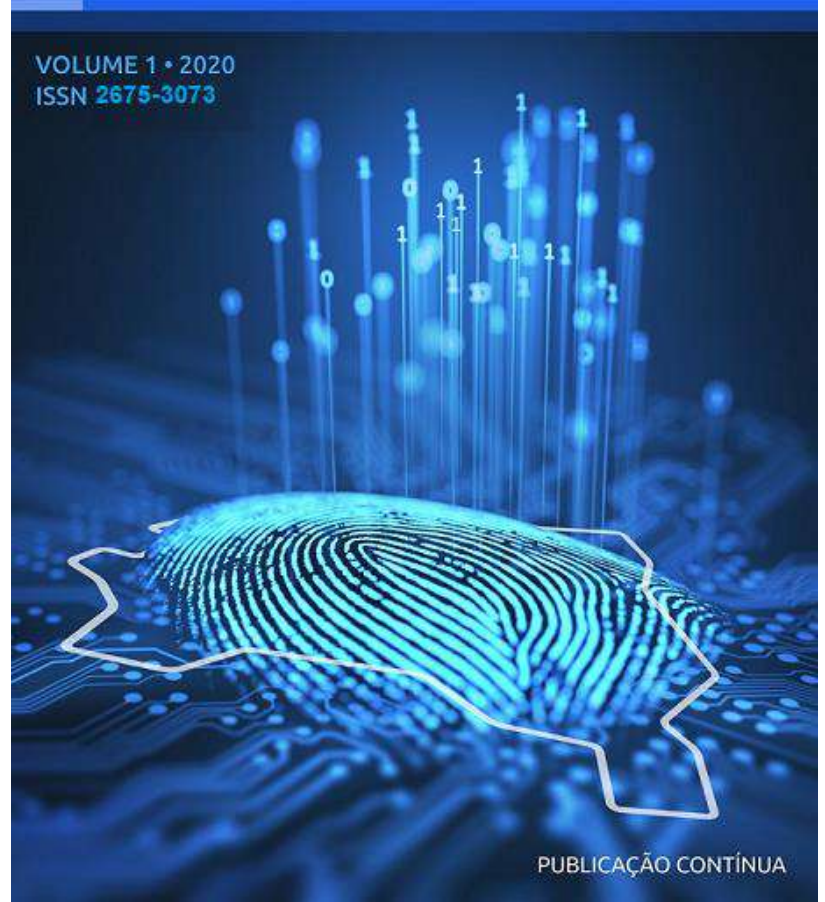




\section{A REDE CARINIANA DO IBICT}

Tem um foco na preservação de acervos locais exclusivos e plataformas de repositório diversas

- Repositórios institucionais

- Sistemas de gerenciamento de ativos digitais

- Plataformas de repositório multimídia

- Arquivos da web

- Repositórios de dados de pesquisa

- Mídia em risco e coleções especiais

- Registros institucionais

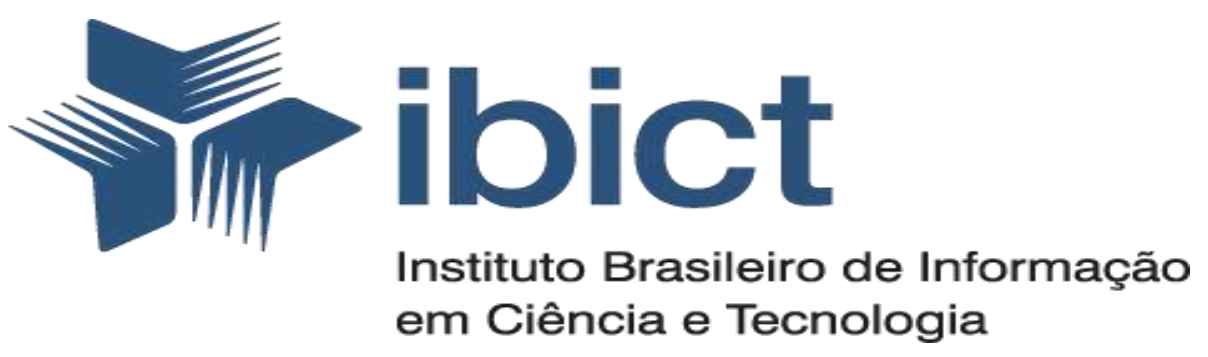




\section{A REDE CARINIANA DO IBICT}

\section{Procura...}

- Fornecer experiência e recursos para desenvolver políticas, procedimentos e fluxos de trabalho locais.

- Fornecer oportunidades de desenvolvimento educacional e profissional.

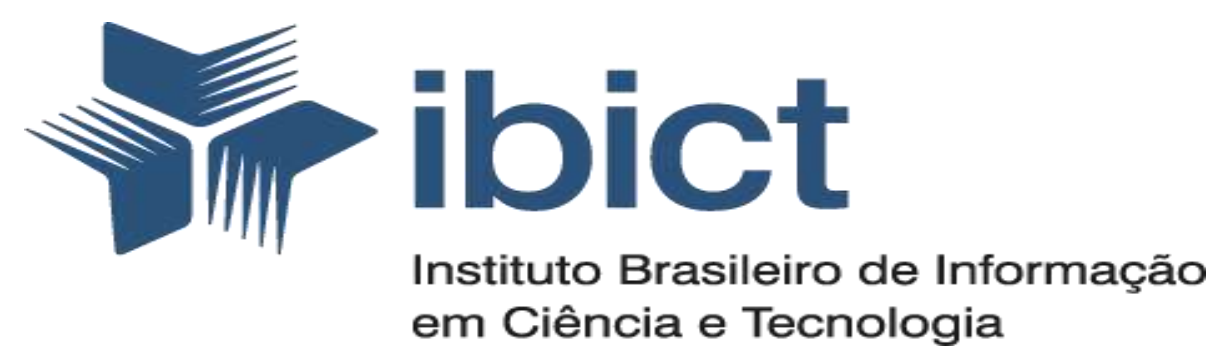

- Ajudar os membros a defenderem recursos

- Advogar como um consórcio para maior conscientização e recursos para a preservação

digital nas instituições 


\section{A REDE CARINIANA DO IBICT}

Colaborar com parceiros externos para fornecer aos membros Da Cariniana ferramentas e serviços

Trabalhar com a comunidade mais ampla para alinhar os esforços da Cariniana com os esforços nacionais e internacionais emergentes

Fornecer treinamento e suporte para plataformas e serviços de preservação

Trabalhar para integrações de plataformas e novas ofertas de serviços

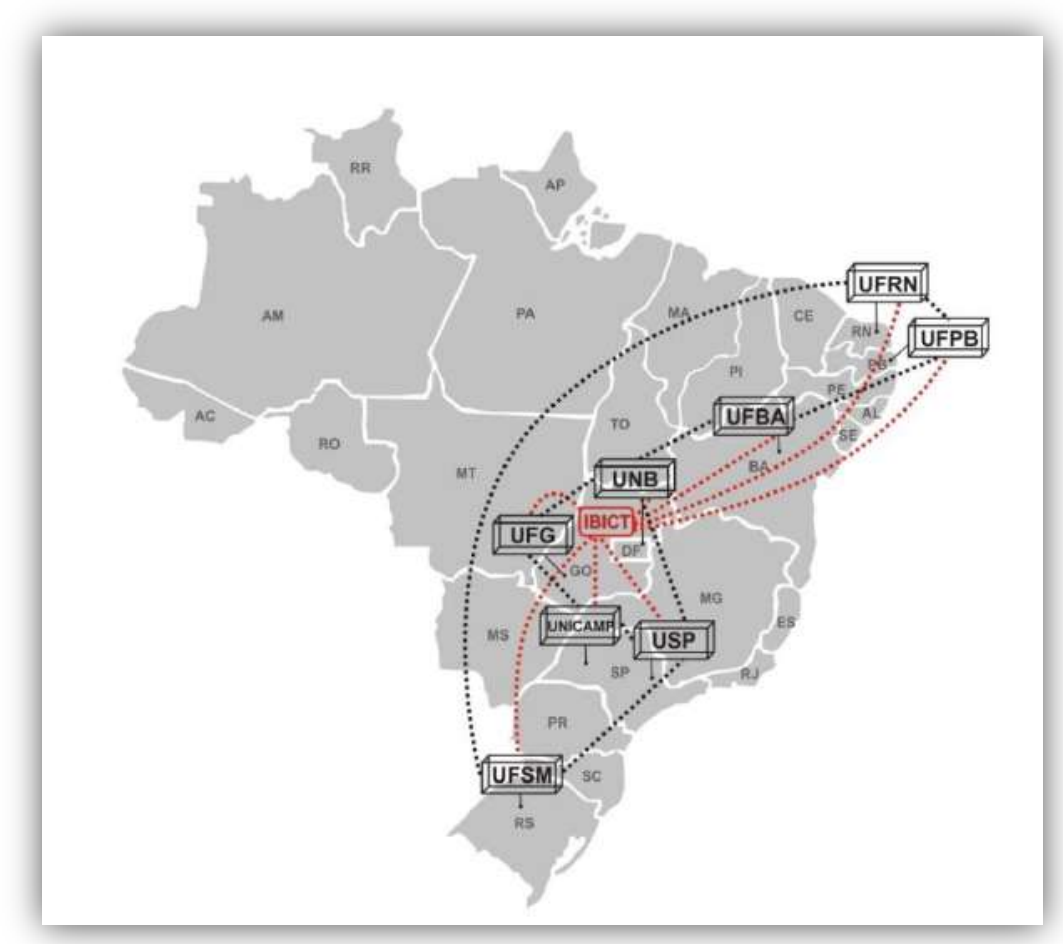




\section{Lepidus}

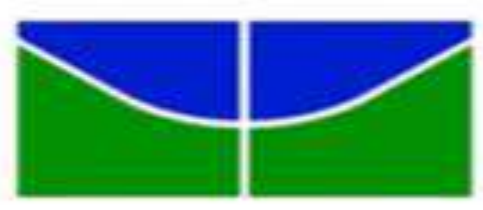

unesp

UNIVERSIDADE ESTADUAL PAULISTA

TUUUO DE MESOUITA FILHO-

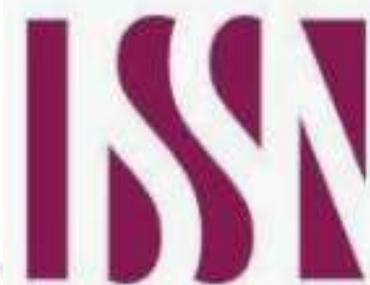

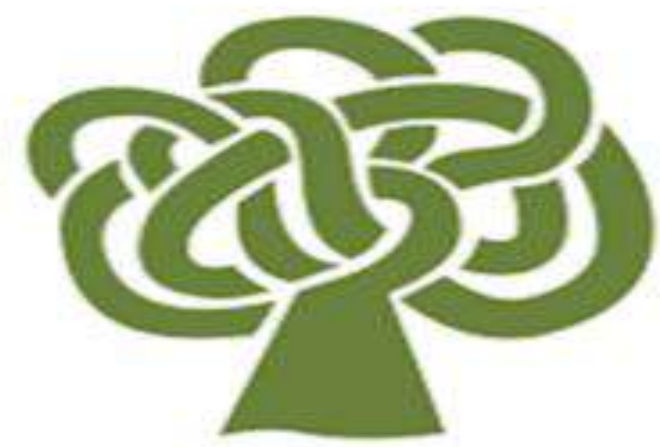

Cariniana

Rede Brasiteira de Servicos de Preservaçáo Digital'

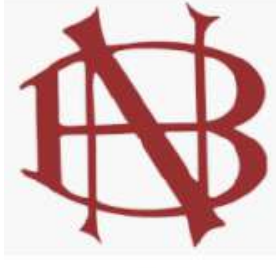

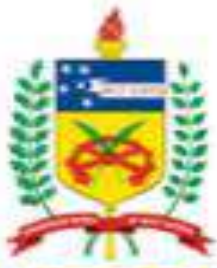

UFSC

\section{UERN}

4. UNIVERSIDADE

18. FEDERAL DOCEARÁ

00

UFG LEGNTVM

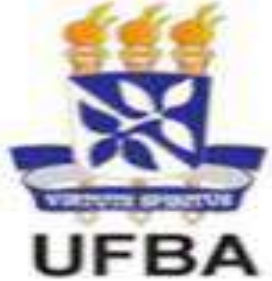

एSP

\section{The Keepers Registry}

Supporting long-term access to journal content

SFU Simon fraser university

LSG

S)

UFRES UNIIEESSIDADE FEDERAL
DO RIO GRANDE DO SUL

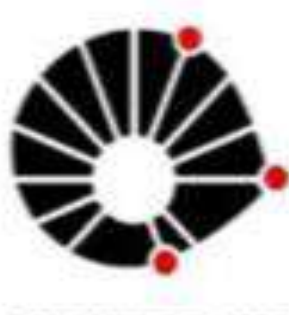

UNICAMP

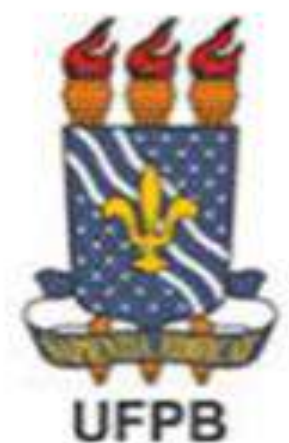

ab df

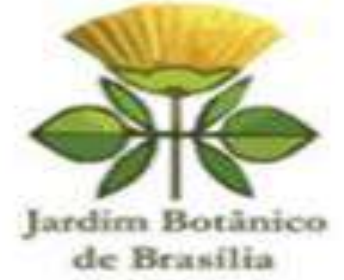

衰主 terra

STANFORD

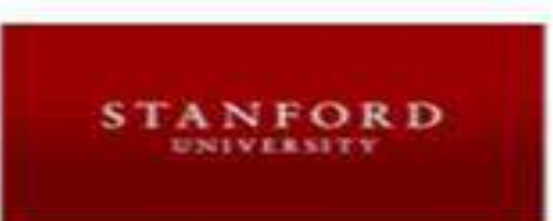


Miguel Ángel Márdero Arellano: Formou-se em Antropologia Social do Instituto Nacional de Antropologia e História (1985), mestrado (1998) e doutorado (2008) em Ciências da Informação pela Universidade de Brasília. Ele trabalha no Instituto Brasileiro de Informação em Ciência e Tecnologia (IBICT) desde 1997, É Tecnologista Senior é coordenador da Rede Brasileira de Serviços de Preservação Digital CARINIANA. Ele é editor pelo Brasil do repositório internacional E-LIS. É membro do Standing Committee of Preservation and Conservation da IFLA (2017-2021). Co-editor da revista Brasileira de Preservação Digital (RBPD) e líder do Grupo de Pesquisa "Estudos e Práticas de Preservação Digital". Email: miguel@ibict.br

É permitida a reprodução parcial ou total desta obra, desde que citada a fonte e autoria, proibindo qualquer uso para fins comerciais. Licença Creative Commons

\section{(1) $\odot \odot$




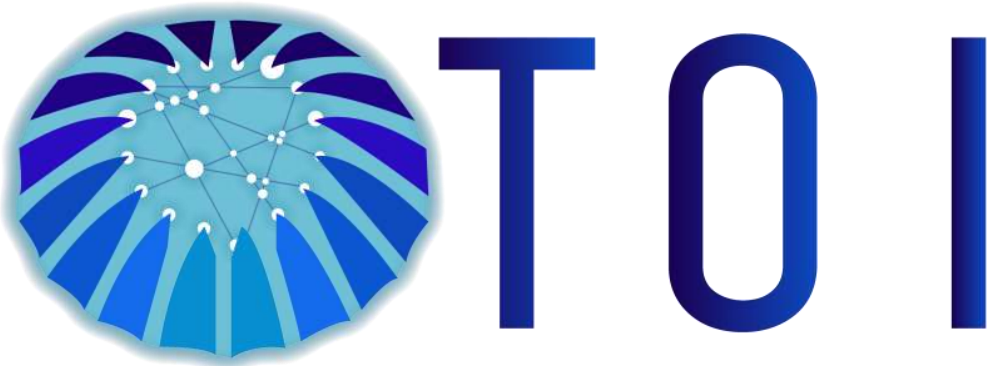

CONGRESSO INTERNACIONAL EM TECNOLOGIA E ORGANIZAÇÃO DA INFORMAÇÃO

III Simpósio Curadoria Digital
TOI - VI Congresso Internacional em Tecnologia e Organização da Informação

LIBRARY AND INFORMATION SCIENCE CONFERENCE

\section{A Digitalização de Acervos no Brasil segundo a}

Pesquisa TIC Cultura

Luciana Piazzon Barbosa Lima Iuciana@nic.b Centro Regional de Estudos para o Desenvolvimento da Sociedade da Informação (Cetic.br)/ Núcleo de Informação e Coordenação do Ponto BR (NIC.br)

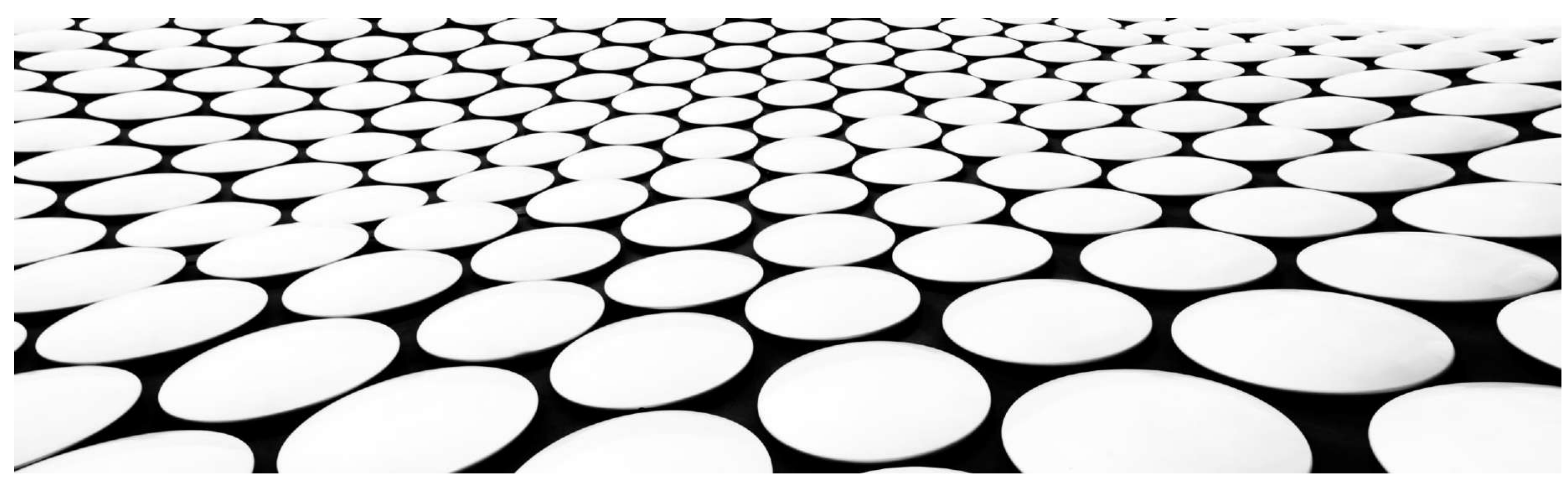




\section{SOBRE $O$ CETIC.BR}

\section{Produção de estatísticas}

TIC para políticas públicas

cyibr

Modelo Multissetorial de Governança da Internet

CULTURA E TECNOLOGIAS

NO BRASIL
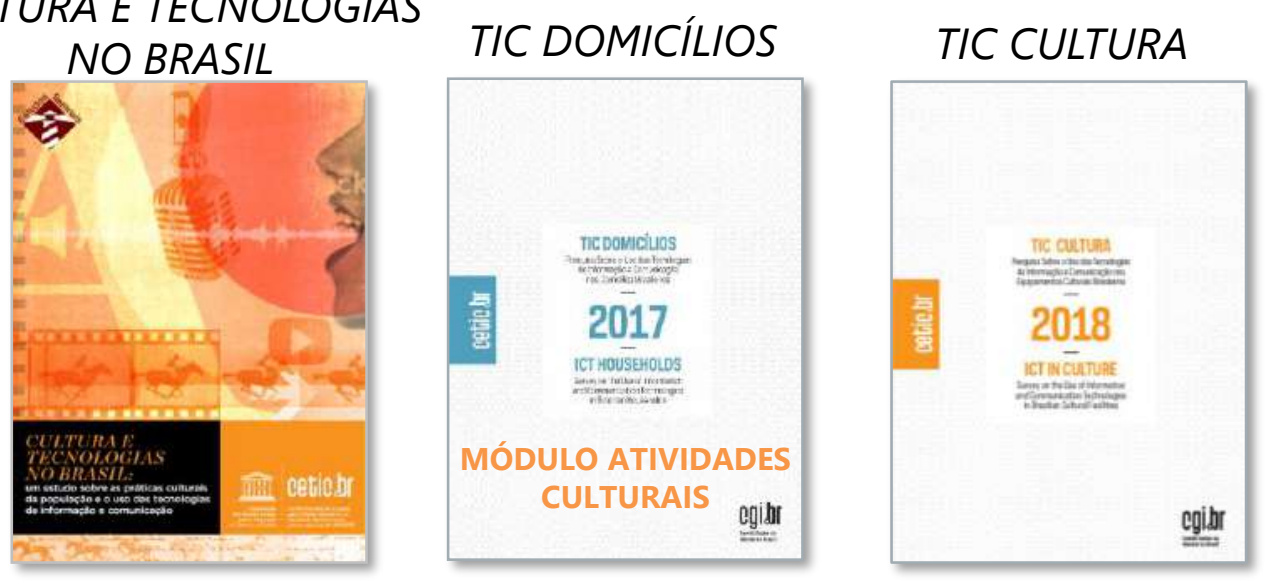

\section{要}

玄

o

○
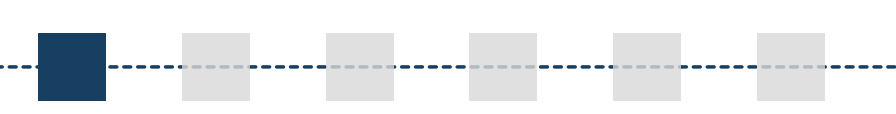

\section{nicbr}

ceticbr

registrodr

$36^{\mathrm{a}}$ Conferência Geral da Unesco aprova o Cetic.br como Centro Categoria II

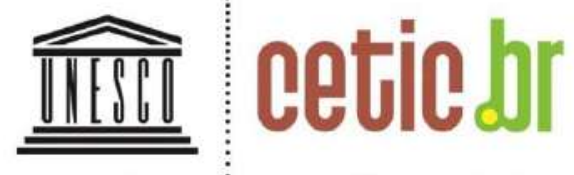

Regional Center for Studies on the
Development of the Information

ducational, Scientific and
Cultural Organization

cetic.dr nichr cogibr 


\section{TIC CULTURA}

\section{Objetivo geral}

Compreender a presença e a adoção das tecnologias de informação e comunicação (TIC) nos equipamentos culturais brasileiros, tanto em sua rotina interna de funcionamento quanto na relação com os seus públicos.

\section{Abrangência geográfica}

Nacional

\section{Período de coleta}

Março a julho de 2018

Método de coleta

Entrevistas por telefone (CATI) a partir de questionário estruturado

\section{Amostra}

3.065 equipamentos culturais

\section{Público-alvo}

Equipamentos culturais brasileiros presentes em cadastros oficiais:

- Arquivos

- Museus

- Bens Tombados

- Pontos de Cultura

- Bibliotecas

- Teatros

- Cinemas 


\section{REGIÃO GEOGRÁFICA}

\% por tipo de equipamento cultural

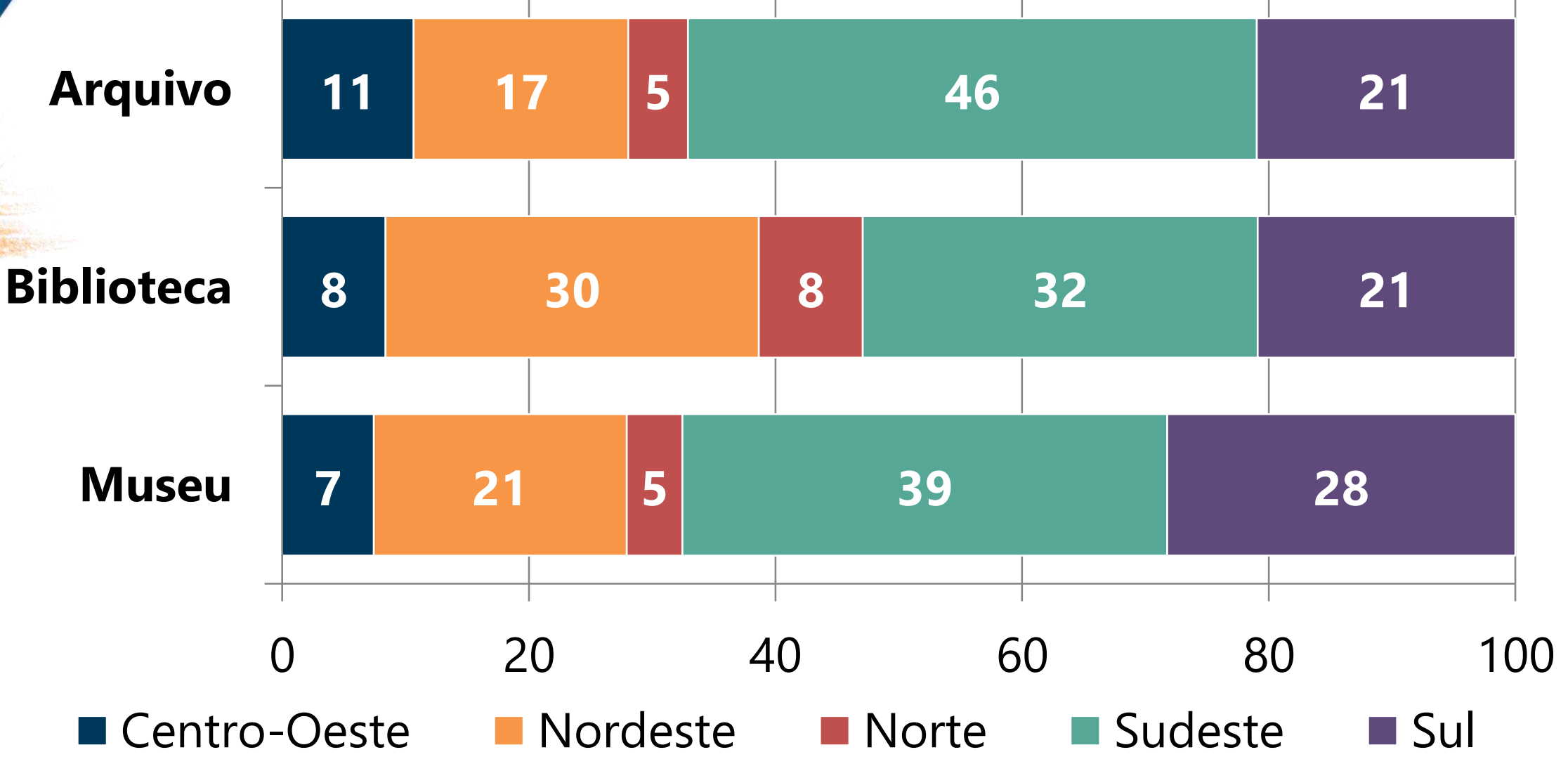




\section{NATUREZA JURÍDICA}

$\%$ por tipo de equipamento cultural

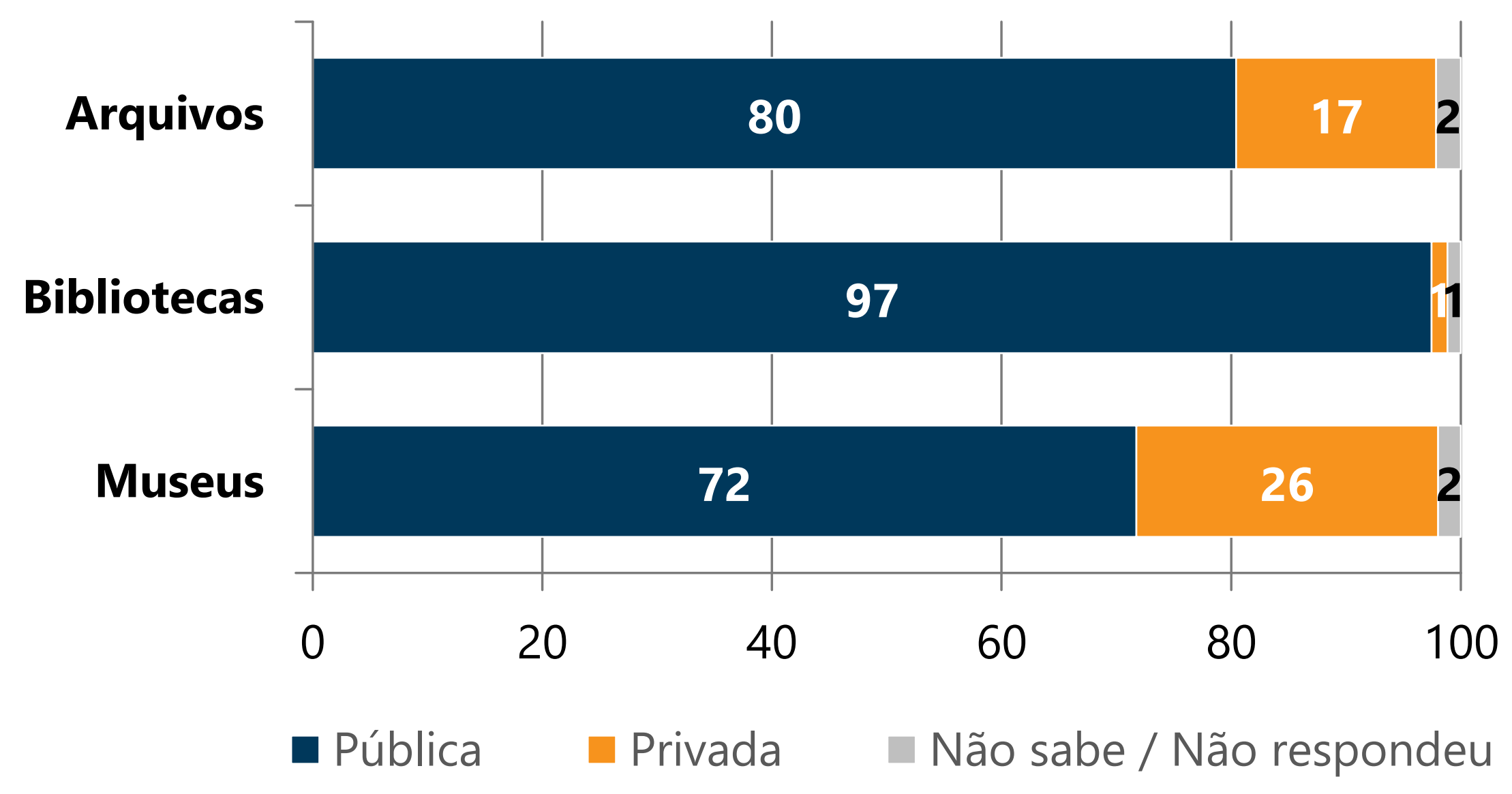




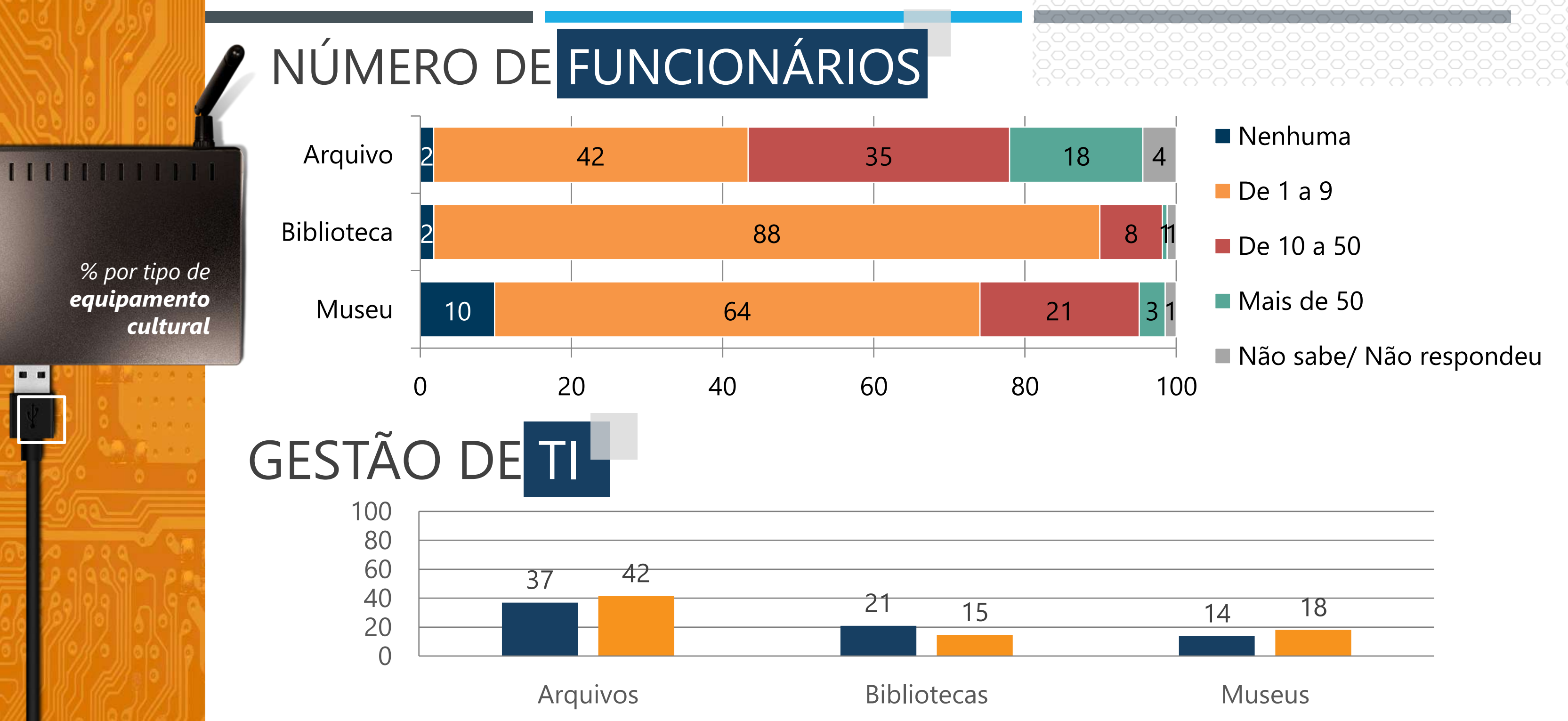

ש Existência de área ou departamento de TI — Contratação de serviços de TI 


\section{USO DE \\ COMPUTADOR E INTERNET}

$\%$ por tipo de equipamento cultural

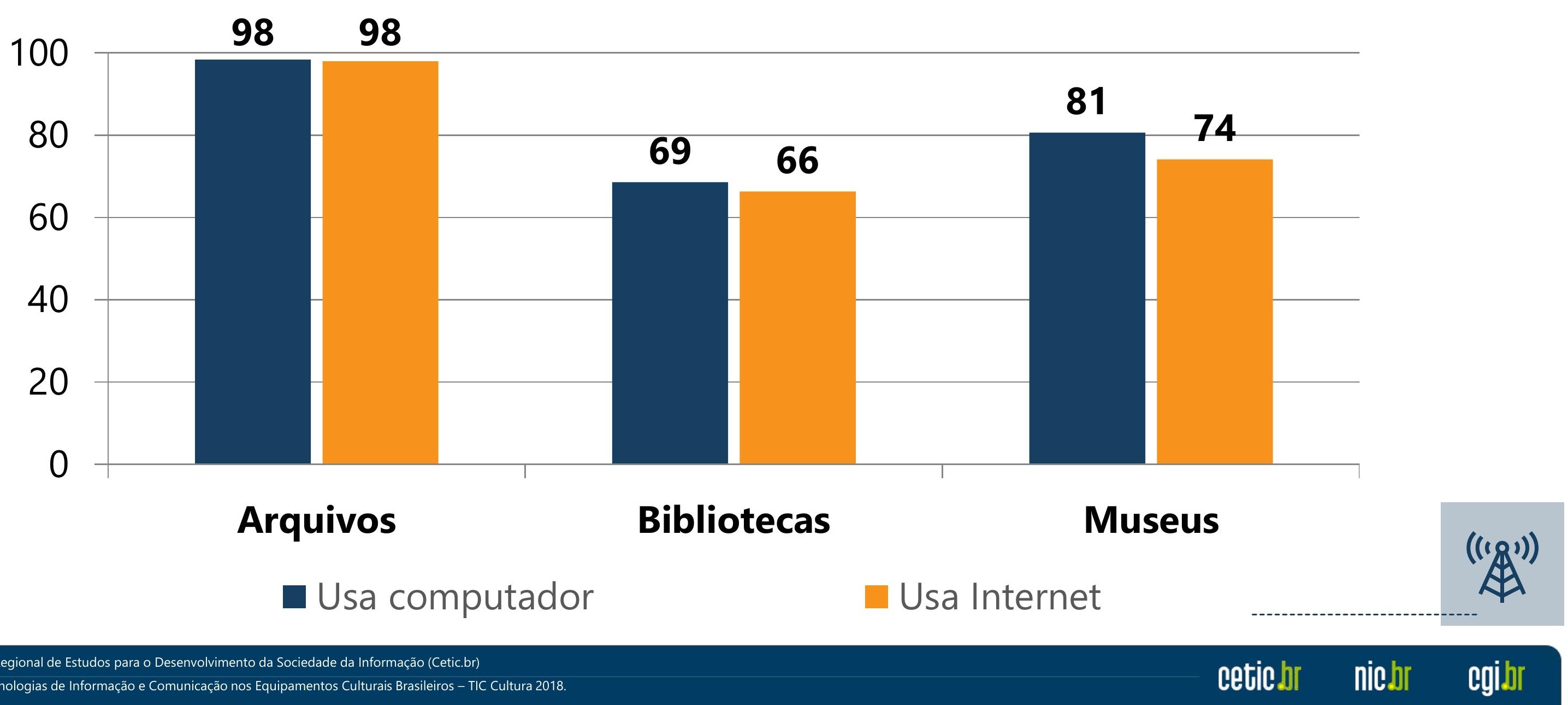




\section{PRESENÇA NA INTERNET EM WEBSITE OU REDE SOCIAL ON-LINE}

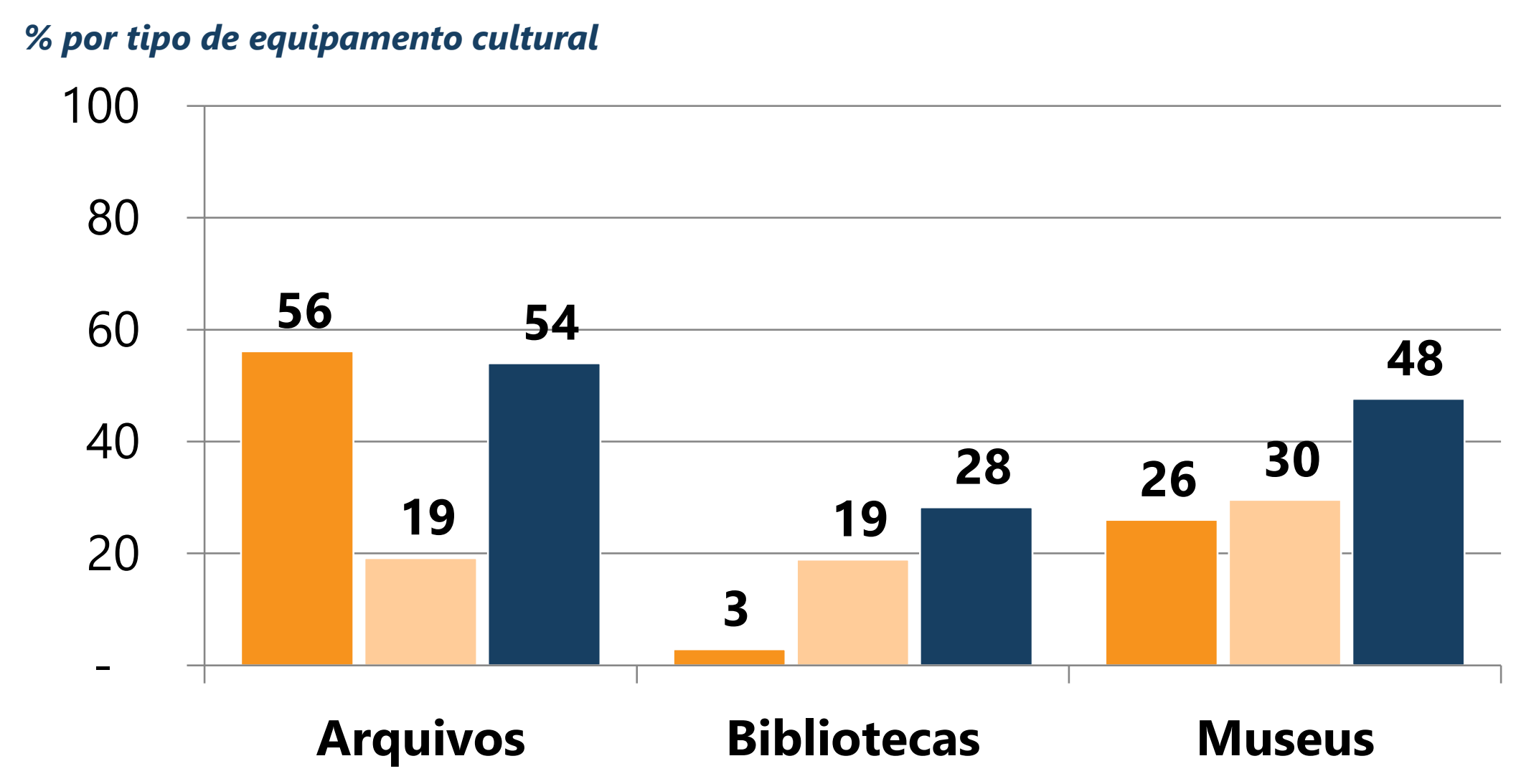

Website próprio Website de terceiros घ Perfil em plataforma ou rede social on-line 


\section{DISPONIBILIZAÇÃO DE CATÁLOGO DO ACERVO NA INTERNET}

\% por tipo de equipamento cultural

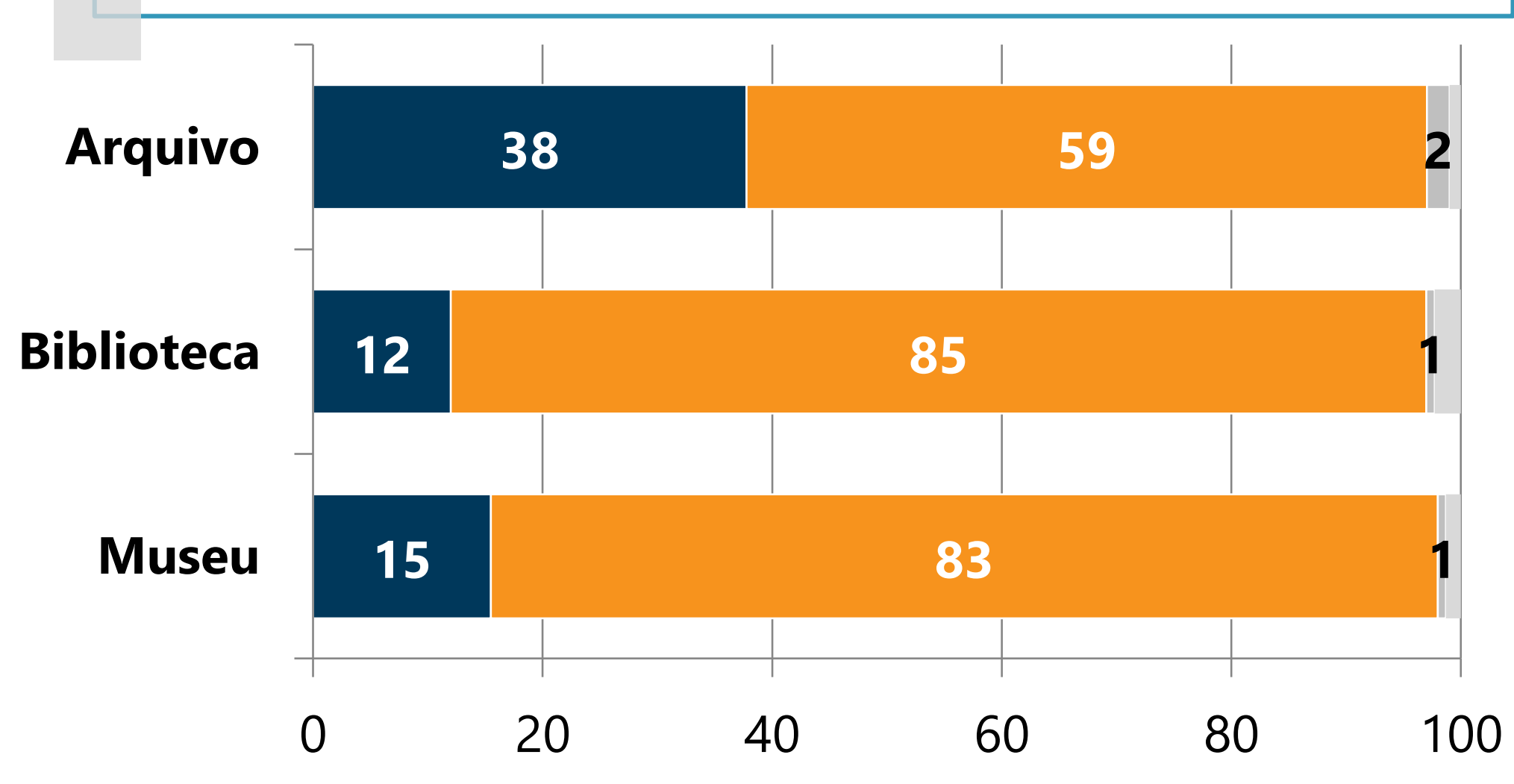

- Sim $\square$ Não $\square$ Não sabe/ não respondeu $\square$ Não se aplica
USO DE SOFTWARE PARA CATALOGAÇÃO DE ACERVO

\begin{tabular}{|l|c|}
\hline Arquivo & 21 \\
\hline Biblioteca & 18 \\
\hline Museu & 13 \\
\hline
\end{tabular}

100 


\section{TIPO DE ACERVO EXISTENTE}

\% por tipo de equipamento cultural

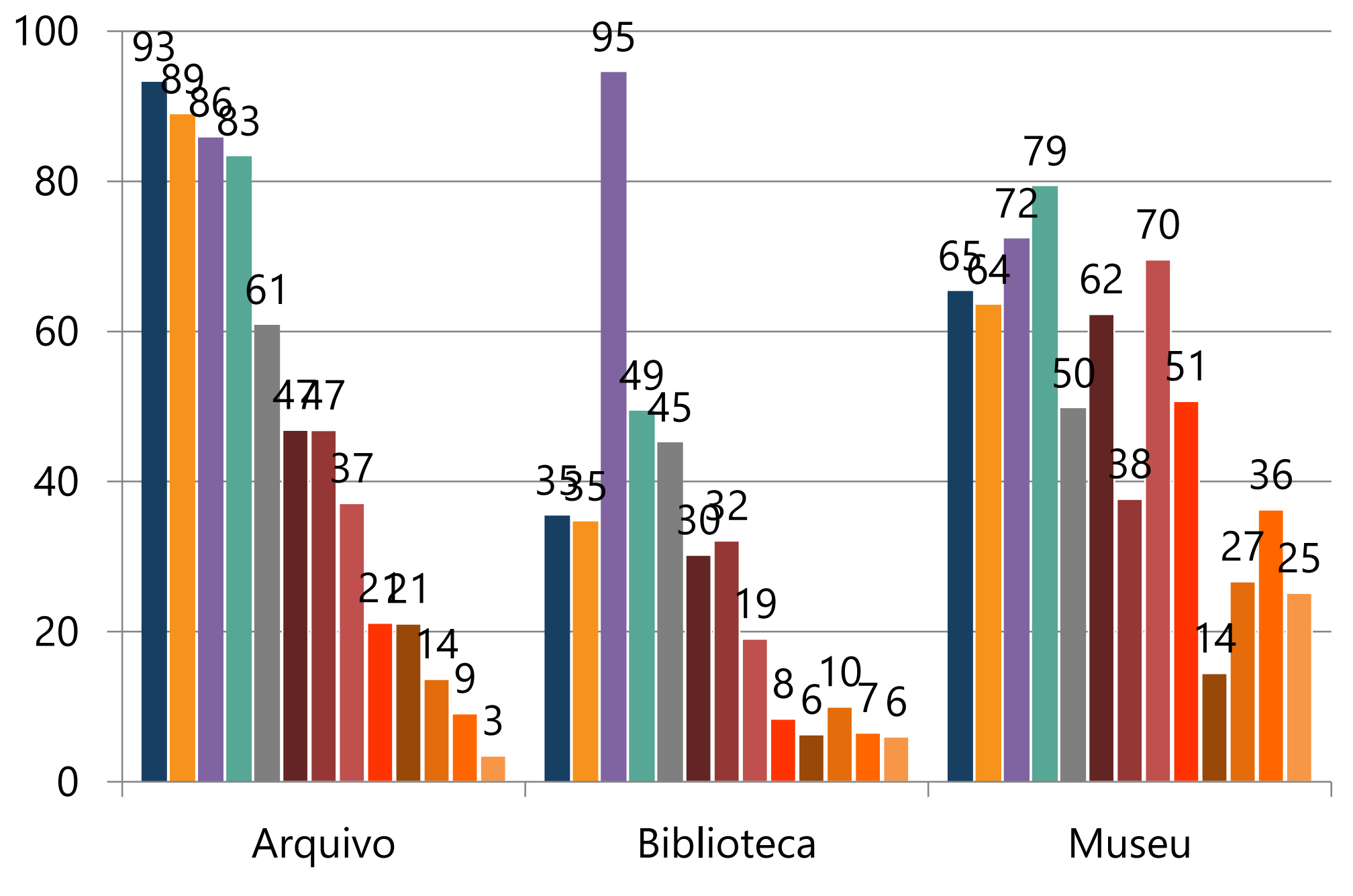

Documentos oficiais históricos ou registros arquivísticos

- Manuscritos ou documentos originais

- Livros, revistas ou jornais

- Fotografias, cartazes, mapas ou partituras

- Filmes ou gravações de vídeo

Desenhos, pinturas ou gravuras

- Músicas ou outras gravações de áudio

Móveis, objetos artesanais, roupas, moedas ou objetos de uso diário

- Esculturas ou instalações

- Recursos interativos digitais, como desenhos tridimensionais, sites ou software 


\section{PRESENÇA, DIGITALIZAÇÃO E DISPONIBILIZAÇÃO DE ACERVO NA INTERNET}

$\%$ por tipo de equipamento cultural

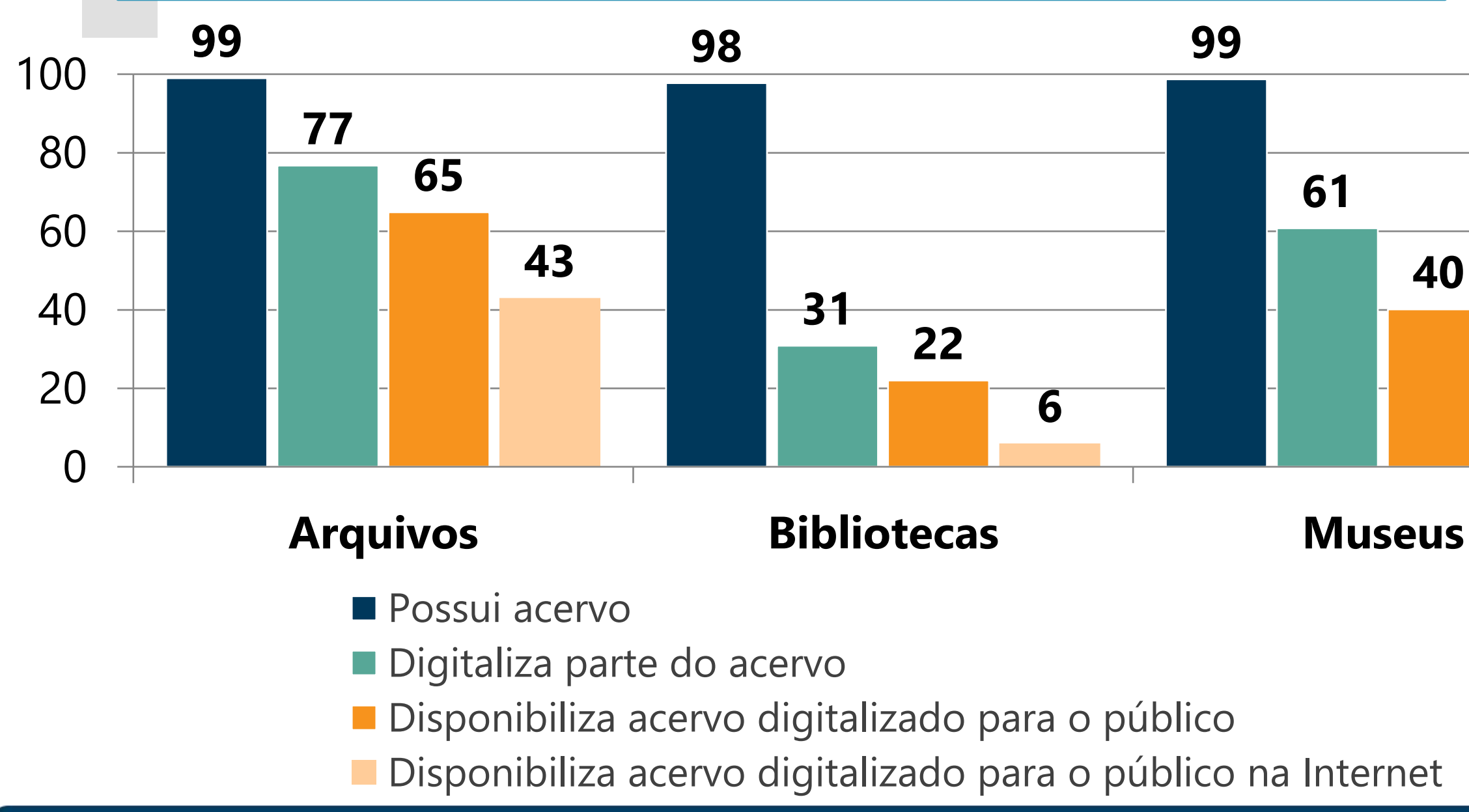




\section{FORMA DE DISPONIBILIZAÇÃO DE ACERVO DIGITALIZADO PARA O PÚBLICO}

\% por tipo de equipamento cultural

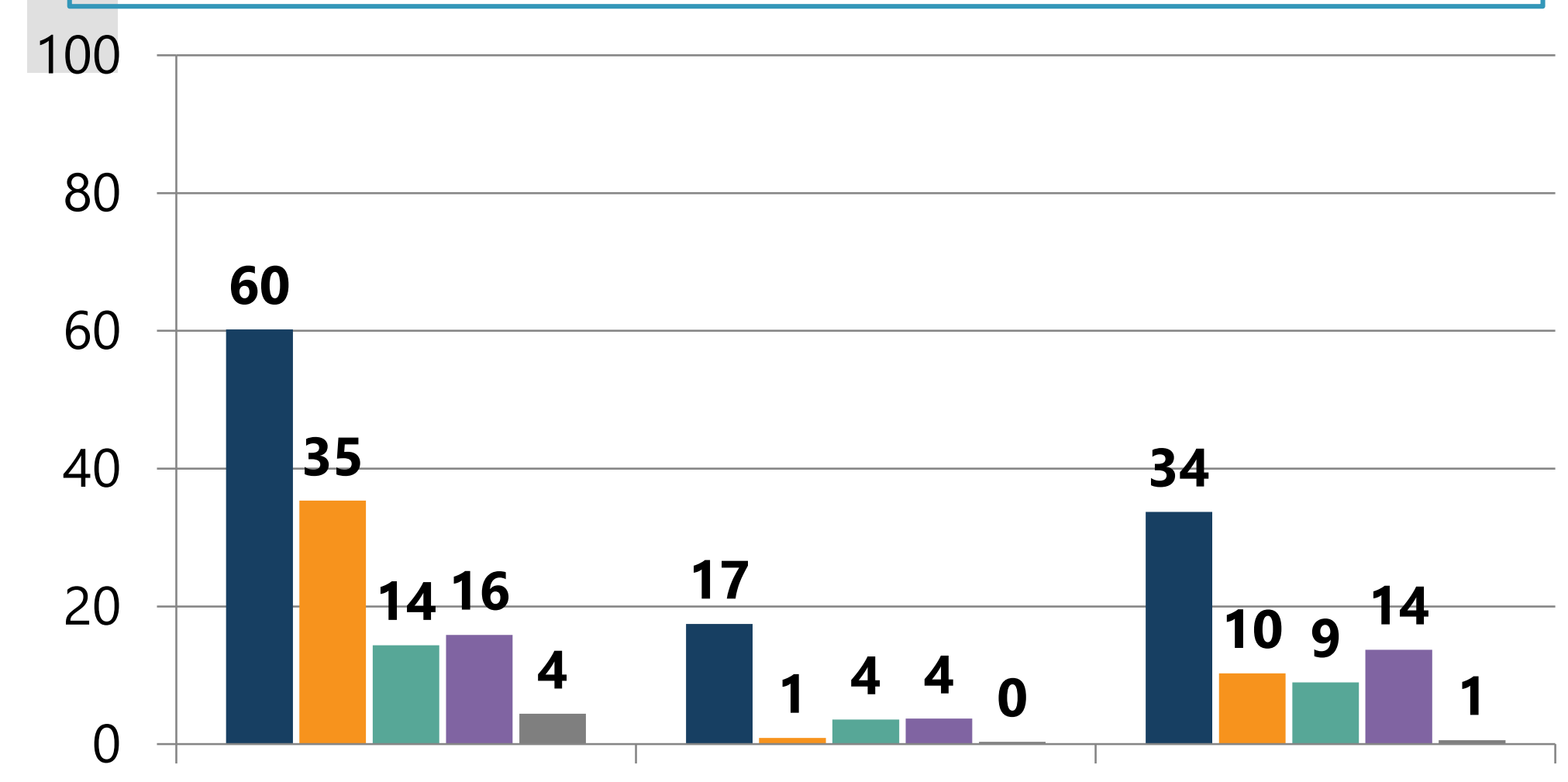

Arquivo

Biblioteca

Museu
No local onde funciona a

instituição

No website da instituição

Em websites de outras instituições

Nas redes sociais em que a instituição está presente

No aplicativo da instituição 

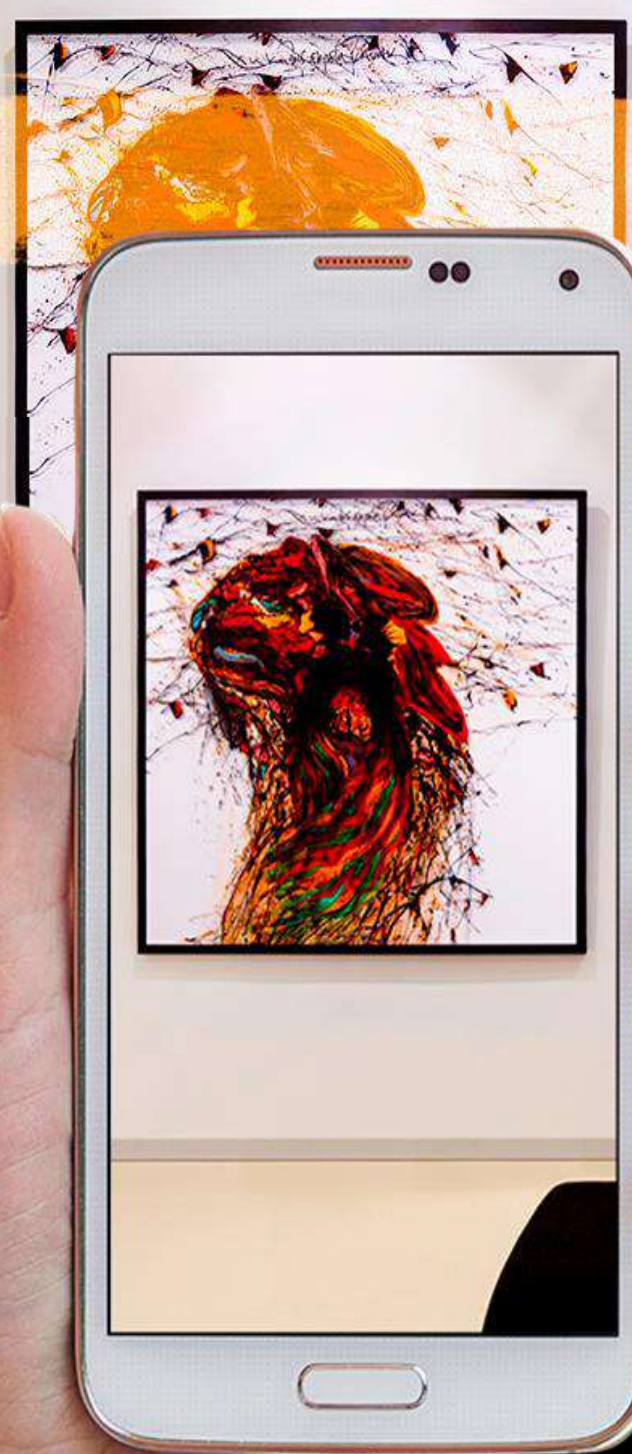

.

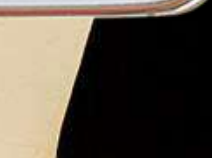

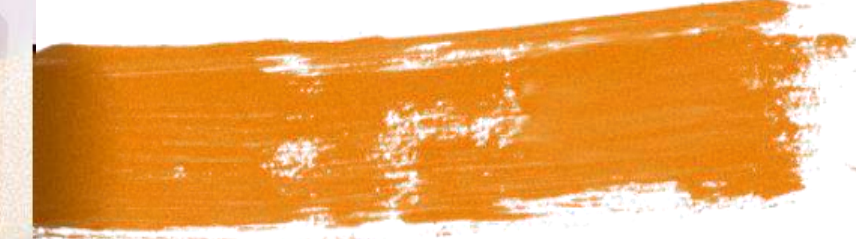

DIFICULDADES PARA

DIGITALIZACAOO DE ACERVOS

\% por tipo de equipamento cultural

\section{Arquivo Biblioteca Museu}

Falta de financiamento

Falta de equipe qualificada

81

56

É difícil garantir a preservação do material digitalizado

Baixa demanda pela digitalização dos materiais

Não é parte da missão da instituição

Direitos autorais restringem a digitalização

- Outras instituições que detêm cópias dos materiais cuidam da digitalização

A digitalização dos materiais é proibida por lei e/ou contrato

Outros

Não se aplica

\begin{tabular}{|c|c|c|}
\hline 81 & 75 & 75 \\
\hline 56 & 69 & 72 \\
\hline 51 & 42 & 42 \\
\hline 19 & 58 & 42 \\
\hline 22 & 40 & 31 \\
\hline 14 & 33 & 19 \\
\hline 13 & 21 & 19 \\
\hline 8 & 18 & 10 \\
\hline 12 & 6 & 7 \\
\hline 2 & 7 & 6 \\
\hline
\end{tabular}



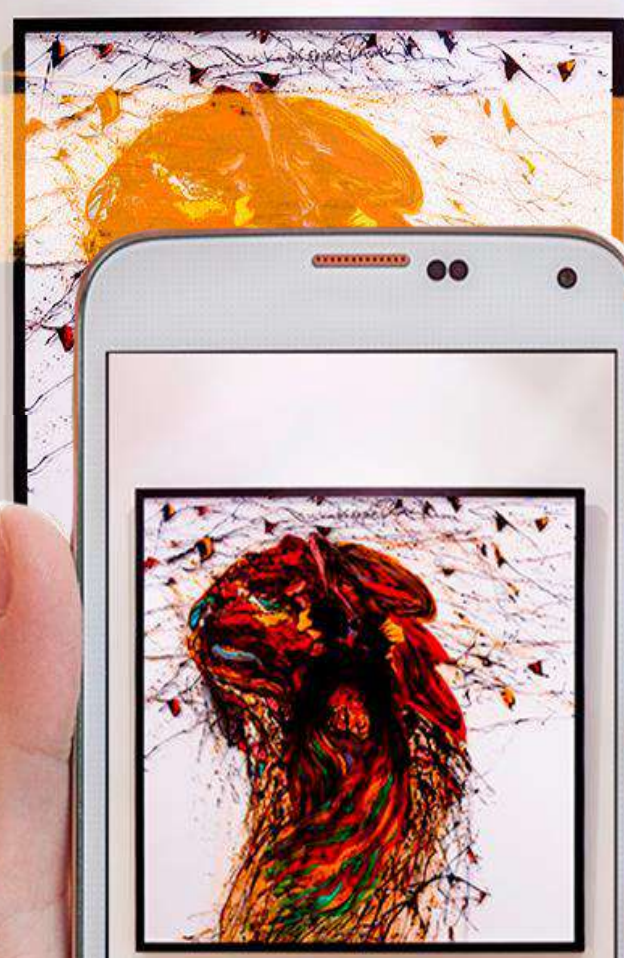

\section{PRINCIPAL DIFICULDADE PARA DIGITALIZAÇÃO DE ACERVOS}

\% por tipo de equipamento cultural

\section{(arquivo biblioteca}

Falta de financiamento

Falta de equipe qualificada

Não é parte da missão da instituição

Baixa demanda pela digitalização dos materiais

Arq
56
14

Outras instituições que têm cópias dos materiais cuidam da digitalização

É difícil garantir a preservação do material digitalizado

Direitos autorais restringem a digitalização A digitalização dos materiais é proibida por lei e/ou contrato

Outros

56
14

4

4

Bblioteca

Museu

Não respondeu

Não se aplica

27




\section{Publicação}

Atividades on-line reduzem ou estimulam o acesso a atividades culturais off-line? O que indicam as pesquisas quantitativas

João Leiva e Ricardo Meirelles

TIC CULTURA

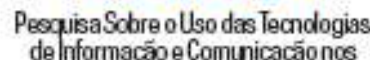
Equipamentas Culturisis Brasileiras

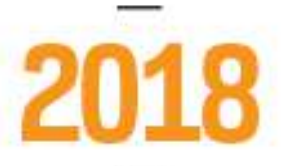

$$
\text { - }
$$

ICT IN CULTURE Survey on the Use of Information and Communication Technologies in Brazilian Cultura Facilities

http://cetic.br/pesquisa /cultura/publicacoes

\section{Juliana Novaes}

Fruição cultural em meios digitais: conectividade para acesso à diversidade cultural

Viviane Riegel, Joana Pellerano, Renato Vercesi Mader e Wilson Roberto Bekesas

Digitalização de acervos: preservação da memória às margens do direito autoral

Projeto Tainacan: experimentos, aprendizados e descobertas da cultura digital no universo dos acervos das instituições memoriais

Dalton Lopes Martins, José Murilo Costa Carvalho Júnior e Leonardo Germani

carva

Financiamento à cultura pela aplicação de TIC: o Programa Matchfunding de Cultura BNDES

Patricia Zendron, Eduardo Bizzo de Pinho Borges, Maria Araujo Parreiras e Vitor Straub de Moraes

\section{DA INTERNET}

\section{Acervos digitais}

Perspectivas, desafios e oportunidades para as instituições de memória no Brasil

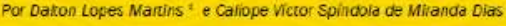

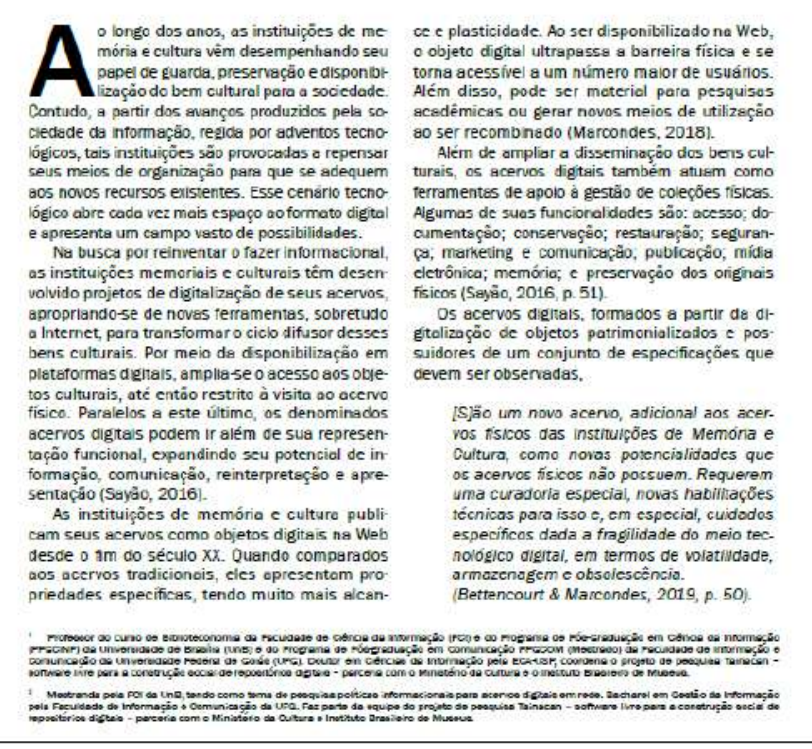

https://cetic.br/publicacao/ ano-xi-n-3-acervos-digitais 


\section{Luciana Piazzon Barbosa Lima}

Bacharel em Relações Internacionais pela Universidade de São Paulo (2008) e Mestre pelo Programa de Pós-Graduação em Estudos Culturais da Escola de Artes, Ciências e Humanidades da Universidade de São Paulo (2013). Atua no campo dos Estudos e Políticas Culturais. De 2013 a 2016, foi assessora da Secretaria Municipal de Cultura de São

Paulo, responsável pela coordenação do Plano Municipal de Cultura e produção de informações e indicadores. Desde 2017, coordena a pesquisa TIC Cultura no Centro Regional de Estudos para o Desenvolvimento da Sociedade da Informação (Cetic.br), do Núcleo de Informação e Coordenação do Ponto BR (NIC.br), ligado ao Comitê Gestor da Internet no Brasil (CGI.br).

E-mail: luciana@nic.br

É permitida a reprodução parcial ou total desta obra, desde que citada a fonte e autoria, proibindo qualquer uso para fins comerciais Licença Creative Commons

\section{(i) $\circledast \ominus$}

BY

NC

ND

\section{w w w. c e t i c.br}

\section{cetichdr nichs cogibr}




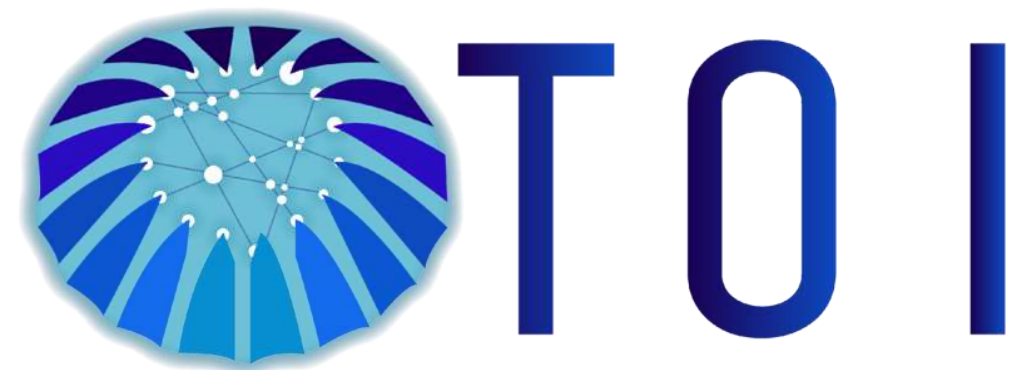

CONGRESSO INTERNACIONAL EM TECNOLOGIA E ORGANIZAÇÃO DA INFORMAÇÃO
TOI - VI Congresso Internacional em Tecnologia e Organização da Informação

\section{LIBRARY AND INFORMATION SCIENCE CONFERENCE}

Creative Commons e seu uso na disponibilização de acervos culturais

Juliana Monteiro julianamonteiro47@gmail.com Creative Commons Brasil

\section{Simpósio Curadoria Digital}

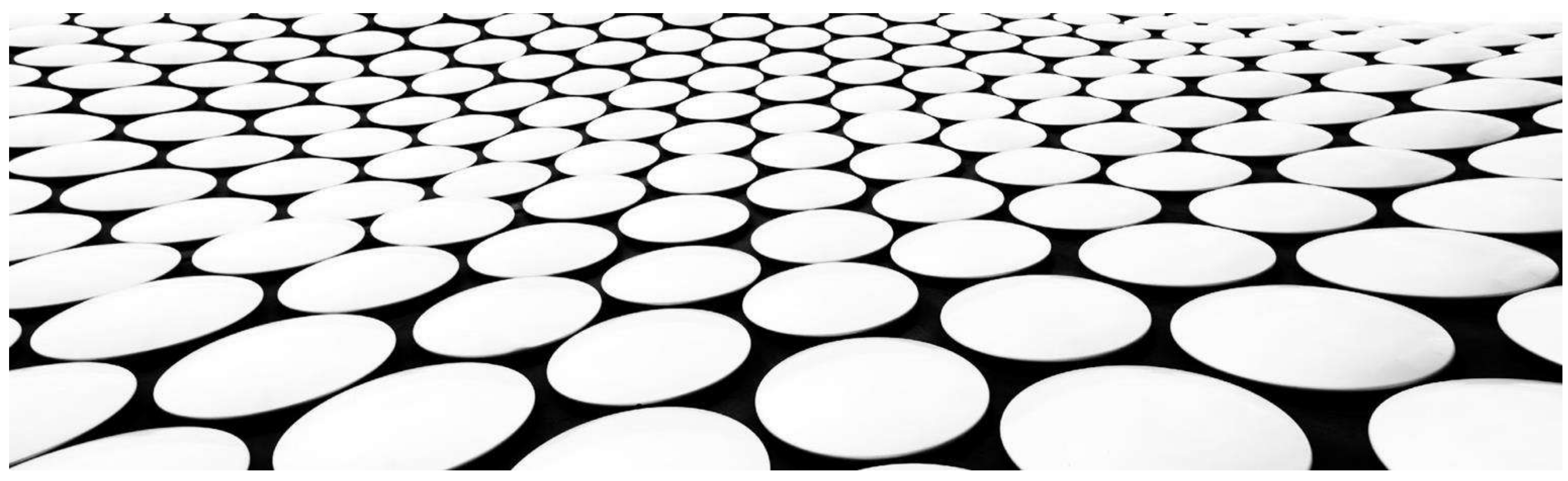




\section{AGENDA}

- Direitos autorais

- O que é acesso aberto?

- O que é Creative Commons?

- Quais são as licenças?

- Práticas de licenciamento das instituições brasileiras 
DIREITOS AUTORAIS 


\section{DIREITOS AUTORAIS}

Lei 9610/1998

Art. 11. Autor é a pessoa física criadora de obra literária, artística ou científica.

Art. 18. A proteção aos direitos de que trata esta Lei independe de registro. 


\section{DIREITOS AUTORAIS}

Obras protegidas - as criações do espírito, expressas por qualquer meio ou fixadas em qualquer suporte, tangível ou intangível, atual ou futuro.

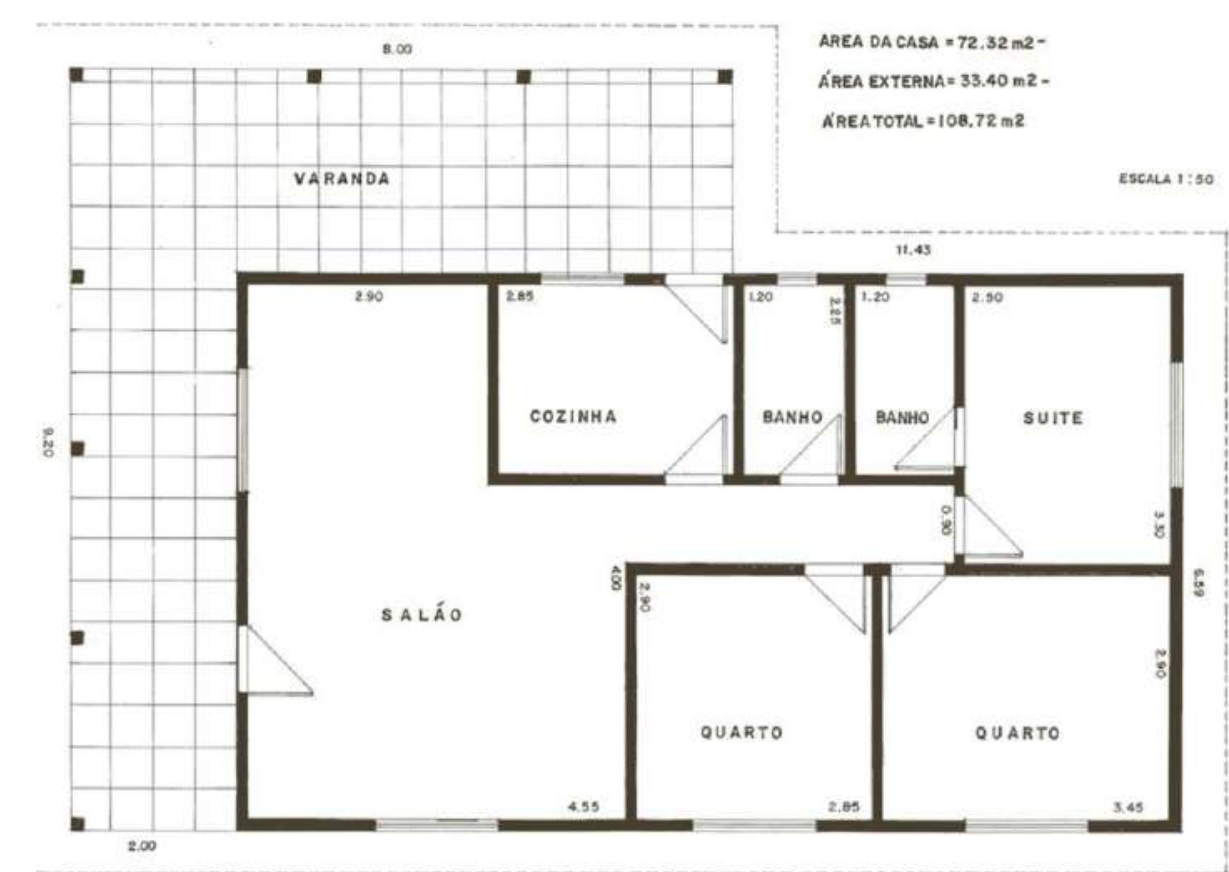




\section{DIREITOS AUTORAIS}

A lei de direitos autorais não protege:

- Ideias

- Fórmulas

- Textos de leis

- Imagem pessoal 


\section{DIREITOS AUTORAIS}

Direito de autor no Brasil:

- Direito moral

- Direito patrimonial

- Direitos conexos 


\section{DIREITOS AUTORAIS}

- Direito moral

- Reivindicar autoria

- Atribuição como autor da obra

- Integridade

- Ineditismo

- Retirar de circulação

- Modificar a obra

- Ter acesso a exemplar único 


\section{DIREITOS AUTORAIS}

- Direito patrimonial

- Reprodução parcial ou total

- Edição

- Adaptação e outras transformações

- Tradução

- Inclusão em fonograma ou produção audiovisual

- Distribuição por diferentes meios

- Utilização para diferentes fins (incluindo exposição de obras de artes plásticas) 


\section{DIREITOS AUTORAIS}

- Direitos conexos

- Intérprete

- Radiodifusão

- Produtor 
DIFERENTES CAMADAS DE PROTEÇÃO QUE DEMANDAM AUTORIZAÇÕES ESPECÍFICAS POR PARTE DAS PESSOAS QUE SÃO AUTORAS OU DETÉM O DIREITO DE AUTOR 


\section{O QUE É ACESSO ABERTO?}




\section{O QUE É OPEN ACCESS?}

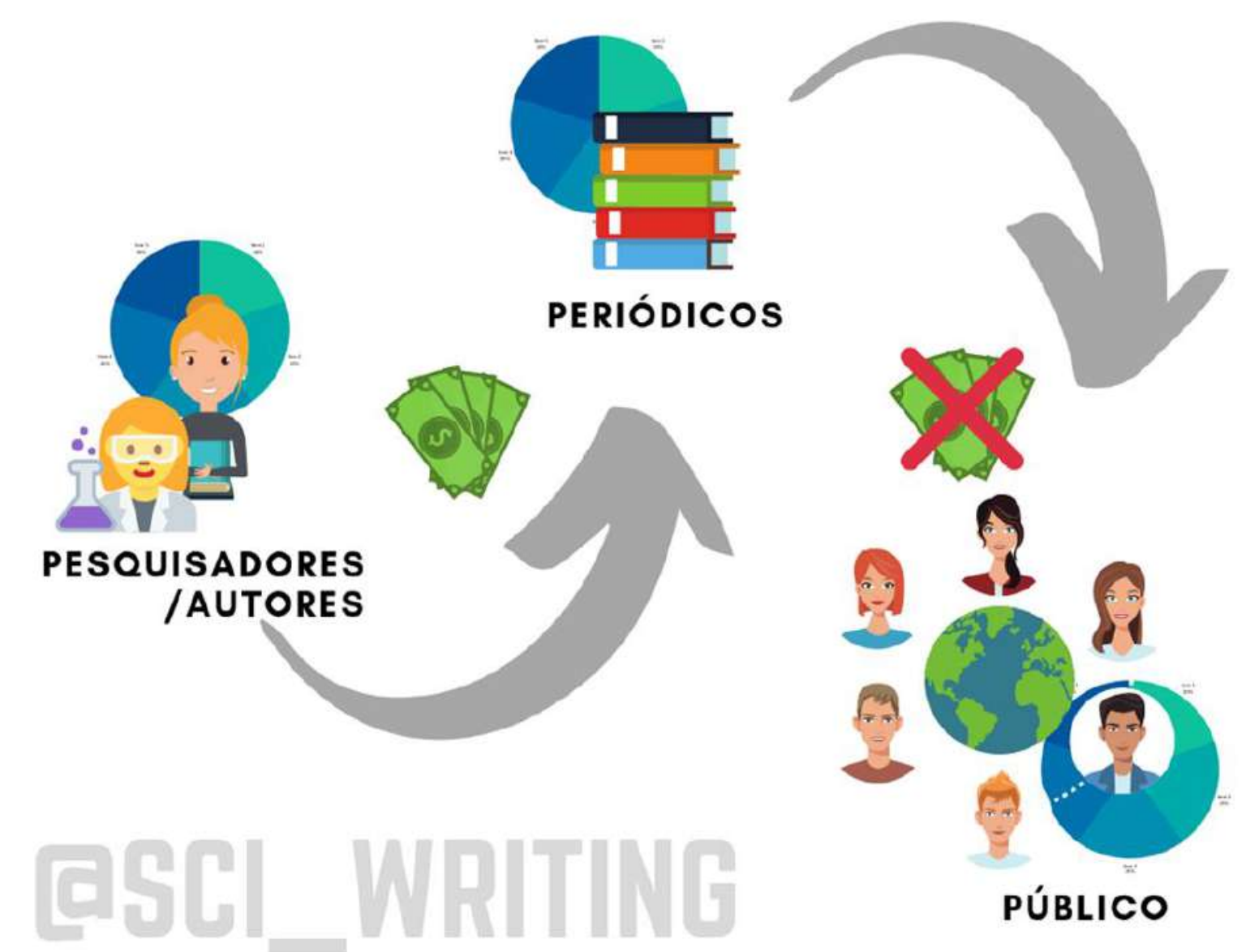




\section{ACESSO ABERTO}

"Acesso aberto significa que o conteúdo, material ou dado liberado está disponível para qualquer um que queira utilizá-lo, reutilizá-lo ou distribuí-lo, de forma gratuita, com a única obrigação de mencionar o autor do conteúdo original, quando requerido."

(Declaração sobre acesso aberto ao patrimônio cultural, 2019, tradução livre)

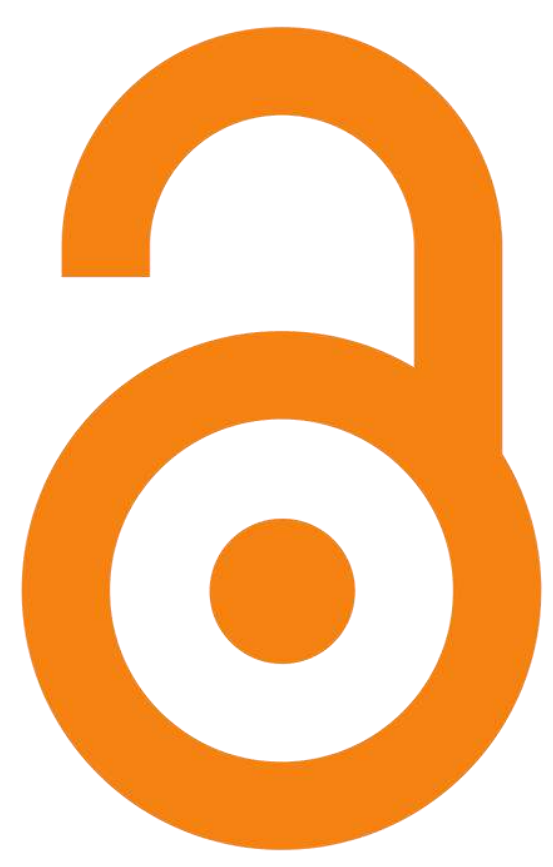




\section{ACESSO ABERTO}

- Disponibilidade

- Reuso e redistribuição

- Participação universal

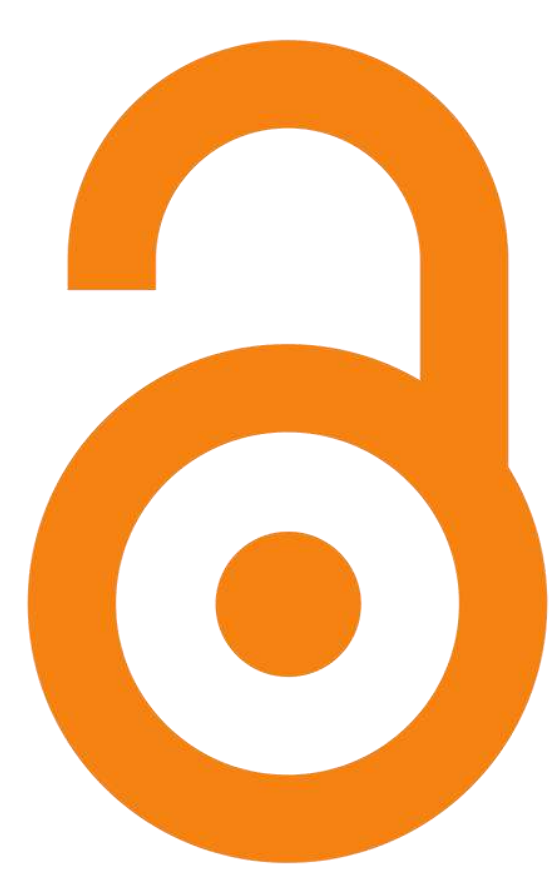




\section{ACESSO ABERTO}

- Perspectiva conceitual

- Perspectiva tecnológica

- Perspectiva jurídica

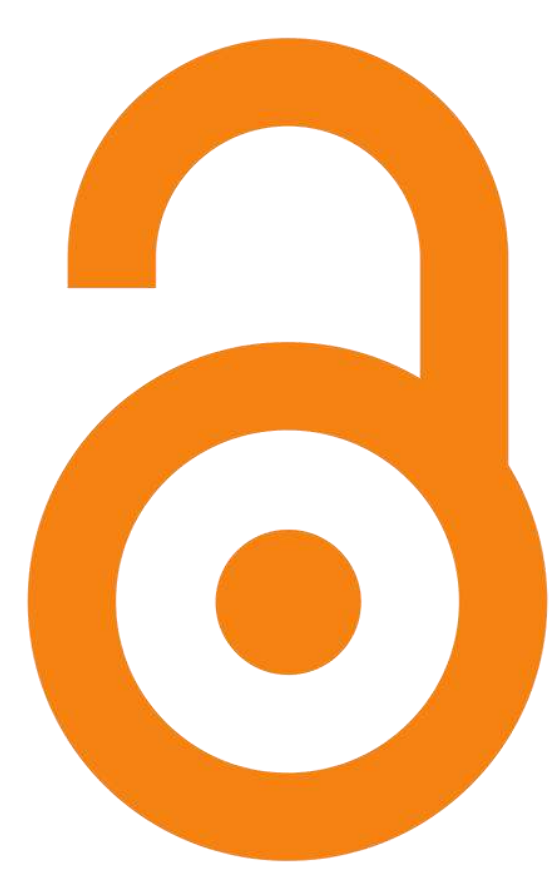


O QUE É CREATIVE COMMONS? 
Um jeito simples, padronizado, legalmente robusto de garantir algumas permissões às obras autorais e a seus dados 


\section{UMA ALTERNATIVA}

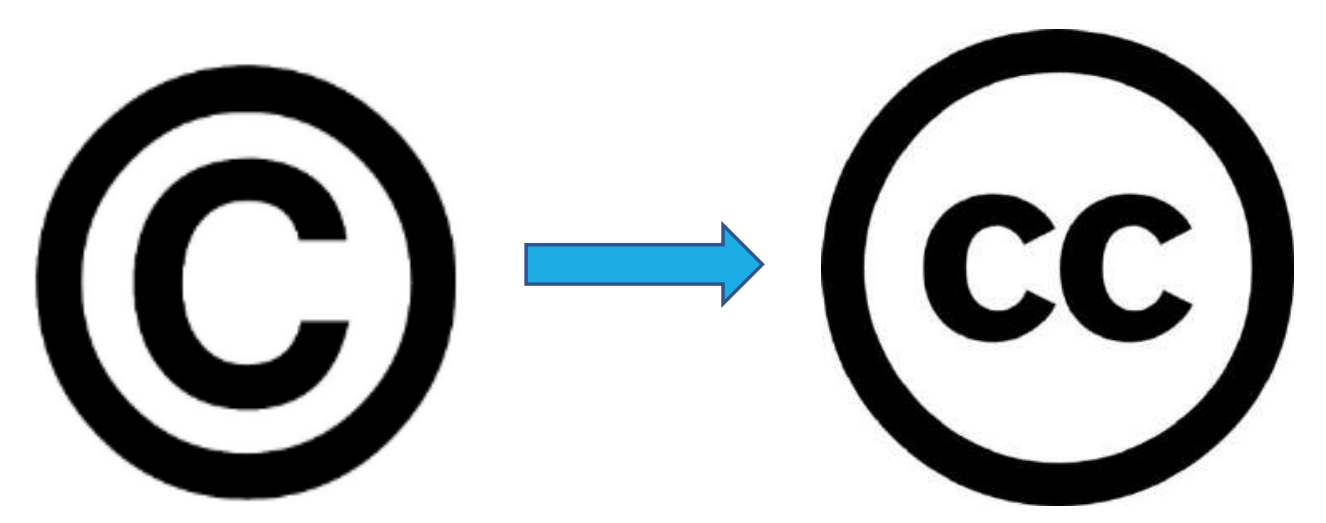

Todos os

direitos

Alguns direitos

reservados

reservados 


\begin{tabular}{|c|c|}
\hline & $\begin{array}{l}\text { eative } \\
\text { ominons }\end{array}$ \\
\hline \multicolumn{2}{|c|}{ CREATIVE COMMONS LICENSED WORKS } \\
\hline 2017 & $1,471,401,740$ \\
\hline 2016 & $1,204,935,537$ \\
\hline 2015 & $1,118,900,000$ \\
\hline 2014 & $882,000,000$ \\
\hline 2010 & $400,000,000$ \\
\hline 2006 & $140,000,000$ \\
\hline
\end{tabular}




\section{$\checkmark$ YouTube}

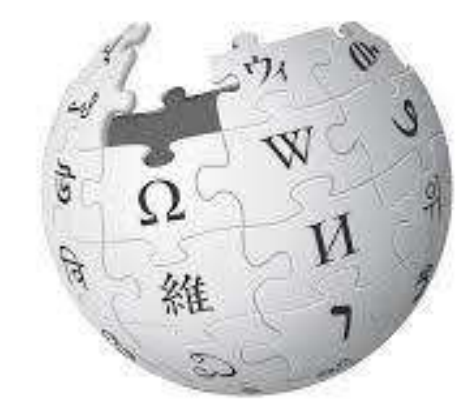

WIKIPÉDIA

A enciclopédia livre 
QUAIS SÃO AS LICENÇAS? 


\section{LICENÇAS}

Permite detentores de licenças fornecer permissões para cópia e reuso para o público, de acordo com seu desejo ou necessidade 


\section{ELEMENTOS}

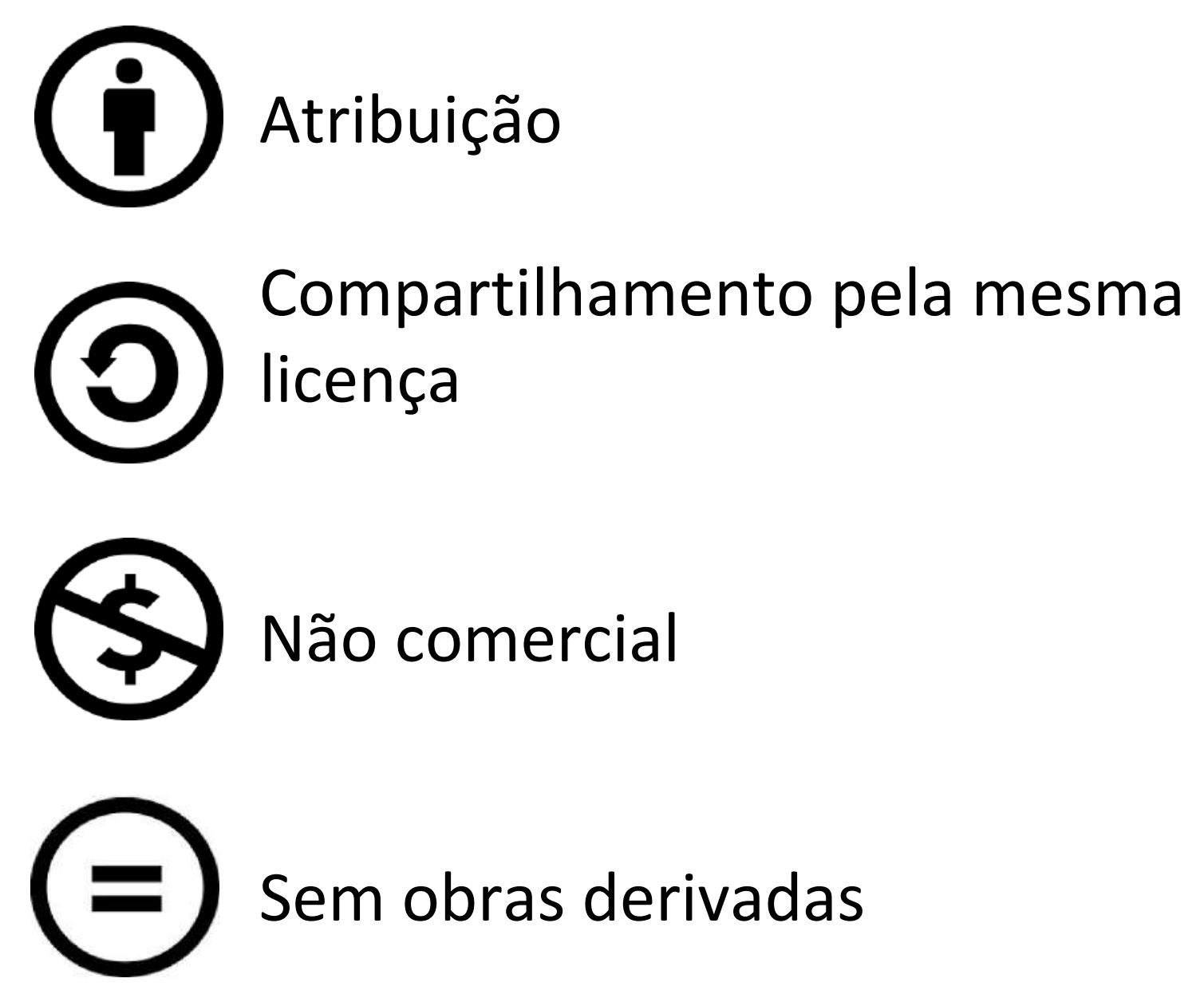




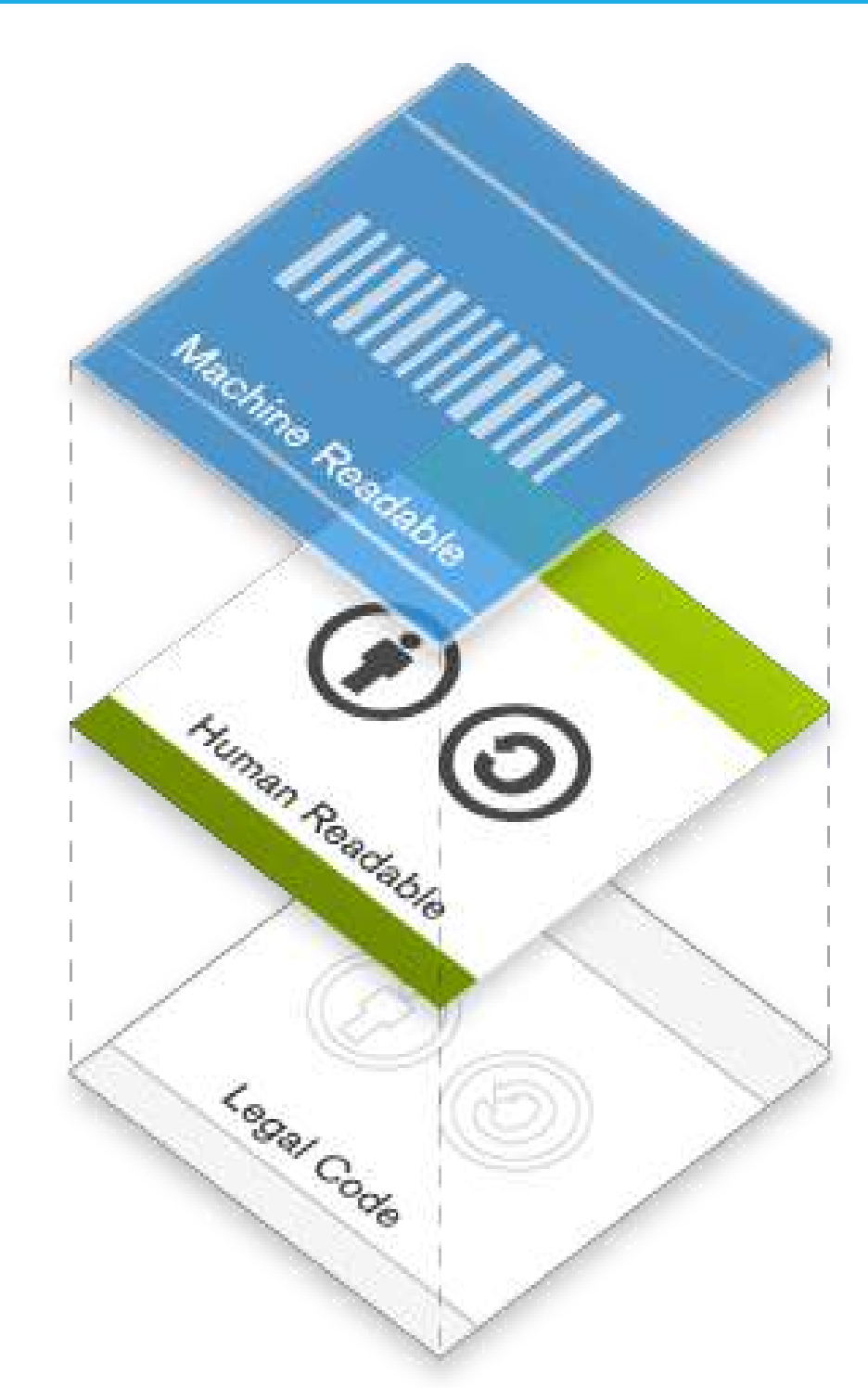




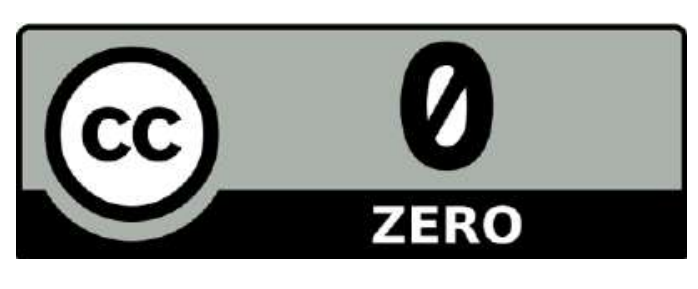

- Cópia

- Obras derivadas

- Uso comercial e não comercial

- Dedicação feita pelo autor em vida 
Thousands of Exhausted Things, or why we dedicated MoMA's collection data to the public domain

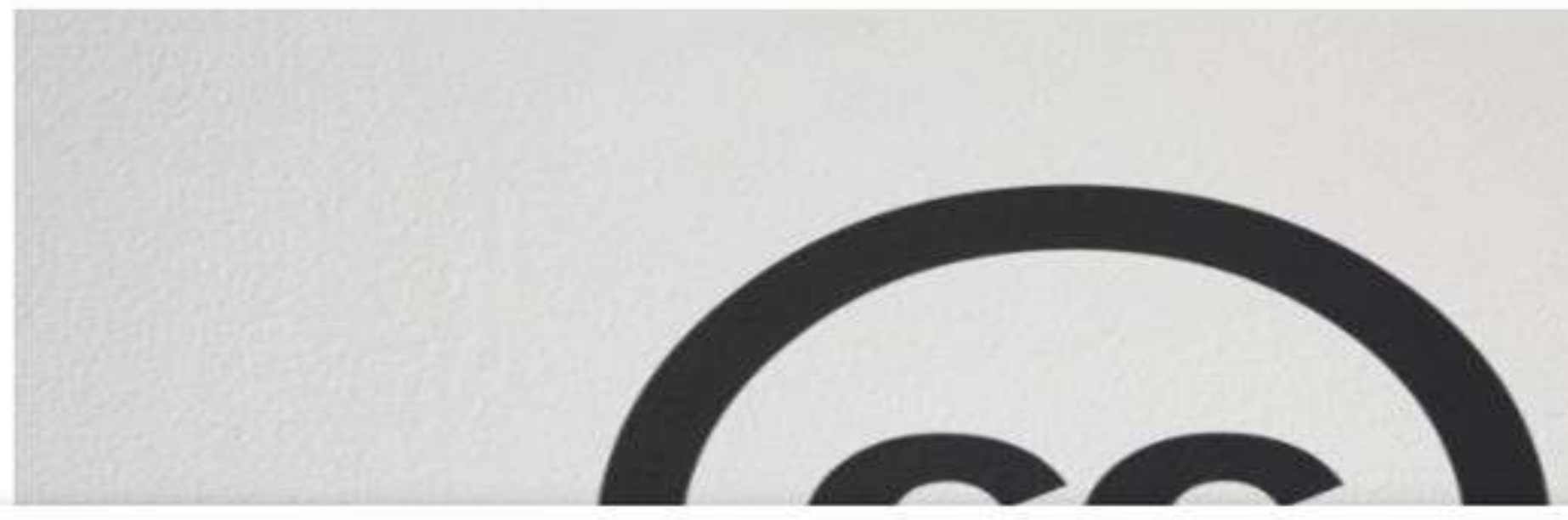


e GitHub, Inc. [US] | https://github.com/MuseumofModernArt/collection

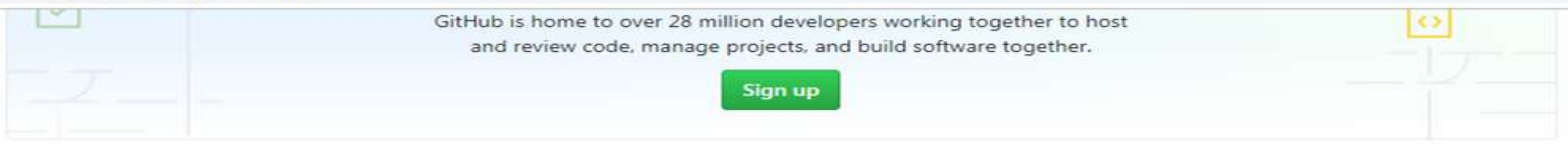

The Museum of Modern Art (MoMA) collection data

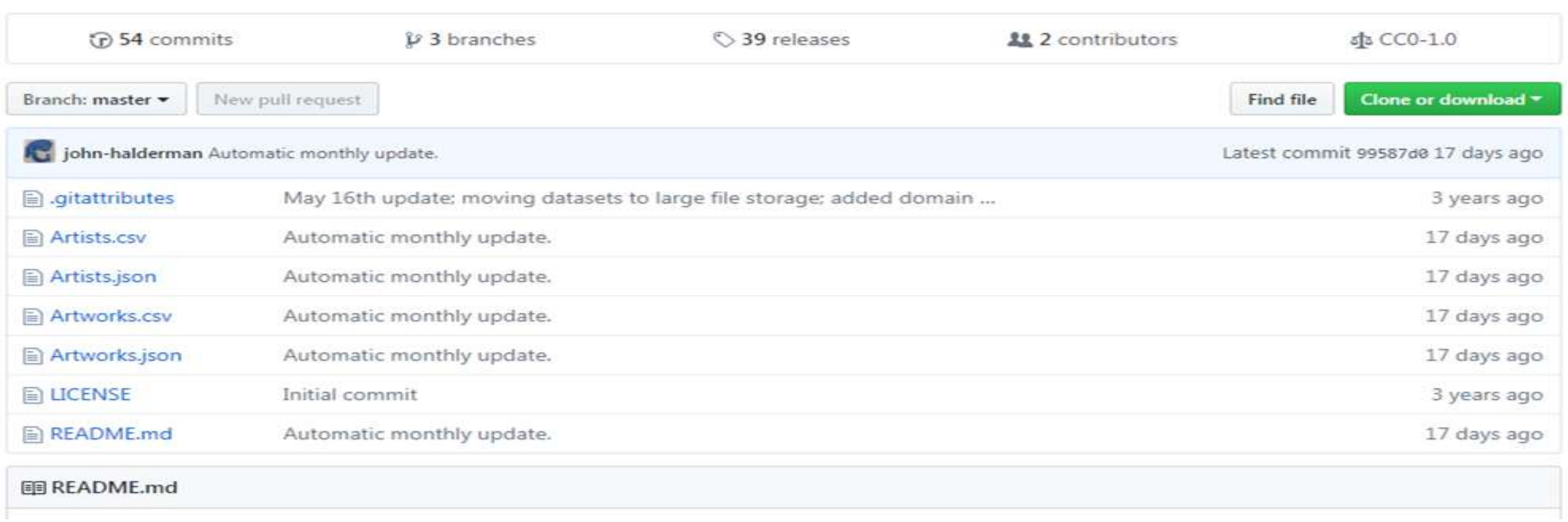


ConstituentID, DisplayName, ArtistBio, Nationality, Gender, BeginDate, EndDate, Wiki QID, ULAN

1, Robert Arneson, "American, 1930-1992", American, Male, 1930,1992,,

2, Doroteo Arnaiz, "Spanish, born 1936", Spanish, Male, 1936, 6,

3 , Bill Arnold, "American, born 1941", American, Male, 1941, 0 ,

4, Charles Arnoldi, "American, born 1946", American, Male, 1946, 0, Q1063584, 500027998

5 , Per Arnoldi, "Danish, born 1941", Danish, Male, 1941, 0 ,

6, Danilo Aroldi, "Italian, born 1925", Italian, Male, 1925, 0 ,

7, Bill Aron, "American, born 1941", American,Male, 1941, 0 , ,

9, David Aronson, "American, born Lithuania 1923", American, Male, 1923, 0, Q5230870, 500003363

10, Irene Aronson, "American, born Germany 1918", American, Female, 1918, 0, Q19748568, 500042413

11, Jean (Hans) Arp, "French, born Germany (Alsace). 1886-1966", French, Male, 1886, 1966, Q153739,500031000

12,Jüri Arrak, "Estonian, born 1936", Estonian, Male,1936, 0 ,

13,J. Arrelano Fischer, "Mexican, 1911-1995", Mexican, Male,1911, 1995, ,

15, Folke Arstrom, "Swedish, 1907-1997", Swedish, Male, 1907, 1997, ,

16, Cristobal Arteche, "Spanish, 1900-1964", Spanish, Male, 1900,1964,

18, Artko, , , , $, 0,0$,

19, Richard Artschwager, "American, 1923-2013", American, Male, 1923, 2013, Q568262, 500114981

21, Ruth Asawa, "American, 1926-2013", American, Female, 1926, 2013 , Q7382874, 500077806

22, Isidora Aschheim, Israeli, Israeli, Female, $\theta, \theta$,

23, Charles Robert Ashbee, "British, 1863-1942", British, Male, 1863, 1942, Q614071, 500030367

24, Donald Ashcraft, "American, born 1927", American, Male, 1927, 0,

25, E. M. Ashe, "American, 1867-1941", American, Male, 1867,1941, ,

26 , Göran Aslin, "Swedish, born 1940", Swedish, 1940,0,,

27 , Erik Gunnar Asplund, "Swedish, 1885-1940", Swedish, Male, 1885, 1940, Q312070, 500011232

28 , Geneviève Asse, "French, born 1923", French, Female, 1923, 0, Q1978192, 500025324

30, Sergio Asti, "Italian, born 1926", Italian,Male, 1926, 0 ,

31, Dana Atchley, "American, 1941-2000", American, Female, 1941, 2000 ,

32, Atelier Eggers, French, French, , $\theta, \theta$, ,

33, A.A.P., American, American, $, \theta, \theta$,

34, Alvar Aalto, "Finnish, 1898-1976", Finnish, Male, 1898, 1976, Q82840, 500002617

35, Aino Aalto, "Finnish, 1894-1949", Finnish, Female, 1894, 1949, Q273511, 500024110

36, Eero Aarnio, "Finnish, born 1932", Finnish, Male, 1932, 0 , Q707025, 500270610

37 , Jules Aarons, "American, 1921-2008", American, Male, 1921, 2008,

38, Magdalena Abakanowicz, "Polish, 1930-2017", Polish, Female, 1930, 2017,0158080,500084577

39, James Abbe, "American, 1883-1973", American, Male, 1883, 1973, Q321301, 500026671

40 , Jussuf Abbo, "Palestinian, 1888-1953", Palestinian, Male, 1888, 1953, ,

41, Berenice Abbott, "American, 1898-1991", American, Female, 1898, 1991, Q231861, 500020631

42, Nobuya Abe, "Japanese, 1913-1971", Japanese, Male,1913,1971, ,

43, Abe Shiro (pen Name: Suichiku), "Japanese, born 1900", Japanese, Male, 1900, 0, ,

44, Robert Abel, "American, born 1937", American, Male, 1937,0, Q7341326,

46, Sigmund Abeles, "American, born 1934", American, Male, 1934, $\theta$,

47, Raimund Abraham, "American, born Austria. 1933-2010", American, Male, 1933, 2010, Q78819,500031964

40 Tyor Abrabams "British hor 1935" British.Male 1935 . 011714362599912378 

Atualizado en

Agosto 31, 2018

english

españo

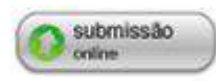

- sobre nós

- corpo editorial

instruções aos autores

$\rightarrow$ assinaturas

métricas

$\checkmark$ SCIElo

- Scimago

Boletimdo Museu Paraense

Emillio Goeldi:Ciencias.

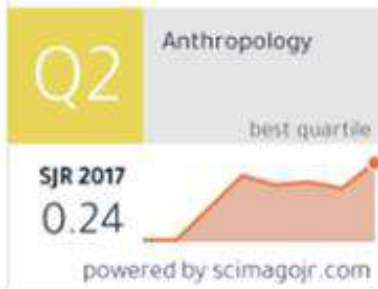

powered by scimagoir com

- Google Scholar

2017
indice h5: 5

mediana h5: 10

mais detalhes

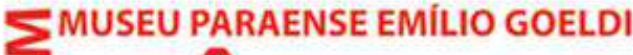 ÊCIÊNCIAS DHUMANAS}

Pesquisa

Entre uma ou mais palavras Todos os indices • Neste Periódico

Pesquisa

Publicação de

MCTI/Museu Paraense Emílio Goeldi

versăo impressa ISSN 1981-8122versăo On-line ISSN 2178-2547

Missão

Publicar trabalhos originais nas áreas de Antropologia, Arqueologia, Linguistica

Indigena e em disciplinas correlatas.

Boletim do Museu Paraense Emílio Goeldi. Série Ciências Humanas 


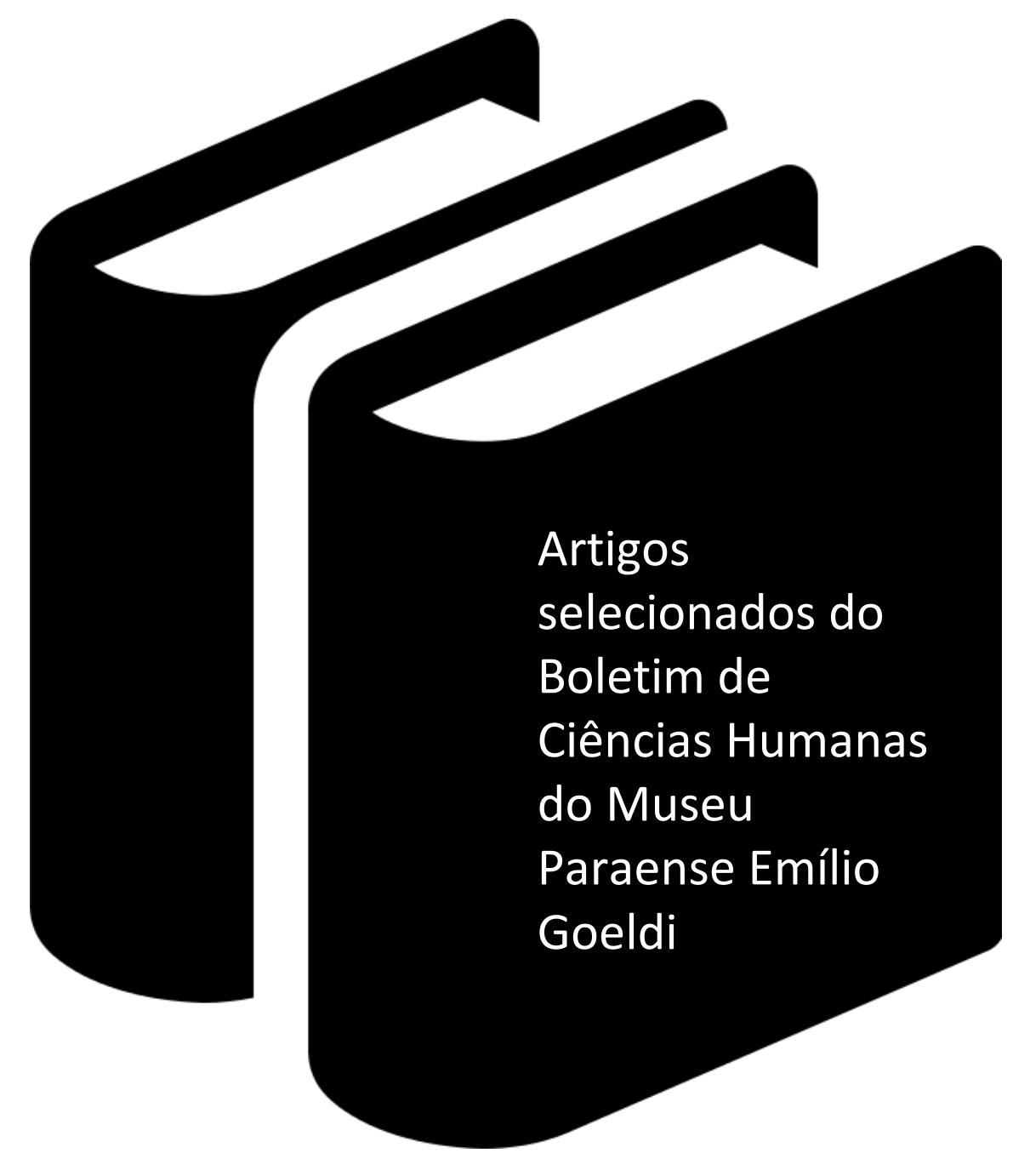

Os créditos do detentor dos direitos autorais deve aparecer na mesma página da ficha catalográfica, junto com os créditos do autor ou autores do livro 


\section{livrorin culturn}

O Lojas Atendimentoe Televendas a Vendas corporativas

Q (8) Entreou cadastre-se

농

$\equiv$ COMPREPOR CATEGORIA $\vee$ EXPLORECULTURA $\vee$ CULTURAINDICALISTAS MINHACULTURA CULTURAEMCURSO EVENTOS

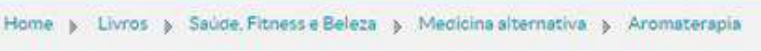

- AROMATERAPIA

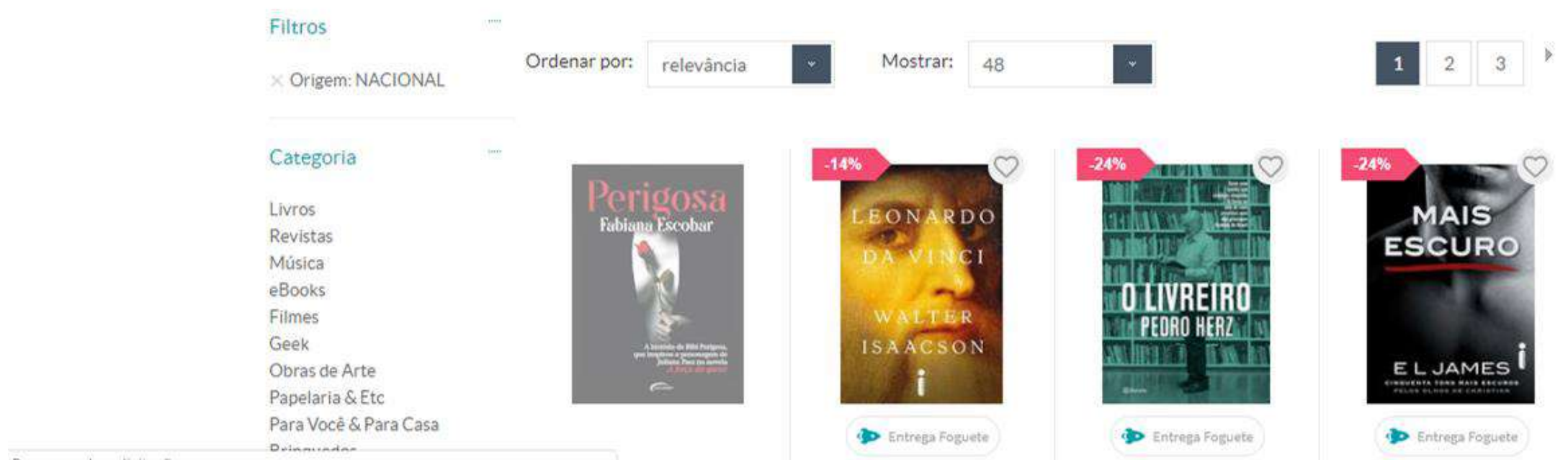




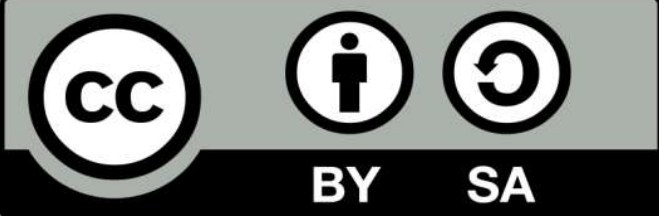

- Exige atribuição

- Cópia

- Obras derivadas

- Uso comercial e não comercial

- Uso da mesma licença 


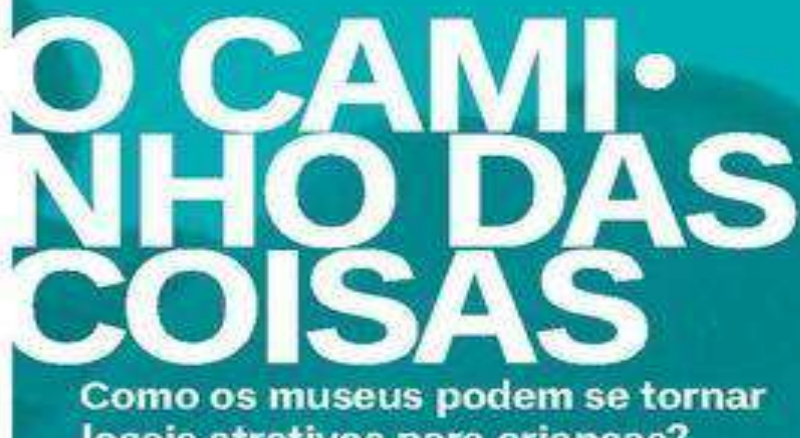

locais atrativos para crianças?
Crédito: Paola Maués, Adilson Medeiros dos Santos, Aline Oliveira, Ana Menezes, Bruna Marques, Conrado Secassi, Guilherme Ramalho, Isabela Maia, José Pedro Viviani, Juliana Barros, Luiz Gregório G. de Camargo, Paulo Rogério dos Santos, Raquel Freitas.

Fonte: Museu da Imigração de São Paulo. 
Parte final com:

-Os créditos dos autores originais e do detentor dos direitos

-Informação de que aquele material possui a licença CC BY SA

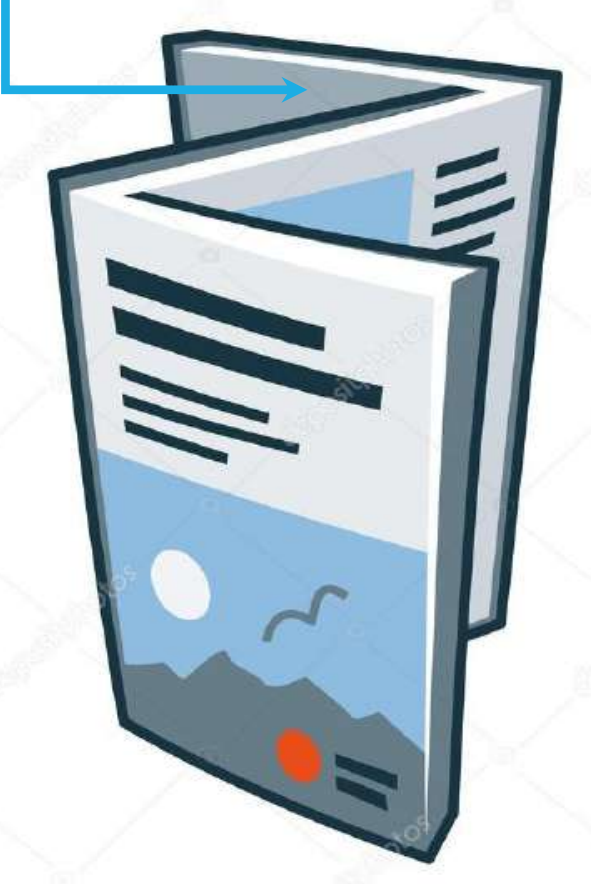


(c)

(i) $(9$

BY NC ND

- Exige atribuição

- Cópia X

- Obras derivadas X

- Uso comercial X

- Uso não comercial $\downarrow$ 


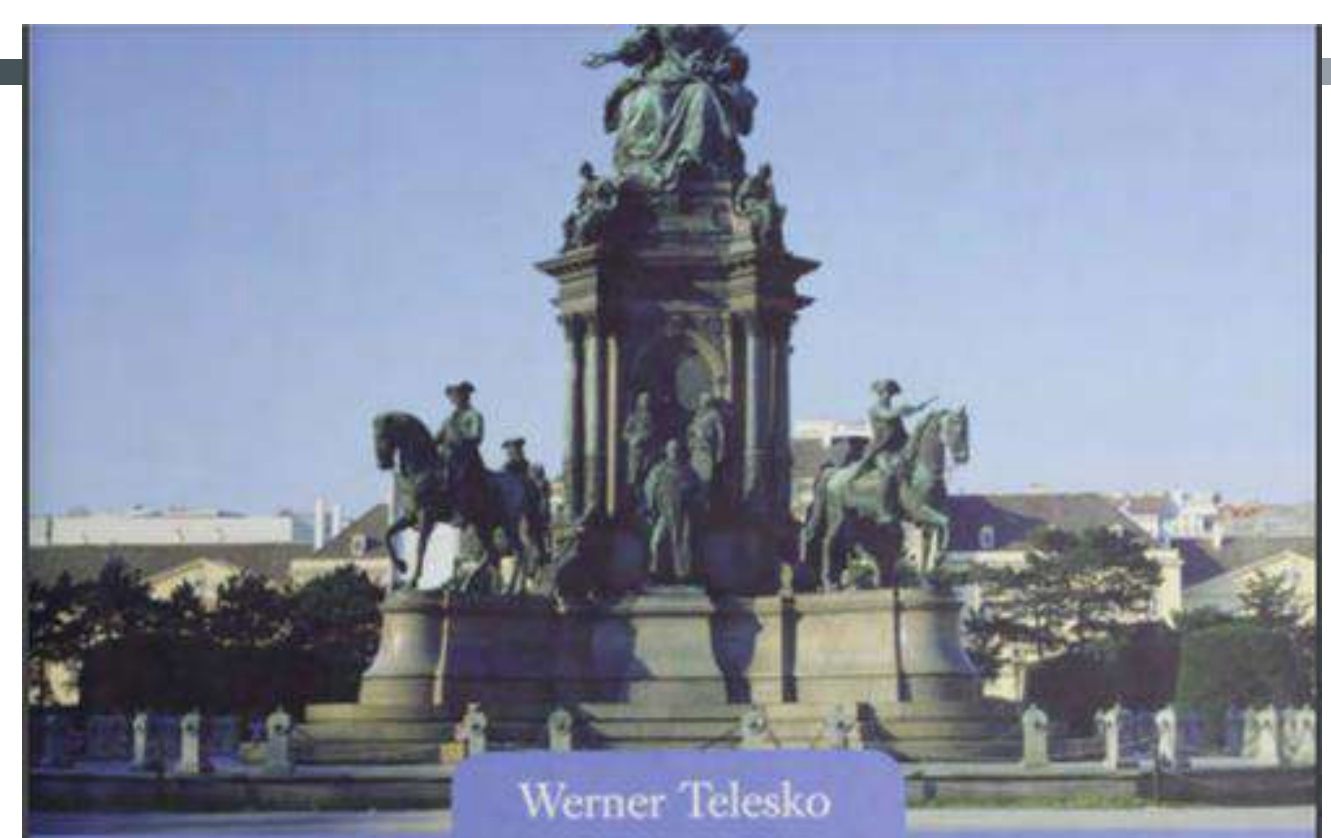

\section{Geschichtsraum Österreich}

Die Habsburger und ihre Geschichte

in der bildenden Kunst des 19 . Jahrhunderts
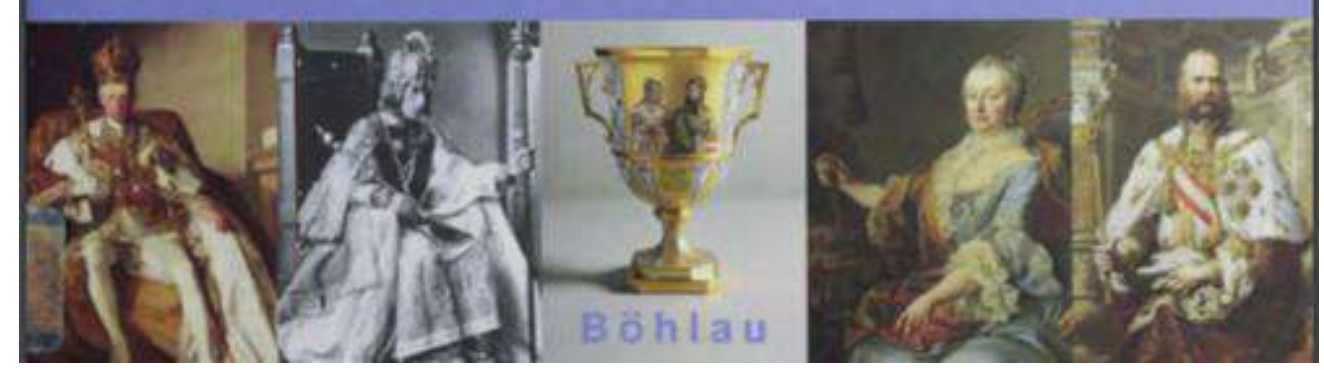


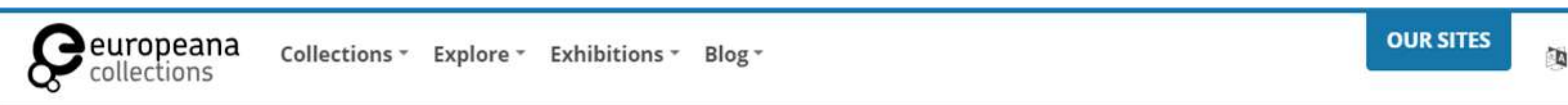

(1) Media Metadata

Title

\section{Geschichtsraum Österreich | Telesko,Werner}

The history is intended as the first comprehensive examination of the role of Austrian history in the visual arts of the Habsburg monarchy between 1804 and 1918. At its centre are the following three key questions: What status did the general preoccupation with history acquire? What where the favorite historical subjects for artistic representation? What significance did the Habsburgs " own history (almost endlessly "extendible" all the way back to its fictitious mythical beginnings) hold for the issues of the day? Works of art contribute to the creation of traditions in a double sense: a given work simultaneously contains and creates history. A work of art is also a medium for social identification, facilitating

\section{\pm DOWNLOAD}

FIND OUT MORE

View at OAPEN Foundation E

CAN I USE IT?

Limited Re-use (ㄷ) (1) (2) () CC BY-NC-ND E

SHARE

(๑○ค๑ 
PRÁTICAS DE LICENCIAMENTO DAS INSTITUIÇÕES BRASILEIRAS 
$>$ Há instituições que possuem políticas alinhadas com as licenças abertas

$>$ Há instituições que restringem qualquer tipo de uso e adotam o "Todos os direitos reservados"

> Há instituições que não informam qual é a licença de seus materiais ou dos materiais por ela distribuídos 
$>$ Há instituições que mudam de licença de acordo com a situação

$>$ Há instituições que mudam o padrão de licenciamento ao longo dos anos

> A informação de "Política de Acesso Aberto" nos sites das instituições não implica, necessariamente, em uma licença altamente permissiva 
Juliana Monteiro é museóloga pela UFBA, com especialização em Gestão Pública pela FESP-SP e mestra em Ciência da Informação pela ECA-USP. Atua na área de gestão de coleções há 12 anos. Trabalhou como museóloga do Museu da Energia de São Paulo (2007-2008); como assistente de coordenação da Unidade de Preservação do Patrimônio Museológico da Secretaria de Estado da Cultura (2008-2015), onde coordenou o Comitê de Política de Acervo dos Museus. Posteriormente, foi gestora do Núcleo de Preservação do Museu da Imigração de São Paulo (2015-2016). Colaborou na revisão técnica e tradução das normas SPECTRUM 4.0 e Categorias de Informação do CIDOC, lançadas em português em 2014. É membro também do COMCOL-ICOM e do conselho consultivo do ICOM Brasil. É professora do curso técnico de Museologia da ETEC Parque da Juventude desde 2010, dando aulas sobre documentação e bancos de dados para museus. Presta consultoria para projetos culturais variados como consultora freelancer desde 2016. É representante nacional da empresa Sistemas do Futuro, especializada em software de gestão de acervos culturais. É coordenadora da área de instituições de memória do capítulo brasileiro do Creative Commons, realizando palestras e formações sobre abertura de acervos. Já atuou também na articulação entre projetos Wikimedia e instituições culturais, como membro do Grupo Wiki Educação Brasil. É embaixadora regional para países da comunidade lusófona da campanha internacional Arte+Feminismo 2019. Entre seus principais interesses estão a discussão sobre a ampliação do acesso a acervos culturais e seu uso por meio de ferramentas e plataformas presentes na web. Email: julianamonteiro47@gmail.com

É permitida a reprodução parcial ou total desta obra, desde que citada a fonte e autoria, proibindo qualquer uso para fins comerciais. Licença Creative Commons

\section{(1) $(\Theta$}




\section{AUTORES BIOGRAFIA}

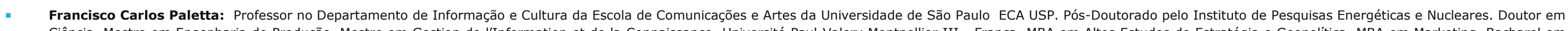

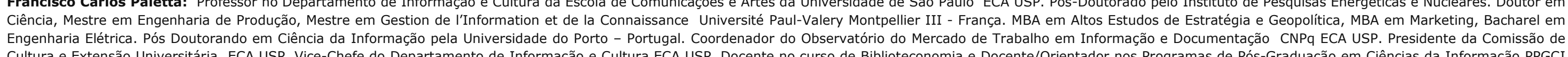

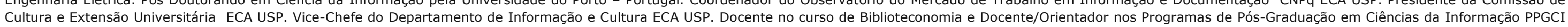
ECA USP; e Mestrado Profissional em Gestão da Informação da ECA USP.

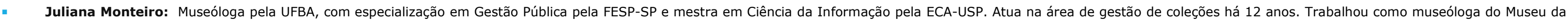

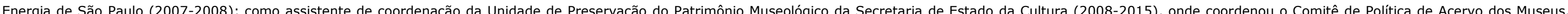

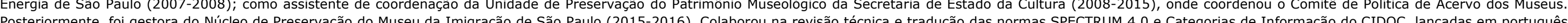

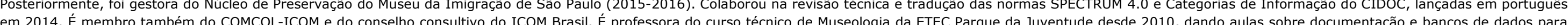

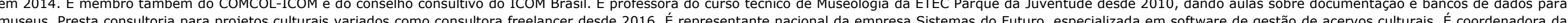

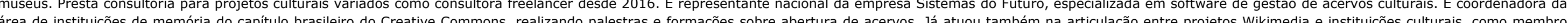

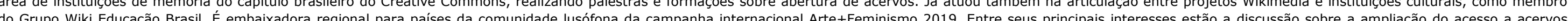
culturais e seu uso por meio de ferramentas e plataformas presentes na web.

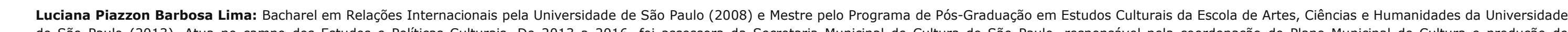

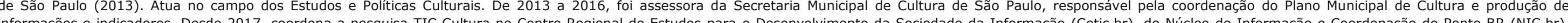

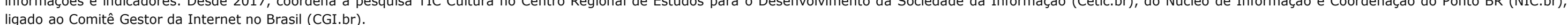

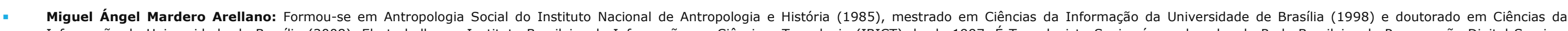

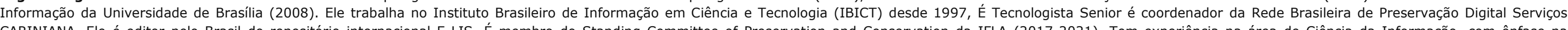

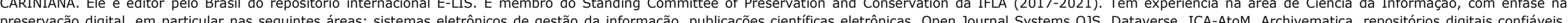

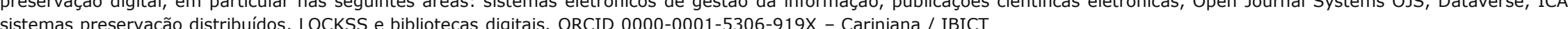

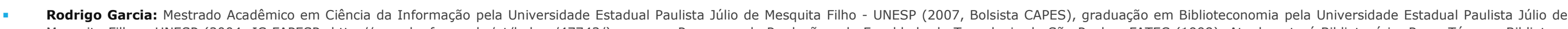

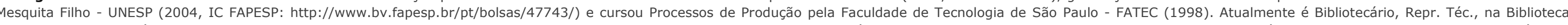

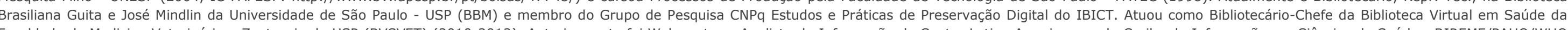

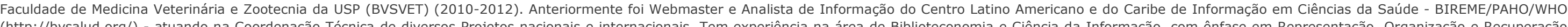

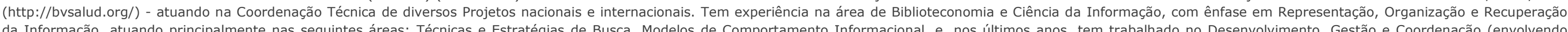

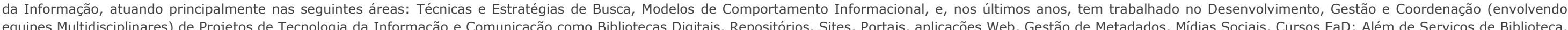

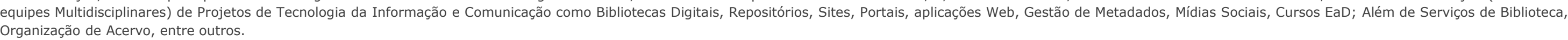

\section{(1) $(3)$}




\section{SÉRIE TECNOLOGIA E ORGANIZAÇÃO DA INFORMAÇÃO}

CURADORIA DIGITAL E POLÍTICAS DE DIGITALIZAÇÃO

NOTAS SIMPÓSIO CURADORIA DIGITAL - TOI 2020

\section{ORGANIZAÇÃo}




\section{eco}

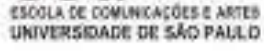

\section{CCEx}

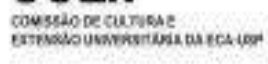

TSP

\section{CBD}

PRCEU

OBSERVATORIO

DO MERCADO DE TRABALHO

DO PROFISSIONAL OA INFORMACÁO

FOMENTO

\section{TFAPESP}

COLBBORAÇKL CIENTIFICA

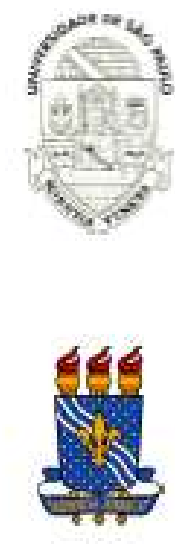

BВBLOTECAS EM COLABORAÇב̆o

\section{Biblioteca ECA}

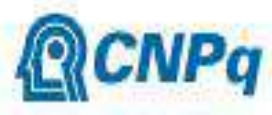
-

Biblioteca Brasiliana ejose Mindlin
PARCEIROS INSTITUCIONAIS
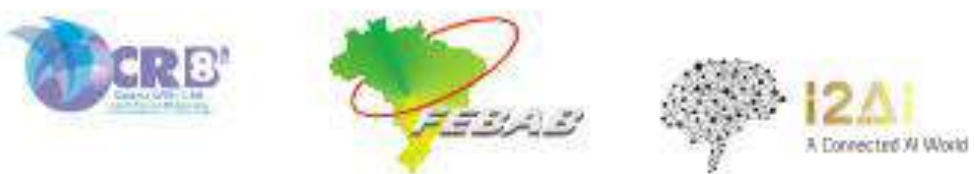

\section{U.PORTO}

$$
\text { Demerald }: \text { : : SBGC }
$$

uc3m | $\begin{aligned} & \text { Uriversidad } \\ & \text { Carlos III } \\ & \text { de Madrid }\end{aligned}$

$.111,1 / 1$,
CISCO

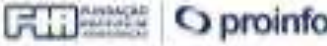

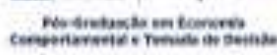


LECTURES NOTES 















